\title{
Molecular and cellular mechanisms of glucocorticoids in the treatment of acute graft-versus-host disease
}

\author{
Dissertation
}

\author{
for the award of the degree \\ "Doctor rerum naturalium (Dr. rer. nat.)" \\ Division of Mathematics and Natural Sciences \\ of the Georg-August University Göttingen
}

\author{
submitted by \\ Jennifer Theiss-Sünnemann \\ born in \\ Hagen (Westf.), Germany
}

Göttingen, 2012 
Thesis Supervisor:

Prof. Dr. Holger M. Reichardt

Doctoral Committee:

Prof. Dr. Holger M. Reichardt

Cellular and Molecular Immunology

$\left(1^{\text {st }}\right.$ Referee $)$

University of Göttingen Medical School, Göttingen

Prof. Dr. Steven A. Johnsen

$\left(2^{\text {nd }}\right.$ Referee $)$

Molecular Oncology

University of Göttingen Medical School, Göttingen

Dr. med. Tobias Pukrop

Haematology/Oncology

University of Göttingen Medical School, Göttingen

Date of the oral examination: 15.05 .2012 


\section{Declaration}

I hereby declare that I have written this $\mathrm{PhD}$ thesis entitled "Molecular and cellular mechanisms of glucocorticoids in the treatment of acute graft-versus-host disease" independently and with no other sources and aids than quoted. This thesis has not been submitted elsewhere for any academic degree.

Jennifer Theiss-Sünnemann

April 2012

Göttingen, Germany 


\section{Abstract}

Haematopoietic stem cell transplantation (HSCT) is often the only curative therapy for haematopoietic malignancies and some inherited diseases of the haematopoietic system. A major side effect of HSCT and a cause of morbidity and mortality is acute graft-versus-host disease (aGvHD). aGvHD is mediated by donor T cells after activation by alloantigens and can cause severe damage of skin, the gastrointestinal tract, liver and lung. Glucocorticoids (GCs) are the gold standard first-line therapy of aGvHD, but their mode of action and the target cells, which mediate beneficial effects in the therapy of aGvHD, remain poorly defined. It was the aim of this study to obtain insight into the mode of GC action in aGvHD.

This work shows that the glucocorticoid receptor (GR) in T cells is essential for treatment of aGvHD with GCs, whereas its dimerisation, which is required for transactivation, is mostly dispensable. Moreover, GR-dimerisation in host tissues or the GR in myeloid cells, such as macrophages, is also dispensable for GC treatment. Whilst T cell cytokines like interferon (IFN)- $\gamma$, interleukin (IL)-2 and interleukin (IL)-17 are diminished after GC treatment, their reduction alone is not sufficient for therapy. Rather lowering of target organ infiltration and of cytotoxic T cell activity, which is abrogated if mice are transplanted with T cells that are deficient for the GR, appear to be crucial for treatment success.

In contrast, endogenous GCs require both, the GR in donor T cells and its dimerisation, for their effect and they also require dimerisation of the GR in host tissues. If GR-dimerisation in the recipient is abrogated, there is an increase of cytokines produced by host cells, such as monocyte chemotactic protein (MCP)-1 and interleukin (IL)-6. Remarkably, GR-dimerisation-deficient recipients also show dysregulated energy expenditure, which may be responsible for exaggerated aGvHD. Collectively, these results indicate that treatment of aGvHD with selective GC agonists may be a promising therapy option for aGvHD, and that the role of energy expenditure in aGvHD is an interesting aspect to further investigate when searching for new treatment options. 


\section{Table of contents}

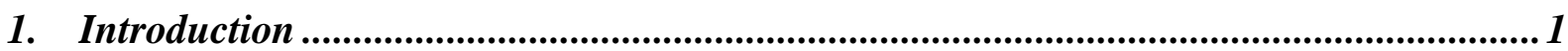

1.1. Haematopoietic stem cell transplantation ....................................................................1

1.2. Acute graft-versus-host disease (aGvHD) .....................................................................1

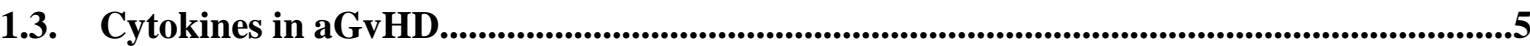

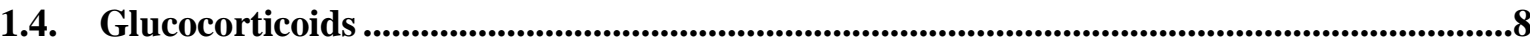

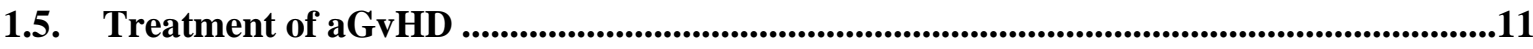

1.6. Objective...............................................................................................................................................12

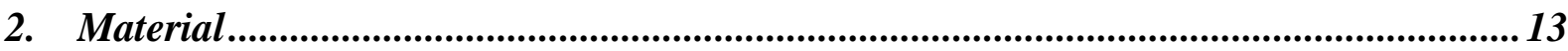

2.1. General equipment ................................................................................................................13

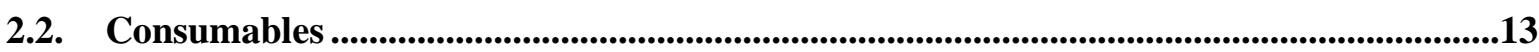

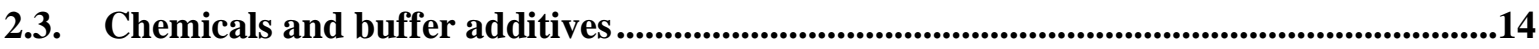

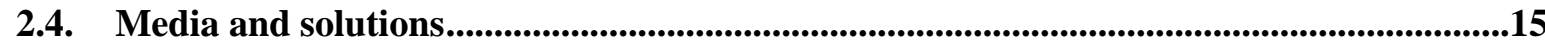

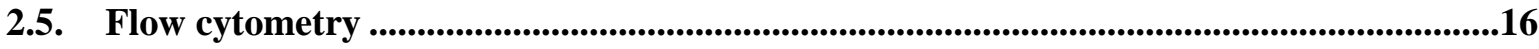

2.6. Magnetic Activated Cell Sorting (MACS) ............................................................17

2.7. Enzyme Linked Immunosorbant Assay (ELISA) .......................................................17

2.8. Cytometric Bead Array (CBA) .....................................................................................................18

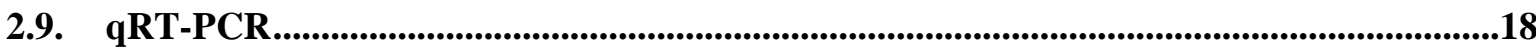

2.10. Temperature and blood glucose ....................................................................................................19

2.11. Cell lines ..........................................................................................................................................................20

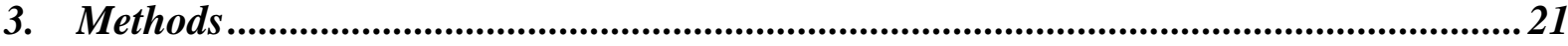

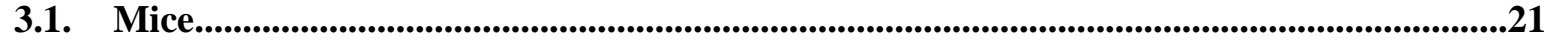

3.2. Preparation of lymphocyte single cell suspensions ...................................................................21

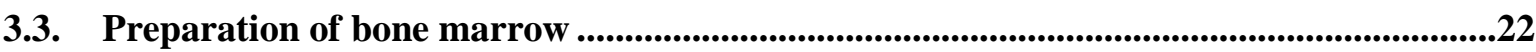

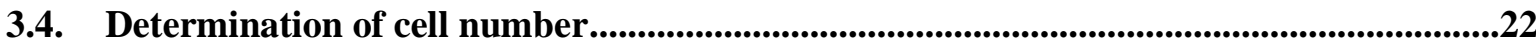

3.5. T cell purification ...............................................................................................................................22

3.6. T cell depletion of bone marrow..................................................................................................23

3.7. Bone Marrow Derived Macrophages (BMDMs) ........................................................................24

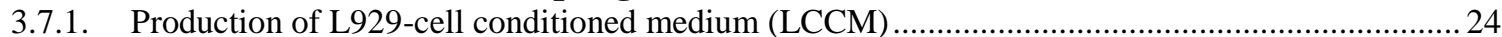

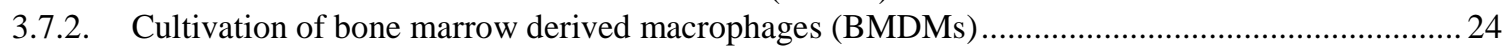

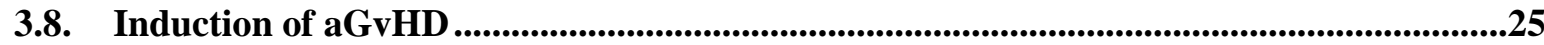

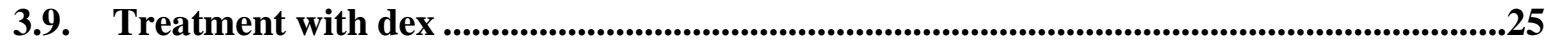

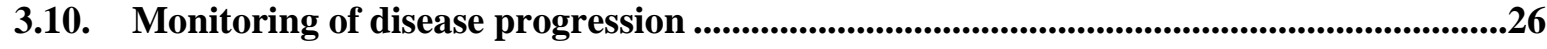

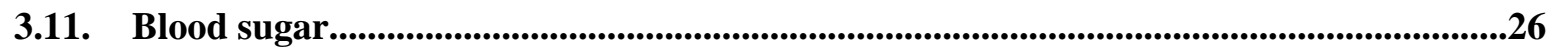

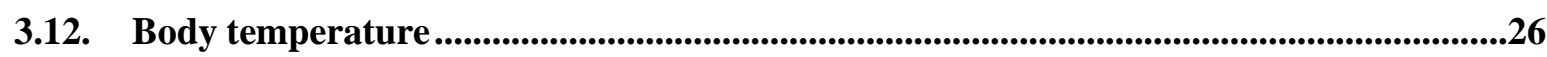

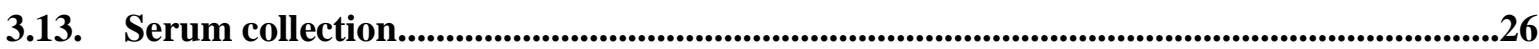

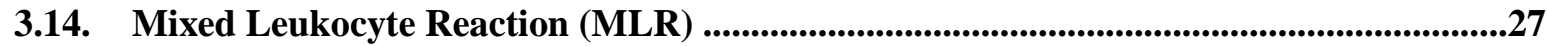




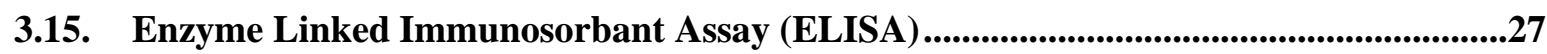

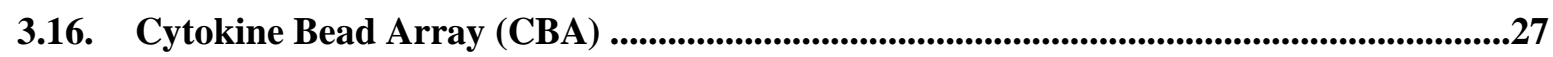

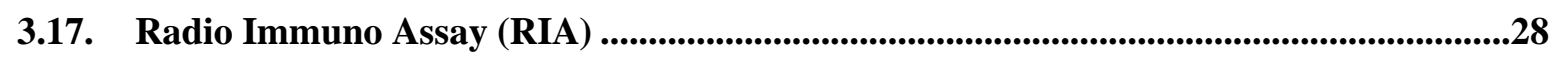

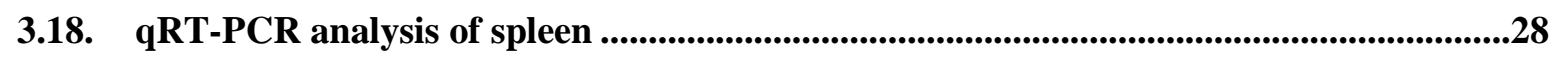

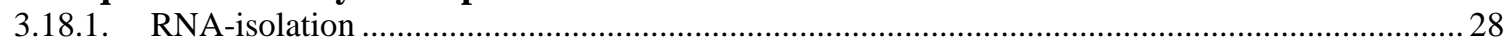

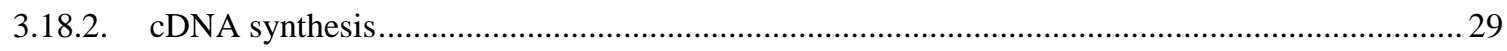

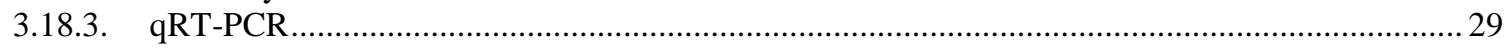

3.19. Isolation of lymphocytes from lung and liver for FACS analysis..................................29

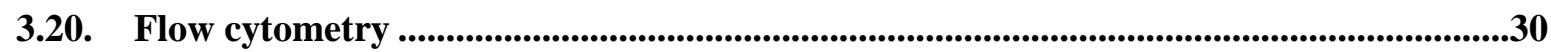

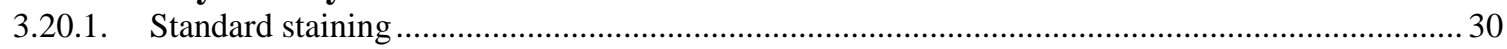

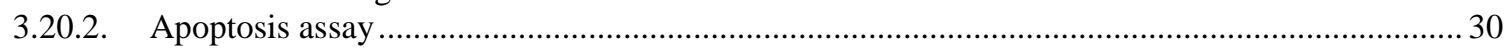

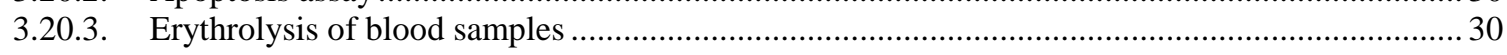

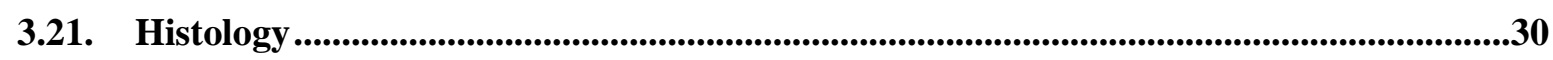

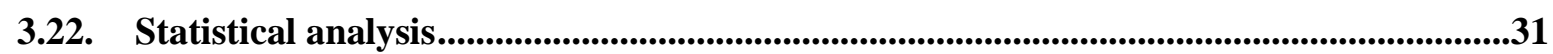

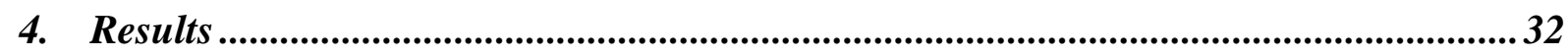

4.1. Characterisation of the aGvHD in vivo model ..............................................................32

4.2. Mortality ...............................................................................................................................34

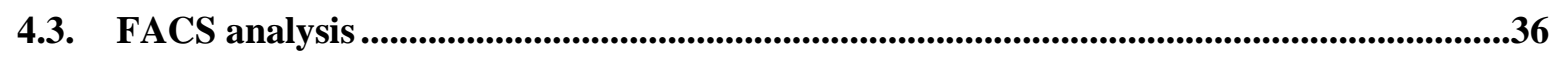

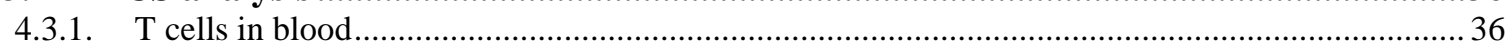

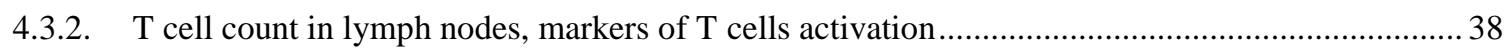

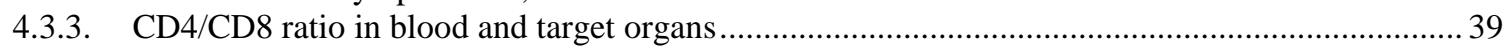

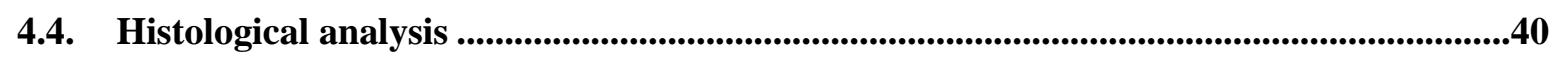

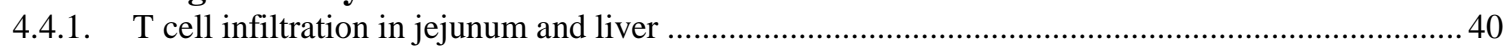

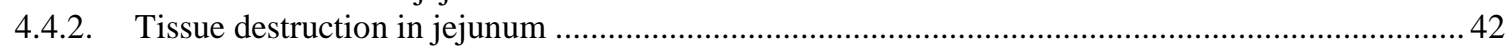

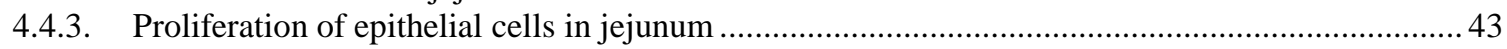

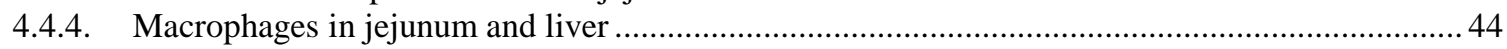

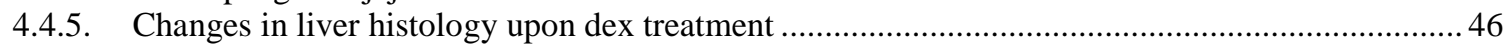

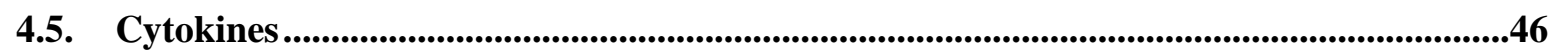

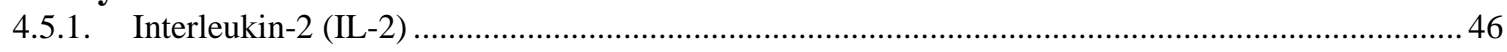

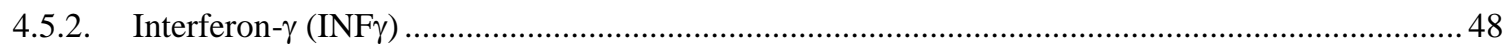

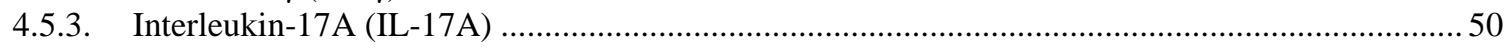

4.5.4. Interleukin-6 (IL-6) and monocyte chemotactic protein-1 (MCP-1) ……….................................. 52

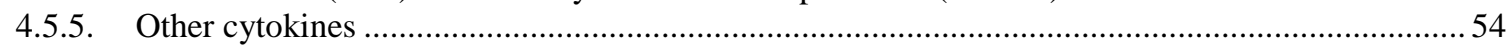

4.6. Cytotoxic $\mathrm{T}$ cell effector function ................................................................................................55

4.7. Endogenous glucocorticoids ...............................................................................................................56

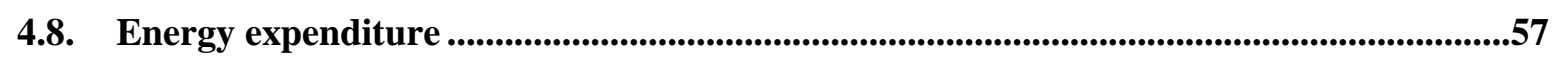

4.9. Mixed Leukocyte Reaction as an in vitro aGvHD model .................................................59

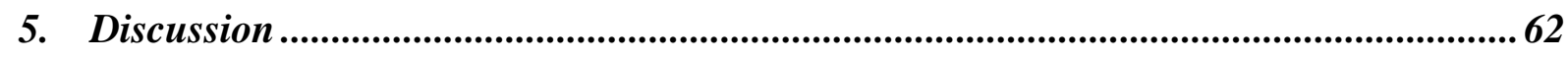

5.1. The role of different aspects of acute graft-versus-host disease (aGvHD) pathogenesis for the mode of action of endogenous and therapeutic glucocorticoids (GCs) .............................62

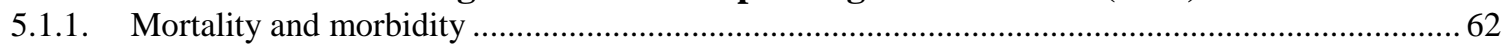

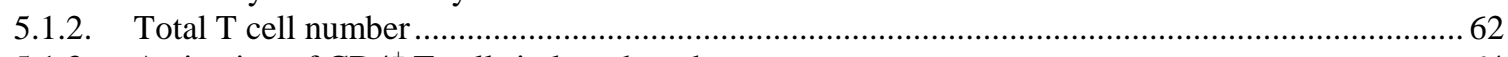

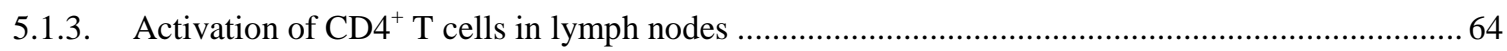

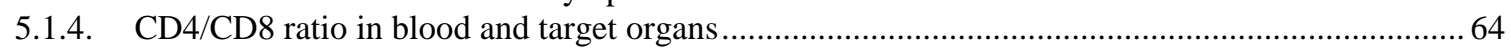

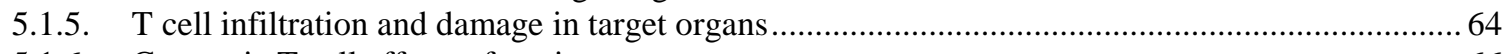

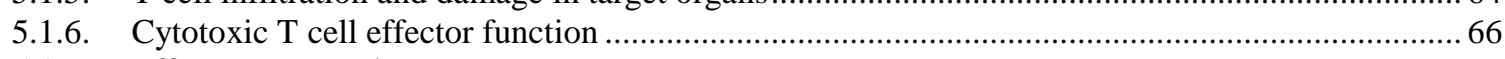

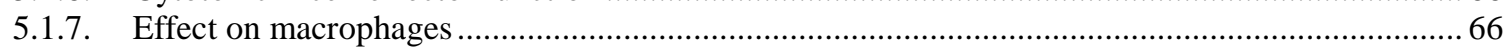

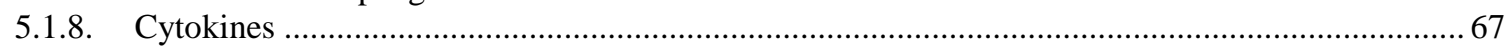




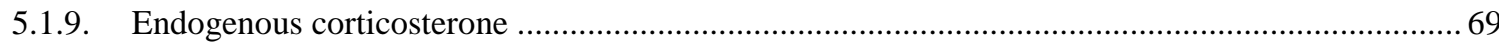

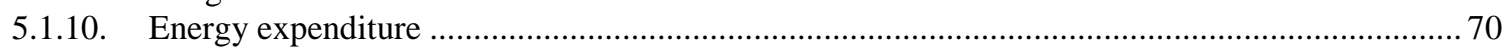

5.2. The role of the GR and its molecular modes in different tissues.....................................71

5.2.1. The role of the GR and its dimerisation in donor T cells for endogenous control of aGvHD ....... 71

5.2.2. The role of the GR and its dimerisation in donor $T$ cells for the treatment of aGvHD with GCs .. 72

5.2.3. The role of GR dimerisation in host cells for endogenous control of aGvHD ............................ 73

5.2.4. The role of GR dimerisation in host cells for the treatment of aGvHD with GCs ...................... 74

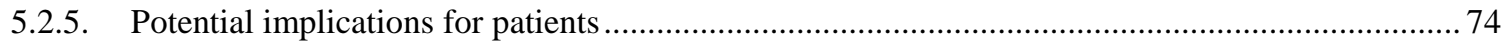

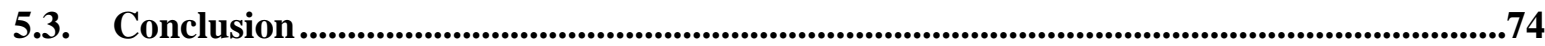

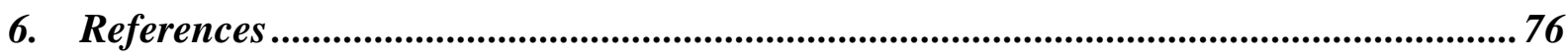




\section{List of figures}

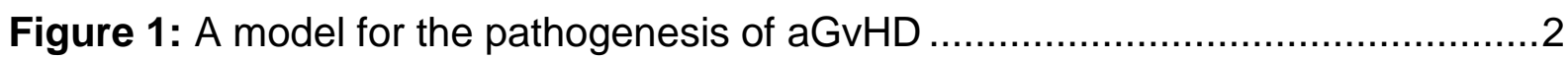

Figure 2: Chemical structure of cortisone ..................................................

Figure 3: Chemical structure of dexamethasone ............................................. 11

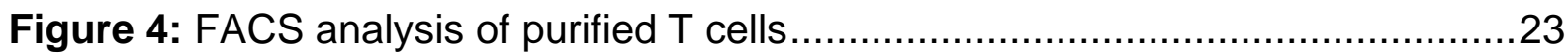

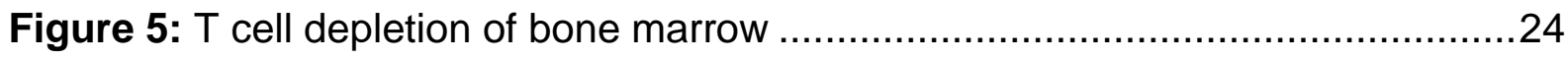

Figure 6: Bone marrow derived macrophages..........................................25

Figure 7: Scheme of aGvHD induction, therapy and analysis ............................25

Figure 8: Mortality and morbidity after aGvHD induction ...............................32

Figure 9: T cell expansion after transplantation ...............................................

Figure 10: T cell infiltration in target organs in the early post-transplantation phase 34

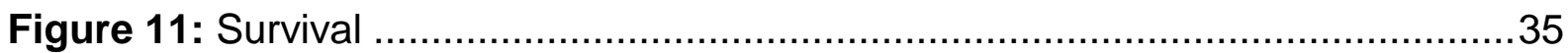

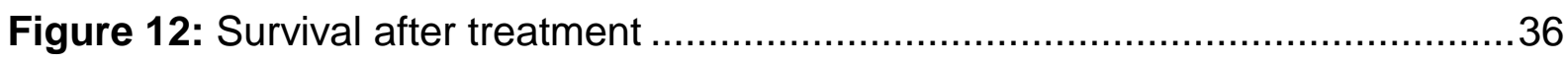

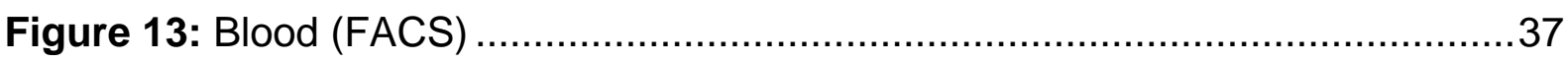

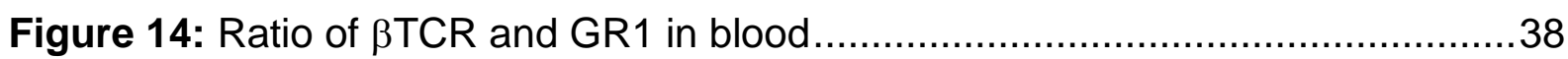

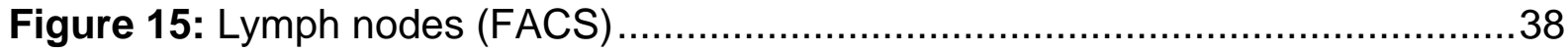

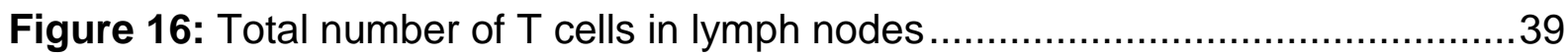

Figure 17: Percentage of activated CD4 ${ }^{+} \mathrm{T}$ cells in lymph nodes ..........................39

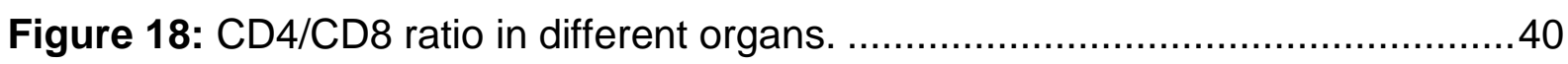

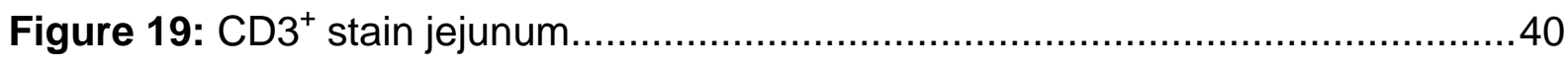

Figure 20: Number of $\mathrm{T}$ cells in jejunum ................................................... 41

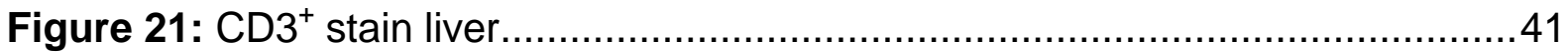

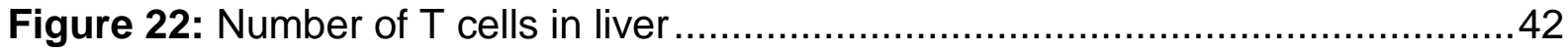

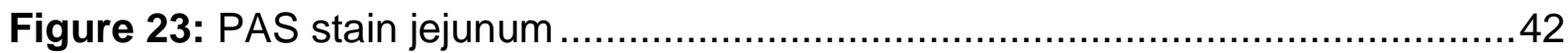

Figure 24: Number of goblet cells in jejunum ........................................... 43

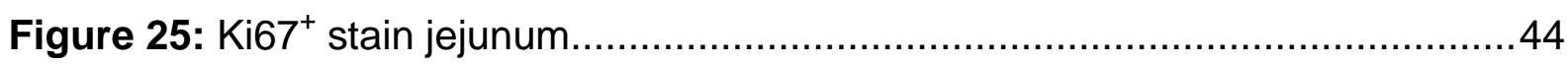

Figure 26: Proliferation in jejunum ..................................................... 44

Figure 27: $\mathrm{HR3}^{+}$stain jejunum and $\mathrm{F} 4 / 80^{+}$stain liver .................................... 45

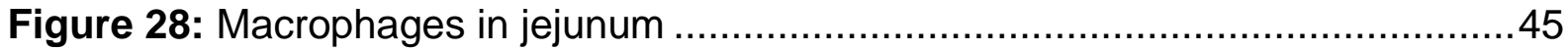

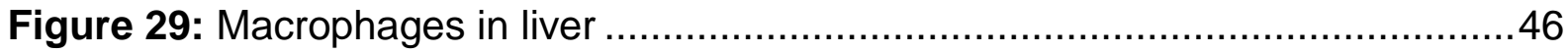

Figure 30: HE stain liver ................................................................... 46

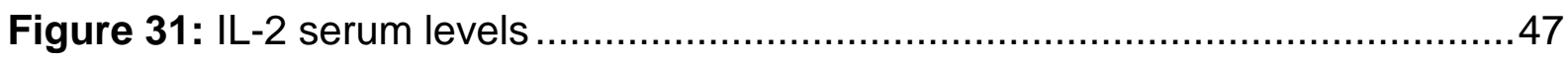

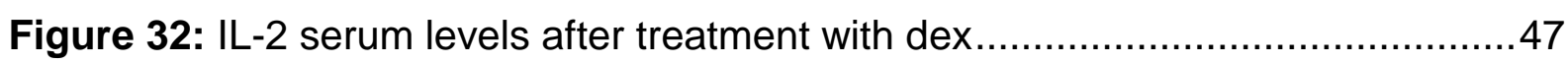




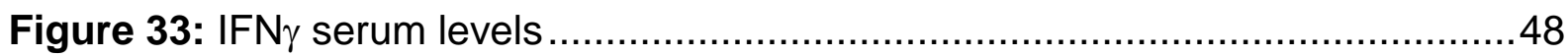

Figure 34: IFN $\gamma$ serum levels after treatment with dex......................................... 49

Figure 35: IFN $\gamma$ serum levels after treatment with dex (2) ..................................49

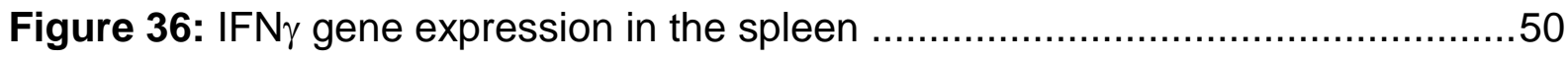

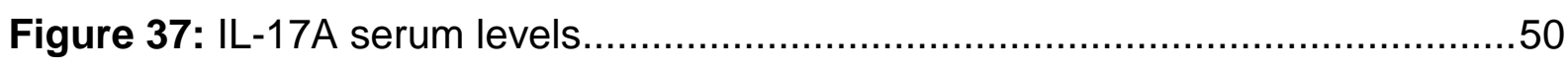

Figure 38: IL-17A serum levels after treatment with dex …..............................51

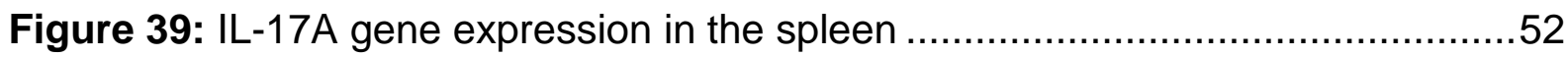

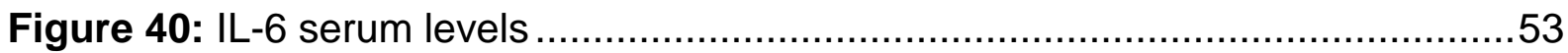

Figure 41: IL-6 serum levels after treatment with dex......................................53

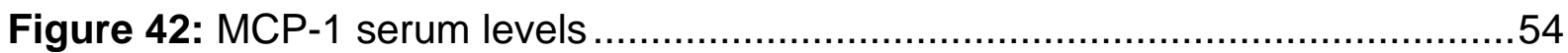

Figure 43: MCP-1 serum levels after treatment with dex.................................54

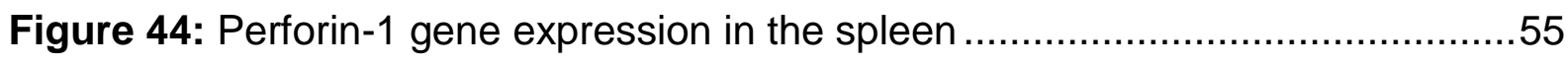

Figure 45: Granzyme B gene expression in the spleen ...................................56

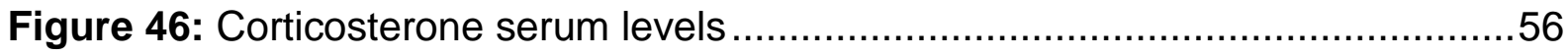

Figure 47: Corticosterone serum levels after treatment with dex.........................57

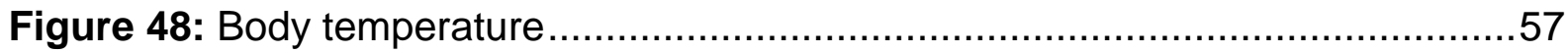

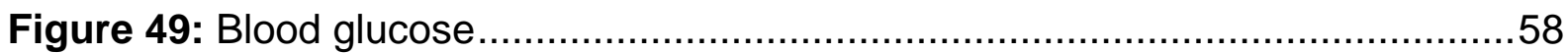

Figure 50: Blood glucose after treatment with dex (GR ${ }^{\mathrm{lckCre}}$ and $\mathrm{GR}^{\mathrm{dim}}$ donors) .......58

Figure 51: Blood glucose and body temperature ( $G R^{\text {dim }}$ recipients) ......................59

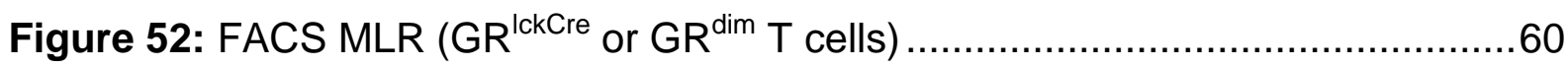

Figure 53: IL-2 in supernatant of MLR (GR ${ }^{\text {lckCre }}$ or $\mathrm{GR}^{\mathrm{dim}} \mathrm{T}$ cells) .........................60

Figure 54: FACS MLR (GR ${ }^{\text {lysMCre }}$ or $\mathrm{GR}^{\text {dim }}$ macrophages)..................................61

Figure 55: IL-2 in supernatant of MLR (GR ${ }^{\text {lysMCre }}$ or $\mathrm{GR}^{\mathrm{dim}}$ macrophages) ...............61 


\section{List of abbreviations}

\begin{tabular}{|c|c|c|c|}
\hline aGvHD & $\begin{array}{l}\text { acute graft-versus-host } \\
\text { disease }\end{array}$ & HSCT & $\begin{array}{l}\text { haematopoietic stem } \\
\text { cell transplantation }\end{array}$ \\
\hline AIA & antigen-induced arthritis & IFN & interferon \\
\hline AICD & $\begin{array}{l}\text { activation-induced cell } \\
\text { death }\end{array}$ & IL & interleukin \\
\hline APCs & antigen presenting cells & Jak & Janus kinase \\
\hline BMT & $\begin{array}{l}\text { bone marrow } \\
\text { transplantation }\end{array}$ & LPS & lipopolysaccharide \\
\hline CBA & cytokine bead array & MHC & $\begin{array}{l}\text { major histocompatibility } \\
\text { complex }\end{array}$ \\
\hline CHS & contact hypersensitivity & miHA & $\begin{array}{l}\text { minor histocompatibility } \\
\text { antigen }\end{array}$ \\
\hline dex & dexamethasone & MLR & $\begin{array}{l}\text { mixed leukocyte } \\
\text { reaction }\end{array}$ \\
\hline DISC & $\begin{array}{l}\text { death-inducing } \\
\text { signalling complex }\end{array}$ & NK cell & natural killer cell \\
\hline DNA & deoxyribonucleic acid & NO & nitric oxide \\
\hline EAE & $\begin{array}{l}\text { experimental } \\
\text { autoimmune } \\
\text { encephalomyelitis }\end{array}$ & PBSCs & $\begin{array}{l}\text { peripheral blood stem } \\
\text { cells }\end{array}$ \\
\hline ELISA & $\begin{array}{l}\text { enzyme-linked } \\
\text { immunosorbent assay }\end{array}$ & PMA & $\begin{array}{l}\text { phorbol 12-myristate } 13 \text { - } \\
\text { acetate }\end{array}$ \\
\hline FADD & $\begin{array}{l}\text { Fas-associated death } \\
\text { domain }\end{array}$ & RIA & radio immuno assay \\
\hline GC & glucocorticoid & s.e.m. & standard error of mean \\
\hline GR & glucocorticoid receptor & socs & $\begin{array}{l}\text { suppressor of cytokine } \\
\text { signalling }\end{array}$ \\
\hline GR $^{\text {IckCre }}$ & Ick-Cre GR ${ }^{\text {floxfflox }}$ & Stat & $\begin{array}{l}\text { signal transducer and } \\
\text { activator of transcription }\end{array}$ \\
\hline GR $^{\text {lysMCre }}$ & LysM-Cre GR flox/flox & TCR & T cell receptor \\
\hline GvL & graft-versus-leukaemia & Th & T helper \\
\hline HLA & $\begin{array}{l}\text { human leukocyte } \\
\text { antigen }\end{array}$ & TNF & tumour necrosis factor \\
\hline HPA axis & $\begin{array}{l}\text { hypothalamic-pituitary- } \\
\text { adrenal axis }\end{array}$ & wt & wild type \\
\hline
\end{tabular}




\section{Introduction}

\subsection{Haematopoietic stem cell transplantation}

The first successful human bone marrow transplantation was performed in 1968 by Robert A. Good, who cured an immunodeficient infant using bone marrow from a matched sibling (Gatti et al., 1968). Soon afterwards, E. Donnall Thomas began to conduct first experiments with leukaemia patients (Thomas et al., 1957). For his work on haematopoietic stem cell transplantation (HSCT) he was awarded, along with Joseph E. Murray, the Noble Prize for Physiology or Medicine in 1990 (http://www.nobelprize.org/nobel_prizes/medicine/laureates/1990/press.html).

Indications for allogenic HSCT include acute myeloblastic leukaemia, lymphoblastic leukaemia and lymphoid malignancies, but also non-malignant disorders, such as severe immunodeficiency and paroxysmal nocturnal hemoglobinuria (reviewed in Holowiecki, 2008). And in spite of recent advances in the treatment of some forms of leukaemia and lymphomas in the form of drugs like rituximab (Maloney et al., 1997), for some malignancies HSCT even remains the only available curative treatment. In recent years, peripheral blood stem cells (PBMCs) have become the preferred source of haematopoietic stem cells over bone marrow aspiration (reviewed in Cutler and Antin, 2001).

Even before the first successes of transplantation medicine, it was discovered that recipients of allogeneic bone marrow grafts can develop a graft-versus-host reaction (Billingham, 1959). In addition, Barnes and Loutit noted that leukaemic mice transplanted with allogeneic bone marrow were cured more effectively than mice transplanted with syngenic bone marrow. But they also observed that some died, not from leukaemia, but from "wasting and chronic diarrhoea" (Barnes and Loutit, 1957). The deleterious effect of allogeneic transplantation was initially named "secondary disease" before it was termed graft-versus-host disease (GvHD) (e.g. Van Bekkum et al., 1959). The protective effect of allogeneic bone marrow against leukaemia is now recognised as graft-versus-leukaemia (GvL) effect.

\subsection{Acute graft-versus-host disease (aGvHD)}

GvHD is one of the most frequent complications after HSCT and responsible for a major percentage of transplant-related mortality and morbidity. Other important 
complications are relapse (in case of malignancies) and infection (Gratwohl et al., 2005). In fact, a meta-analysis showed that the use of PBSCs has a slightly increased risk for aGvHD compared to transplantation of bone marrow (Cutler et al., 2001).

For the occurrence of aGvHD three requirements, as postulated by Billingham, have to be fulfilled: (1) the graft has to contain immunologically competent cells, (2) the recipient must be immunocomprimised and unable to reject those cells and (3) the recipient must express antigens not present in the donor that can be recognised as foreign (Billingham, 1966). The immunocompetent cells in the graft that cause aGvHD have been identified as mature T cells (Korngold and Sprent, 1978) and, in fact, the disease severity correlates with the number of transfused T cells (Kernan et al., 1986).

aGvHD is often viewed as a three-step process (Figure 1) (Ferrara et al., 2009):

1) Tissue damage caused by the underlying disease and/or conditioning

2) Activation and expansion of transplanted T cells

3) Effector phase.

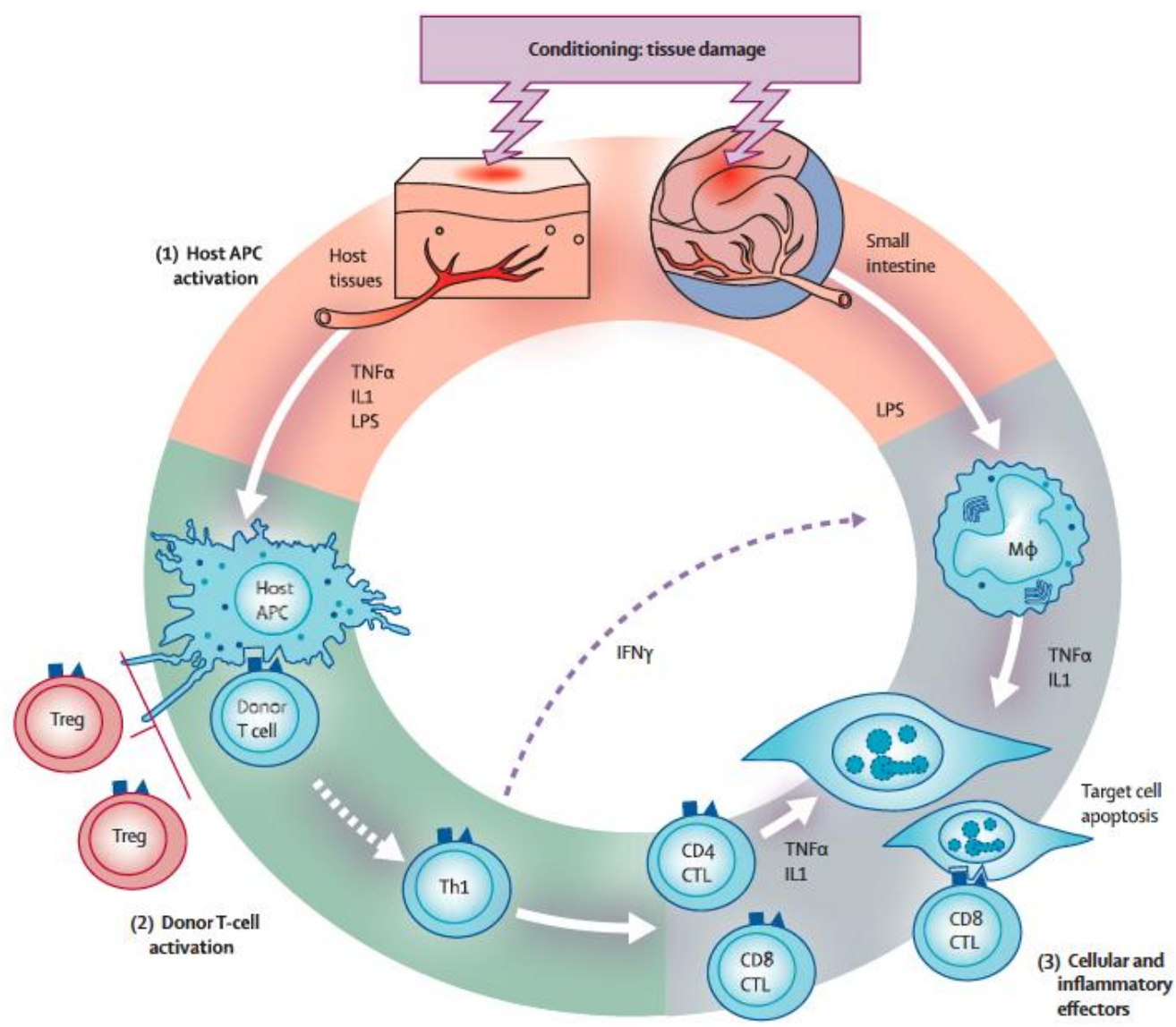

Figure 1: A model for the pathogenesis of aGvHD. Conditioning causes tissue damage, which activates the innate immune system. Host APCs are activated and prime alloreactive T cells that mount a Th1 response. 
Cytotoxic $\mathrm{T}$ cells migrate into the target organs where they cause tissue damage and in turn activate other immune cells. More cytokines are released resulting in a cytokine storm. (Reprinted from The Lancet, Vol. 373, James L M Ferrara, John E Levine, Pavan Reddy, Ernst Holler, Graft-versus-host disease, Pages No. 1550-61, Copyright (2009), with permission from Elsevier.)

Both, underlying malignancies and the conditioning regimen, which usually involves radio- and/or chemotherapy, can cause tissue damage. This releases danger signals, such as the secretion of inflammatory cytokines like tumour necrosis factor (TNF)- $\alpha$ and interleukin (IL)-1. Also, LPS from bacteria, which for example colonise the gut, may translocate across damaged epithelial barriers. This stimulates the innate immune system and leads to the upregulation of MHC-molecules and adhesion molecules (Hill et al., 1997).

This is the pro-inflammatory environment the donor T cells encounter upon transplantation. If $T$ cells are now presented with alloantigens by host antigen presenting cells (APCs), they are activated through co-stimulation and start to expand (Shlomchik et al., 1999). The antigens present in the recipient and absent in the donor are prominently the major histocompatibility complex (MHC). The mouse model in this work is based on such a MHC-mismatched transplantation. In a clinical situation, most transplants are MHC-matched or only mismatched for 1 or 2 loci. However, aGvHD can also be caused by minor histocompatibility antigens (miHAs) and $40 \%$ of HLA-matched recipients develop aGvHD (Ferrara 2009). In humans, HA1-5 have been identified as miHAs if presented in the context of HLA-A1 and A2, of which only HA-1 significantly correlates with aGvHD of grade II or more severe (Goulmy et al., 1996). Some miHAs are also encoded by the $Y$ chromosome and there is an increased risk in males receiving bone marrow from a female donor (Wang et al., 1995). Upon activation T cells start to expand and produce high amounts of IL-2 during proliferation. aGvHD is classically considered to be a Th1dominant disease in which IFN $\gamma$ is a key player.

In the effector phase, cytotoxic $T$ cells infiltrate the target tissues and cause damage due to direct cytotoxic mechanisms and inflammatory cytokine production.

Cytotoxic T cells kill their targets using the perforin/granzyme or the Fas/Fas ligand pathway. When a cytotoxic $T$ cell recognises a target cell via TCR/MHC interaction, perforin and granzymes are released from cytotoxic granules. Perforin integrates into the membrane of the target cell forming a pore through which granzymes can enter the cell to induce apoptosis (reviewed in Trapani and Smyth, 2002). 
Binding of Fas ligand leads to trimerisation of the Fas receptor and formation of the death-inducing signalling complex (DISC) together with the adaptor protein Fasassociated death domain (FADD) and caspase-8. Caspase-8 is then activated and mediates cell death either directly by activating other caspases or with the help of a mitochondrial feedback-loop (Scaffidi et al., 1998).

Both pathways were found to be important in experimental models of aGvHD. The transplantation of $\mathrm{T}$ cells deficient for either perforin or Fas ligand across MHC barriers results in delayed mortality in sublethally irradiated recipients, while the transplantation of $T$ cells deficient for both cytolytic pathways fails to induce aGvHD (Braun et al., 1996). This, however, may also be due to the fact that double deficient T cells lack the capability to overcome the host immune response (e.g. NK cells) in sublethally irradiated recipients (Jiang et al., 2001). Nevertheless, both pathways are involved in aGvHD pathogenesis.

Furthermore, T cell cytokines activate other inflammatory cells, such as macrophages, which in turn produce IL-1 and TNF $\alpha$ that cause tissue damage (Hill et al., 1999). Eventually, this leads to the generation of a cytokine storm (Antin and Ferrara, 1992).

aGvHD is defined as occurring within 100 days after transplantation. It can occur within days of the transplant in HLA mismatched transplantation pairs, but less intense conditioning, MHC-matching and pharmacological prophylaxis often delay the onset and newer practice separates acute and chronic GvHD on the basis of pathological presentation (Ferrara and Deeg, 1991).

aGvHD mainly affects skin, the gastrointestinal tract, liver (Martin et al., 1990) and possibly also the lung (Cooke et al., 1996). In skin, it presents with a maculopapular rash. Gastrointestinal symptoms feature nausea, anorexia, watery and/or bloody diarrhoea and abdominal pain. Liver aGvHD consists of cholestatic hyperbilirubinaemia (Ferrara et al., 2009). Also, the immune system itself is target of the GvH reaction and aGvHD leads to profound immunodeficiency. The activation and expansion of alloreactive T cells leads to vast AICD, which also affects nonalloreactive bystander $\mathrm{T}$ cells and thus impairs immune reconstitution (Brochu et al., 1999).

Intestinal aGvHD is central to the pathogenesis of aGvHD, with much mortality and morbidity caused by malnutrition, fluid loss and increased intestinal permeability (Hedberg et al., 1968). Mowat and Socié describe the development of intestinal 
pathology as follows: The intestine is damaged by the conditioning, and LPS from the gut microbiota is released and induces the alloreactive response. In the first phase of intestinal damage, the proliferative phase, $T$ cells start to infiltrate the epithelium and produce IFN $\gamma$. Other host cells, like macrophages, are activated, MHC is upregulated and barrier and digestive functions are impaired. This initial damage is compensated by increased proliferation of stem cells and epithelial turnover, resulting in crypt hyperplasia. When aGvHD progresses, in the destructive phase, macrophages cause damage via NO, as well as cytokines like TNF $\alpha$ and IL-1. This phase is also characterised by cytotoxic T cell activity. This leads to atrophy of villi and destruction of tissue architecture. In the final stage, the terminal phase, necrosis occurs, there is crypt cell apoptosis and matrix metalloproteases destroy the extracellular matrix (Mowat and Socié, 2005).

As there are no pathogens present that explain the tissue specificity of aGvHD, this is often explained by the fact that the target organs are damaged in particular by conditioning or have close contact to the environment (Shlomchik, 2007). Another explanation is that all of these organs are affected in areas that contain many undifferentieated epithelial cells. Therefore, there may be a connection between early surface antigens of epithelial cells and tropism of aGvHD (Ferrara and Deeg, 1991).

\subsection{Cytokines in aGvHD}

Excessive production of cytokines is a characteristic of aGvHD and polymorphisms in cytokines have been associated with the risk for aGvHD.

Interleukin (IL)-2 is transiently produced by activated T cells and has autocrine, paracrine and systemic effects. Its main target are $T$ cells themselves, including regulatory T cells, and it is crucial for clonal expansion (Malek, 2008). But IL-2 also has an effect on other cells; it can for example activate macrophages to produce TNF $\alpha$ (Economou et al., 1989).

While it is generally accepted that IL-2 plays an important role in the pathogenesis of aGvHD, there is no correlation between IL-2 serum levels and the risk of developing aGvHD (Fujii et al., 2006). However, Hua et al. found that higher IL-2 levels after conditioning and after transplantation are associated with higher grade aGvHD. Also, they found that increased IL-2 in the donor after mobilisation of stem cells is associated with higher grade aGvHD (Hua et al., 2010). This is contradictory with the finding that preincubation of T cells with IL-2 inhibits Th1 polarisation and fosters Th2 
polarisation by inducing suppressor of cytokine signalling (SOCS)-3 (Zhao et al., 2010). Increased IL-2 was also found to be associated with the development of intestinal aGvHD (Takatsuka et al., 2000).

Experiments have been performed where mice suffering from aGvHD were injected with recombinant IL-2. If IL-2 is administered one week after transplantation it aggravates disease severity, whereas when it is administered immediately after transplantation, it has a protective effect against aGvHD (Sykes et al., 1990).

Serum levels of soluble IL-2 receptor correlate with severity of aGvHD and are a good marker (Grimm et al., 1998; Kami et al., 2000). Monoclonal antibodies against the soluble IL-2 receptor have been successfully used for the treatment of steroidrefractory aGvHD (Bay et al., 2005; Pinana et al., 2006; Schmidt-Hieber et al., 2005; Willenbacher et al., 2001).

IL-2 induces the production of IFN $\gamma$, which plays a central role in the pathogenesis of aGvHD. Interestingly, IFN $\gamma$ can mediate both, disease enhancing as well as protective effects. IFN $\gamma$ is produced by activated T cells and is considered a major Th1 cytokine. It enhances antigen presentation by inducing MHC molecules. It also upregulates the expression of adhesion molecules and chemokines and therefore facilitates the recruitment of effector cells to the target organs. Furthermore, it can upregulate Fas and FasL and increase apoptosis of target cells. In macrophages, IFN $\gamma$ increases the lysosomal activity and induces production of effector molecules such as NO and several cytokines (reviewed in Schroder et al., 2004).

During the pathogenesis of aGvHD cytotoxic T cells and Th1 cells produce large amounts of IFN $\gamma$, which, in turn, primes macrophages to produce pro-inflammatory cytokines like TNF $\alpha$ and IL-1. IFN $\gamma$ is therefore associated with the cytokine storm in aGvHD and increased serum levels of IFN $\gamma$ in patients were found to be associated with severe intestinal aGvHD (Takatsuka et al., 2000).

On the other hand, it has been found that the prophylactic injection of exogenous IFN $\gamma$ is protective against aGvHD (Brok et al., 1993) and the transplantation of IFN $\gamma^{-1-}$ T cells into lethally irradiated hosts aggravates aGvHD (Welniak et al., 2000). This contradictory role possibly derives from the fact that IFN $\gamma$ is required for activationinduced cell death (AICD) and that in an IFN $\gamma$ deficient situation the T cell pool does not contract as consequence of the massive expansion due to strong alloreactive 
stimulation, which would in a regular immune response against a pathogen be the case (Li et al., 2001; Refaeli et al., 2002).

For many classical Th1 diseases, such as multiple sclerosis, recent findings have shown that Th17 cells play an important role. It was revealed that mice deficient for IFN $\gamma$ are susceptible for experimental autoimmune encephalomyelitis, an animal model for multiple sclerosis (reviewed in Bettelli et al., 2007). As a similar effect is found in aGvHD, where the transplantation of transplantation of IFN $\gamma$-deficient T cells causes exacerbated aGvHD (Welniak et al., 2000), it is possible that the same applies for aGvHD and therefore the influence of IL-17 in aGvHD is currently highly debated. IL-17 levels early after transplantation are not predictive for aGvHD incidence (Cho et al., 2011), but Dander et al. found that patients with active aGvHD had an increased number of Th17 cells and increased serum levels of IL-17, and that upon improvement of aGvHD, Th17 levels decreased (Dander et al., 2009).

Other studies showed that the role of Th17 cells in aGvHD is tissue specific. Th17 cells appear responsible for skin GvHD, while Th1 cells cause gut and liver GvHD and Th2 cells seem responsible for lung GvHD (Carlson et al., 2009; Yi et al., 2009). Another approach is to view Th17 cells and IL-17 in the context of the Th1 response. The transplantation of IL-17 deficient T cells can cause exacerbated aGvHD, which may be explained by the fact that in the absence of a Th17 response, the balance shifts in favour of a deleterious Th1 response (Yi et al., 2008). Others found that disease onset was delayed if IL-17 was absent (Kappel et al., 2009) or no difference when transplanting IL-17-deficient T cells (Oh et al., 2010).

IL-6 has many effects and can, e.g. promote proliferation and activation of T cells, as well as activation of macrophages. It also has anti-tumour activity and impacts haematopoiesis and therefore may enhance engraftment. IL-6 is produced by many cells. In macrophages it is induced by stimuli such as IFN $\gamma$ and LPS (Akira et al., 1993). It may also be released, amongst other cytokines, by Kupffer cells in the liver that are activated by LPS following gut injury (Fox et al., 1989). Enterocytes can produce IL-6 (Shirota et al., 1990). Lastly, T cells produce IL-6 (Akira et al., 1993).

IL-6 serum levels were found to be increased early after transplantation in patients with transplant-related complications and during the height of symptoms (Schots et al., 2003). Donor polymorphisms for IL-6 are associated with higher risk for aGvHD (Choi et al., 2012). 
Monocyte chemoattractant protein (MCP)-1 or CCL2 is a chemokine, which is produced e.g. by monocytes/macrophages, dendritic cells and vascular endothelial cells. It can be induced by stimuli such as LPS and IL-1. It is chemotactic for monocytes and is associated with monocytic infiltrates (Yadav et al., 2010).

MCP-1 in aGvHD is not well studied. One group found that MCP-1 was significantly increased in patients suffering from aGvHD (Ouyang et al., 2008). Bouazzaoui et al. found an overexpression of MCP-1 RNA in liver and lung in aGvHD (Bouazzaoui et al., 2009). They also found that reduced MCP-1 expression after treatment with prednisolone was associated with less gastrointestinal damage (Bouazzaoui et al., 2011), although they did not find increased MCP-1 expression in the gut in their previous publication (Bouazzaoui et al., 2009).

The anti-inflammatory cytokine interleukin (IL)-10 can regulate Th1 cells, macrophages and also NK cells. Its regulatory function is mediated by direct action on T cells or indirectly by its effect on APCs. It may be produced by macrophages, B cells and regulatory T cells (Couper et al., 2008). High IL-10 production is thought to be protective against aGvHD (Baker et al., 1999; Holler et al., 2000; Takatsuka et al., 1999), although high IL-10 levels in end-stage disease are associated with fatal outcome (Hempel et al., 1997). This may be explained by the theory that IL-10 in early disease is protective, whilst in established aGvHD it is merely upregulated as a response to high amounts of inflammatory cytokines (Takatsuka et al., 1999). It has been implicated that IL-10 is crucial for the inhibition of aGvHD by regulatory $T$ cells in vivo (Hoffmann et al., 2002). Both recipient and donor polymorphisms of IL-10 have been asscociated with the risk of developing aGvHD (Goussetis et al., 2011; Karabon et al., 2005).

Furthermore IL-1 and TNF $\alpha$ are considered crucial for the pathogenesis of aGvHD (Hill et al., 1999).

\subsection{Glucocorticoids}

Glucocorticoids (GCs) are a class of steroid hormones with anti-inflammatory and immunosuppressive properties that are produced in the adrenal glands. Edward C. Kendall, Tadeus Reichstein and Philip S. Hench were awarded the Nobel Prize in Physiology or Medicine in 1950 for their work on the hormones of the adrenal cortex, which lead to the discovery of cortisone (Figure 2) as a therapeutic agent for 
rheumatoid arthritis (http://www.nobelprize.org/nobel_prizes/medicine/laureates/ 1950/press.html).

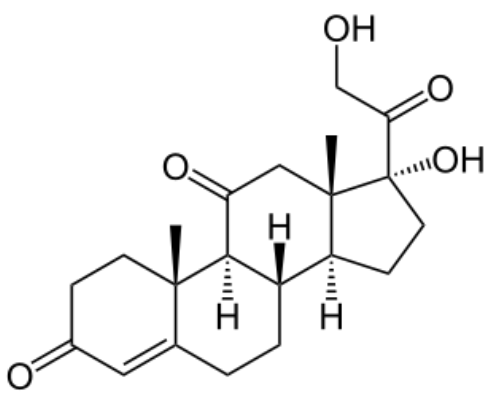

Figure 2: Chemical structure of cortisone.

GCs have since been established as the most widely used treatment for inflammatory diseases such as asthma, multiple sclerosis and allergy, as well as for immunosuppression to prevent organ rejection and many other applications. Not only the therapeutic use of GCs is highly relevant, endogenous GCs are extremely important in regulating the physiological function of the immune system.

GCs mediate their function through the GC receptor (GR) (Miesfeld et al., 1984). In its unbound state the GR resides in the cytoplasm where it is bound to chaperones, such as heat shock proteins (reviewed by Cheung and Smith, 2000). Upon binding of ligand, the GR is released from its chaperones. This exposes the importin that is constitutively associated with the GR and mediates the translocation of the receptor to the nucleus (Freedman and Yamamoto, 2004). The GR can act via two distinct mechanisms: (1) DNA-binding-dependent transactivation and (2) DNA-bindingindependent transrepression.

Transactivation is important for the activation of transcription of anti-inflammatory genes. For DNA-binding, the receptor has to dimerise (Bledsoe et al., 2002). It then binds as a homodimer to GC responsive elements (GREs). DNA-interaction is mediated by the $\mathrm{N}$-terminal zinc-finger motif in the DNA-binding domain (Cheung and Smith, 2000; Luisi et al., 1991). Transcriptional co-activators are recruited to the two transactivation domains and either mediate chromatin remodelling or recruit and stabilize the transcription machinery (reviewed in Tuckermann et al., 2005).

Transrepression, on the other hand, does not require dimerisation or DNA-binding (Reichardt et al., 1998), but is mediated by direct interaction of the GR monomer with inflammatory transcription pathways, such as NF-kB (Reichardt et al., 2001), AP-1 (Tuckermann et al., 1999) and Jak/Stat (Tronche et al., 2004) signalling. This is likely 
mediated by direct binding of the GR to the DNA-bound transcription factors and interference with their transactivation.

In addition, GCs have rapid non-genomic effects that are, as of yet, not well researched (Buttgereit and Scheffold, 2002).

Not only can GCs exert their effects through different molecular modes of action, but since the GR is expressed in most cells, they can also affect many target cell types (Pujols et al., 2002).

GC secretion is regulated by a negative feedback loop of the hypothalamic-pituitaryadrenal (HPA) axis (Keller-Wood and Dallman, 1984; Kretz et al., 1999).

Because of their high potency, GCs unfortunately have many side effects. This includes dysregulation of the glucose metabolism (Pidala et al., 2011), osteoporosis (Canalis et al., 2007) and redistribution of adipose tissue (Peeke and Chrousos, 1995). Also, infections can also occur due to general immune suppression in longterm treatment.

There are indications that the beneficial effects of GC therapy are mediated mainly through transrepression, whereas side-effects are primarily induced by transactivation (Rosen and Miner, 2005), although newer observations call this into question (Baschant et al., 2012; Rauch et al., 2010). New drugs that only target specific mechanisms or some immune cells of the broad spectrum of GC effects are therefore a very interesting alternative (De Bosscher et al., 2005; Linker et al., 2008). However, to develop such drugs that only target the beneficial mechanisms for any disease requires knowledge about how GCs exert their therapeutic function in that particular disease.

Despite their widespread use, the beneficial mechanisms in different diseases have only recently started to be revealed. Even in the same disease, endogenous and therapeutic doses of GCs may play a different role and utilise different ways of action. In phorbol ester (phorbol 12-myristate 13-acetate, PMA) induced oedema formation, which is characterised by infiltration if neutrophils and mononuclear cells, a common model for inflammation, repression of inflammation by GCs is dimerisationindependent and mediated by transrepression (Reichardt et al., 2001). In contact hypersensitivity (CHS), a model for contact dermatitis, GCs require the GR in macrophages and neutrophils for their action. Also, their effect is dimerisationdependent (Tuckermann et al., 2007). In experimental autoimmune encephalomyelitis $(E A E)$, the effect on peripheral T cells is required (Wüst et al., 
2008), specifically the prevention of infiltration (personal communication, Holger Reichardt). In antigen-induced arthritis (AIA), a model for rheumatoid arthritis, it is also the effect on T cells that is crucial, but in this case treatment is dimerisationdependent (Baschant et al., 2012). In sepsis the effect on IL-1b production of macrophages is required, which is dimerisation-dependent (Kleiman et al., 2011). The analysis of these different diseases clearly shows that it is highly dependent on the type of inflammation which cellular and molecular mechanisms are required for GC therapy.

Many synthetic glucocorticoids have been synthesised for optimised use as drugs. Compared to cortisone, dexamethasone (dex) (Figure 3) features an $\alpha$-methylsubstituent at C-16 and at C-9 $\alpha$ a hydrogen atom is substituted by fluorine. Also, it features an additional $\alpha, \beta$-unsaturated functionality in its steroidal A-Ring, and a hydoxyl-function at C-11. Its anti-inflammatory potency is 25 times as high as cortisol and its biological half-life is extended (Cantrill et al., 1975).

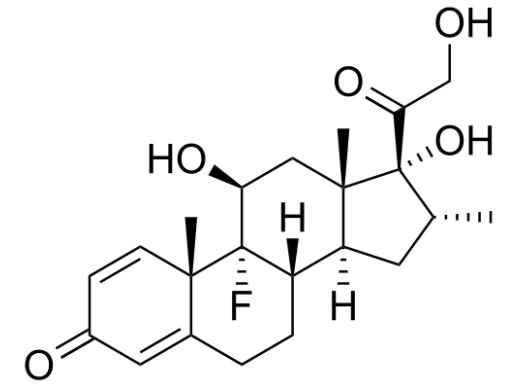

Figure 3: Chemical structure of dexamethasone, a synthetic glucocorticoid.

\subsection{Treatment of aGvHD}

The depletion of T cells prevents the occurrence of aGvHD, but unfortunately it does not improve overall morbidity and mortality, as it increases the risk for graft failure, infections, cytomegalovirus infections, relapse of the underlying malignancy and Epstein-Barr virus-associated lymphoproliferative disorders (reviewed in Poynton, 1988; Wagner et al., 2005). Partial deletion of different T cell subsets did not produce improved results (reviewed in Ferrara et al., 2009).

Usually, cyclosporine A and methotrexate are used as pharmacological prophylaxis (e.g. Storb et al., 1986). Some studies found the use of tacrolimus advantageous over cyclosporine A in preventing aGvHD, but this did not improve overall, diseasefree survival (Ratanatharathorn et al., 1998). Prophylactic immunosuppression is generally continued until about 100 days after transplant and then tapered (Chao et 
al., 2005). Steroids play little role in prevention of aGvHD. The addition of prednisolone to the standard regimen of cyclosporine with methotrexate, although it appears to delay disease onset, does not reduce the overall incidence of aGvHD or improve the overall mortality (Chao et al., 2000).

Despite efforts to develop new therapies for aGvHD, GCs remain the gold standard first-line therapy. It has been presumed that GCs in aGvHD have a direct effect on T cells and that they reduce cytokines (Antin and Ferrara, 1992), but so far little evidence for the mechanisms has been shown. Conceivable mechanisms are apoptosis of T cells, modulation of the T cell response via APCs, modulation of cytokines, reduction of infiltration due to an effect on chemokines and adhesion molecules and reduction of MHC expression.

Because of the long time period for which treatment is often required, there are often considerable side effects, and more targeted therapies are desirable. Also, understanding what is important in GC therapy of aGvHD, might enable to help those patients who are refractory to $\mathrm{GC}$ therapy.

\subsection{Objective}

The aim of this project was to identify the molecular and cellular mechanisms of endogenous and therapeutic GCs in GGvHD. If the cells on which the effect of GCs is important and the molecular mechanisms through which they down-regulate the $\mathrm{GvH}$ response are unravelled, it will become easier to identify risk factors for developing aGvHD and to find more specific therapies, as well as to better understand steroid refractory aGvHD.

It may be particularly challenging to find the important mechanisms for GC therapy in aGvHD, because, since alloantigens are present ubiquitously, most of the adaptive immune system is engaged in its disease process. Manipulation of most inflammatory mediators, such as cytokines, chemokines, adhesion molecules etc., does affect aGvHD in some way (Shlomchik, 2007). A reverse genetics approach was employed, where the GR or certain molecular functions were abrogated in different tissues to identify the crucial mechanisms. 


\section{Material}

If not otherwise specified, all places are in Germany.

\subsection{General equipment}

Table 1: General equipment

Accu-jet@ pro pipette controller

Brand $\mathrm{GmbH}$, Wertheim

Arium $\AA^{\circledR} 611$ laboratory water purification system

Sartorius AG, Göttingen

Centrifuge 5417R for reaction tubes

Centrifuge 5804 for FACS tubes

Eppendorf, Hamburg

Centrifuge multifuge $4 \mathrm{KR}$ for Falcon tubes

Eppendorf, Hamburg

Heraeus, Hanau

Centrifuge Sigma 2-5 for 96 -well plates

SIGMA Laborzentrifugen $\mathrm{GmbH}$,

Osterode am Harz

Electrophoresis power supply 301

Amersham Biosciences, Freiburg

Freezer Hera freeze $-80^{\circ} \mathrm{C}$

Heraeus, Hanau

Freezer Liebherr Comfort $-20^{\circ} \mathrm{C}$

Liebherr-International Deutschland

$\mathrm{GmbH}$, Biberach an der Riss

Freezer VIP plus $-150^{\circ} \mathrm{C}$

SANYO Electric Co., Ltd., Moriguchi,

Osaka, Japan

Incubator, HERACell 240

Heraeus, Hanau

Laminar airflow cabinet, HERASafe

Heraeus, Hanau

Micropipettes $2 \mu \mathrm{l}, 20 \mu \mathrm{l}, 200 \mu \mathrm{l}, 1000 \mu \mathrm{l}$

Gilson, Middleton, Wisconsin, USA

Microscope Primo Star

Microscope Telaval 31

Neubauer improved haemocytometer precicolor

Zeiss, Jena

Zeiss, Jena

Henneberg-Sander GmbH, Giessen-

Lützellinden

pH-Meter 766 Calimatic

Knick Elektronische Messgeräte

GmbH \& Co. KG, Berlin

Gulmay Medical Systems,

RS 225 X-Ray Research System

Camberley, Surrey, UK

Scales TE313S

Sartorius AG, Göttingen

Shaker 3006

Gesellschaft für Labortechnik (GFL),

Burgwedel

UV System with camera and gel imager

Vortex Genie-2

INTAS Science Imaging Instruments

GmbH, Göttingen

Scientific Industries, Bohemia, New

York, USA

Water bath W12

Labortechnik Medingen, Dresden

\subsection{Consumables}

Table 2: Consumables

96-well Suspension Culture Plate, UGreiner bio-one $\mathrm{GmbH}$, Frickenhausen 
bottom

96-well Tissue Culture Plate 96-well Vbottom

96well Suspension Culture Plate, flat bottom

BD Micro-Fine ${ }^{\mathrm{TM}}+\mathrm{U}-100$ Insulin Syringes $1 \mathrm{ml}(29 \mathrm{G} 1 / 2 ")$

BD Microtainer SST tube

Cell culture plates $3.5 \mathrm{~cm}, 6 \mathrm{~cm}, 10 \mathrm{~cm}$

Cell strainer $40 \mu \mathrm{m}$

Cellstar ${ }^{\circledR}$ pipettes $5 \mathrm{ml}, 10 \mathrm{ml}, 25 \mathrm{ml}$

CryoTube ${ }^{\mathrm{TM}}$ Vials

ELISA Plates

FACS tubes

Falcon tubes $15 \mathrm{ml}, 50 \mathrm{ml}$

Filtropur BET50 0.2, $500 \mathrm{~mL}$ Bottle Top

Filter

Filtropur S 0.2, 0.45

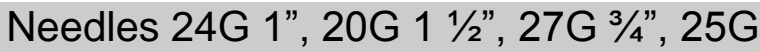

1", 20G $23 / 4 "$

Pipette tips $10 \mu \mathrm{l}, 200 \mu \mathrm{l}, 1000 \mu \mathrm{l}$

Reaction tubes $0.5 \mathrm{ml}$

Reaction tubes $1.5 \mathrm{ml}, 2 \mathrm{ml}$

Syringes $1 \mathrm{ml}$

Syringes $2 \mathrm{ml}, 5 \mathrm{ml}, 10 \mathrm{ml}$
Sarstedt, Nümbrecht

Greiner bio-one $\mathrm{GmbH}$, Frickenhausen

BD Biosciences, Heidelberg

BD Biosciences, Heidelberg

Sarstedt, Nümbrecht

BD Biosciences, Heidelberg

Greiner bio-one $\mathrm{GmbH}$, Frickenhausen

Nunc, Roskilde, Denmark

Nunc, Roskilde, Denmark

BD Biosciences, Heidelberg

Greiner bio-one $\mathrm{GmbH}$, Frickenhausen

Sarstedt, Nümbrecht

Sarstedt, Nümbrecht

B. Braun Melsungen AG, Melsungen

Greiner bio-one $\mathrm{GmbH}$, Frickenhausen

Sarstedt, Nümbrecht

Greiner bio-one $\mathrm{GmbH}$, Frickenhausen

Henke Sass Wolf, Tuttlingen

BD Biosciences, Heidelberg

\subsection{Chemicals and buffer additives}

Table 3: Chemicals and buffer additives

3,3',5,5'-Tetramethylbenzidine

Agarose UltraPure

BSA

$\mathrm{CaCl}_{2} \times 2 \mathrm{H} 2 \mathrm{O}$

Citric acid

Dex water soluble

Dexa-ratiopharm® 100 mg Injektionslösung

D-Glucose

DMSO

DNA ladder $1 \mathrm{~kb}$

EDTA

Ethanol

Ethidium bromide

FCS (stripped)

GIBCO ${ }^{\circledR}$ Penicillin/Streptomycin
SIGMA-Aldrich, Taufkirchen

Invitrogen, Paisley, UK

Carl Roth, Karlsruhe

Merck, Darmstadt

Merck, Darmstadt

SIGMA-Aldrich, Taufkirchen

Ratiopharm GmbH, Ulm

Merck, Darmstadt

Carl Roth, Karlsruhe

Fermentas GmbH, St. Leon-Rot

Serva, Heridelberg

Carl Roth, Karlsruhe

Carl Roth, Karlsruhe

HyClon, Perbio Science, Bonn

Invitrogen, Paisley, UK 


\begin{tabular}{|c|c|}
\hline $\mathrm{H}_{2} \mathrm{O}_{2} 30 \%$ & Carl Roth, Karlsruhe \\
\hline $\mathrm{H}_{2} \mathrm{SO}_{4}$ & Merck, Darmstadt \\
\hline $\mathrm{HCl}$ & Carl Roth, Karlsruhe \\
\hline HEPES & Merck, Darmstadt \\
\hline $\mathrm{KCl}$ & Merck, Darmstadt \\
\hline $\mathrm{KH}_{2} \mathrm{PO}_{4}$ & Merck, Darmstadt \\
\hline $\mathrm{KHCO}_{3}$ & Merck, Darmstadt \\
\hline $\mathrm{Na}_{2} \mathrm{CO}_{3}$ & Merck, Darmstadt \\
\hline $\mathrm{Na}_{2} \mathrm{HPO}_{4} \times 12 \mathrm{H}_{2} \mathrm{O}$ & Merck, Darmstadt \\
\hline $\mathrm{Na}_{3} \mathrm{C}_{6} \mathrm{H}_{5} \mathrm{O}_{7}$ & Carl Roth, Karlsruhe \\
\hline $\mathrm{NaCl}$ & Carl Roth, Karlsruhe \\
\hline $\mathrm{NaH}_{2} \mathrm{PO}_{4} \times \mathrm{H}_{2} \mathrm{O}$ & Merck, Darmstadt \\
\hline $\mathrm{NaHCO}_{3} \times 3 \mathrm{H}_{2} \mathrm{O}$ & Merck, Darmstadt \\
\hline $\mathrm{NaN}_{3}$ & Carl Roth, Karlsruhe \\
\hline $\mathrm{NaOH}$ & SIGMA-Aldrich, Taufkirchen \\
\hline Neomycin trisulfate salt hydrate & SIGMA-Aldrich, Taufkirchen \\
\hline $\mathrm{NH}_{4} \mathrm{Cl}$ & Merck, Darmstadt \\
\hline Percoll & SIGMA-Aldrich, Taufkirchen \\
\hline Tris & Carl Roth, Karlsruhe \\
\hline Tween-20 & Carl Roth, Karlsruhe \\
\hline
\end{tabular}

\subsection{Media and solutions}

GIBCO ${ }^{\circ}$ DMEM+GlutaMAX ${ }^{\mathrm{TM}}-\mathrm{I}$, Invitrogen, Paisley, UK

GIBCO® RPMI 1640+GlutaMAX ${ }^{\mathrm{TM}}$-I, Invitrogen, Paisley, UK

RPMI and DMEM complete:

$+10 \%$ FCS

$+0,01 \%$ Penicillin/Streptomycin

PBS: $\mathrm{pH} 7.4$

$137 \mathrm{mM} \mathrm{NaCl}$

$2.7 \mathrm{mM} \mathrm{KCl}$

$10 \mu \mathrm{M} \mathrm{Na}_{2} \mathrm{HPO}_{4}$

$2.0 \mathrm{mM} \mathrm{KH}_{2} \mathrm{PO}_{4}$

GIBCO ${ }^{\circledR}$ Cell Dissociation Buffer, enzyme free, PBS-based, Invitrogen, Paisley, UK

\section{Erythrocyte lysis buffer}

$168 \mathrm{mM} \mathrm{NH}_{4} \mathrm{Cl}$

$10 \mathrm{mM} \mathrm{KHCO}_{3}$

$0.1 \mathrm{mM}$ EDTA

\section{TAC buffer:}

$20.0 \mathrm{mM}$ Tris/HCl pH 7.2

$155 \mathrm{mM} \mathrm{NH}_{4} \mathrm{Cl}$

\section{Alsevers:}

$27 \mathrm{mM} \mathrm{NaCl}$ 
$125 \mathrm{mM}$ D-Glucose

$3 \mathrm{mM}$ Citric acid

$30 \mathrm{mM} \mathrm{Na}_{3} \mathrm{C}_{6} \mathrm{H}_{5} \mathrm{O}_{7}$

Buffer solutions pH 4, $7+10$, Carl Roth, Karlsruhe

\subsection{Flow cytometry}

FACS Buffer:

PBS pH 7.2

$0.1 \% \mathrm{BSA}$

$0.01 \% \mathrm{NaN}_{3}$

Table 4: FACS antibodies

\begin{tabular}{|c|c|c|c|c|c|}
\hline Specificity & Antigen & Dye & Clone & $\begin{array}{c}\text { Final } \\
\text { dilution }\end{array}$ & Supplier \\
\hline$\alpha$-mouse & CD11b & PE-Cy7 & M1/70 & $1: 2000$ & BD Biosciences \\
\hline$\alpha$-mouse & CD4 & PerCP & RM4-5 & $1: 1000$ & BD Biosciences \\
\hline$\alpha$-mouse & CD44 & bio & IM7 & $1: 2000$ & BD Biosciences \\
\hline$\alpha$-mouse & CD45R/B220 & PE & RA3-6B2 & $1: 1000$ & BD Biosciences \\
\hline$\alpha$-mouse & CD8 $\alpha$ & PE-Cy7 & $53-6.7$ & $1: 2000$ & eBioscience \\
\hline$\alpha$-mouse & F4/80 & fitc & MCA497F & $1: 200$ & AbD Serotec \\
\hline$\alpha$-mouse & I-A[b] & PE & AF6-120.1 & $1: 200$ & BD Biosciences \\
\hline$\alpha$-mouse & I-A[d] & PE & AMS-32.1 & $1: 200$ & BD Biosciences \\
\hline$\alpha$-mouse & TCR $\beta$-chain & fitc & H57-597 & $1: 1000$ & BD Biosciences \\
\hline- & Streptavidin & APC & - & $1: 1000$ & BD Biosciences \\
\hline
\end{tabular}

BD Biosciences, Heidelberg; eBioscience, San Diego, California, USA; AbD Serotec, Oxford, UK

OptiLyse ${ }^{\circledR}$ B Lysing Solution, Beckman Coulter, Krefeld

Annexin Binding Buffer:

$10 \mathrm{mM}$ HEPES/NaOH, $\mathrm{pH} 7.4$

$140 \mathrm{mM} \mathrm{NaCl}$

$2.5 \mathrm{mM} \mathrm{CaCl}_{2}$

in $\mathrm{ddH}_{2} \mathrm{O}$

Cy5 Annexin V, BD Biosciences, Heidelberg

7-AAD, BD Biosciences, Heidelberg

BD FACS Cantoll, BD Biosciences, Heidelberg

BD FACS Diva ${ }^{\mathrm{TM}}$ software version 6.1.2, BD Biosciences, Heidelberg 
BD FACS Flow Sheath Fluid, BD Biosciences, Heidelberg

BD FACS Clean Solution, BD Biosciences, Heidelberg

BD FACS Shutdown Solution, BD Biosciences, Heidelberg

FlowJo version 8.8.6, Tree Star, Inc., Ashland, Oregon, USA

\subsection{Magnetic activated cell sorting (MACS)}

MACS buffer run:

PBS pH 7.2

$2.0 \mathrm{mM}$ EDTA

$0.5 \% \mathrm{BSA}$

MACS buffer rinse:

PBS pH 7.2

$2.0 \mathrm{mM}$ EDTA

Pan T cell Isolation Kit II mouse, Miltenyi Biotec, Bergisch Gladbach

CD90.2 MicroBeads mouse, Miltenyi Biotec, Bergisch Gladbach autoMACS ${ }^{\text {TM }}$ Separator, Miltenyi Biotec, Bergisch Gladbach

Pre-Separation Filters $30 \mu \mathrm{l}$, Miltenyi Biotec, Bergisch Gladbach autoMACS ${ }^{\circledR}$ Columns, Miltenyi Biotec, Bergisch Gladbach

\subsection{Enzyme Linked Immunosorbant Assay (ELISA)}

\section{Coating Buffers:}

Buffer 1: $0.1 \mathrm{M}$ sodium carbonate, $\mathrm{pH} 9.5$

Buffer 2: $0.2 \mathrm{M}$ sodium phosphate, $\mathrm{pH} 6.5$

Assay Diluent: $10 \% \mathrm{v} / \mathrm{v}$ FCS in PBS

Wash Buffer: 0.05\% v/v Tween-20 in PBS

\section{Substrate Buffer:}

$0.1 \mathrm{M}$ Citric Acid

$0.2 \mathrm{M} \mathrm{Na}_{2} \mathrm{HPO}_{4}$

In $\mathrm{ddH}_{2} \mathrm{O}$

TMB solution:

$1 \%$ w/v 3,3',5,5'-Tetramethylbenzidine in DMSO

Substrate Solution:

$10 \% \mathrm{v} / \mathrm{v}$ TMB solution

$2 \% \mathrm{v} / \mathrm{v} \mathrm{H}_{2} \mathrm{O}_{2}(3,5 \%)$

in Substrate Buffer

Stop Solution: $1 \mathrm{M} \mathrm{H}_{2} \mathrm{SO}_{4}$ 


\begin{tabular}{|c|c|c|c|c|}
\hline & $\begin{array}{l}\text { Coating } \\
\text { Buffer }\end{array}$ & $\begin{array}{c}\text { Dilution of } \\
\text { capture } \\
\text { antibody }\end{array}$ & $\begin{array}{l}\text { Dilution of } \\
\text { detection } \\
\text { antibody }\end{array}$ & $\begin{array}{c}\text { Dilution of } \\
\text { Avidin- } \\
\text { HRP }\end{array}$ \\
\hline $\begin{array}{l}\text { ELISA MAX }{ }^{\mathrm{TM}} \text { Standard Set } \\
\text { Mouse IL-1 } \beta \text {, BioLegend }\end{array}$ & Buffer 1 & $1: 200$ & $1: 200$ & $1: 1000$ \\
\hline 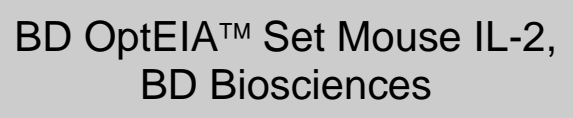 & Buffer 1 & $1: 250$ & $1: 1000$ & $1: 250$ \\
\hline $\begin{array}{l}\text { ELISA MAX }{ }^{\mathrm{TM}} \text { Standard Set } \\
\text { Mouse IL-10, BioLegend }\end{array}$ & Buffer 2 & $1: 200$ & $1: 200$ & $1: 1000$ \\
\hline 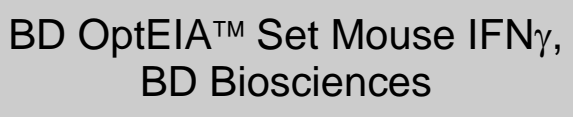 & Buffer 1 & $1: 250$ & $1: 250$ & $1: 250$ \\
\hline $\begin{array}{c}\text { ELISA MAX }{ }^{\mathrm{TM}} \text { Standard Set } \\
\text { Mouse IFN } \gamma \text {, BioLegend }\end{array}$ & Buffer 1 & $1: 250$ & $1: 200$ & 1:1000 \\
\hline $\begin{array}{l}\text { BD OptEIA }{ }^{T M} \text { Set Mouse } \\
\text { TNF } \alpha, \text { BD Biosciences }\end{array}$ & Buffer 2 & $1: 250$ & $1: 500$ & $1: 250$ \\
\hline
\end{tabular}

BD Biosciences, Heidelberg; BioLegend, San Diego, California, USA

BioTek $\circledast$ Power Wave 340 plate reader, BioTek, Bad Friedrichshall BioTek ${ }^{\circledR}$ Gen5 ${ }^{\mathrm{TM}}$ version 1.09, BioTek, Bad Friedrichshall

\subsection{Cytometric Bead Array (CBA)}

BD CBA Mouse/Rat Soluble Protein Master Buffer Kit, BD Biosciences, Heidelberg

BD CBA Mouse IL-1b Flex Set E5, BD Biosciences, Heidelberg

BD CBA Mouse MCP-1 Flex Set B7, BD Biosciences, Heidelberg

BD CBA Mouse IL-10 Flex Set C4, BD Biosciences, Heidelberg

BD CBA Mouse IL-6 Flex Set B4, BD Biosciences, Heidelberg

BD CBA Mouse IL-17A Flex Set C5, BD Biosciences, Heidelberg

FCAP Array version 1.0.2, Soft Flow, Inc., Burnsville, Minnesota, USA

\section{9. $q R T-P C R$}

T18 basic Ultra-Turrax ${ }^{\circledR}$ high-performance disperser, IKA, Staufen

Qiagen RNeasy ${ }^{\circledR}$ Plus Universal Kit, Qiagen, Hilden

iScript $^{\mathrm{TM}}$ cDNA Synthesis Kit, Bio-Rad, Hercules, CA, USA 
Primer: (10 pmol/ $\mu \mathrm{l}$ forward and reverse primer/reaction)

Granzyme B:

5'-TGT GGG CCC CCA AAG TGA CAT-3'

5'-AAA GGC AGG GGA GAT CAT CGG G-3'

Hypoxanthin-Guanin-Phosphoribosyltransferase (HPRT):

5'-GGG ACG CAG CAA CTG ACA TT-3'

5'-GTC CTG TGG CCA TCT GCC TA-3'

Interferon- $\gamma$ (IFN $\gamma)$ :

5'-ACT GGC AAA AGG ATG GTG AC-3'

5'-TGA GCT CAT TGA ATG CTT GG-3'

Interleukin-17A (IL-17A):

5'-TCC AGA AGG CCC TCA GAC TA-3'

II-17A rev: 5'-AGC ATC TTC TCG ACC CTG AA-3'

Perforin 1:

5'-TGT TAA AGT TGC GGG GGA GGG C-3'

5'-GTG GCT GGC TCC CAC TCC AA-3'

F-518 5x Phusion® Reaction Buffer HF with $7.5 \mathrm{mM} \mathrm{MgCl}_{2}$, Thermo Scientific, Waltham, Massachusetts, USA

PfuS polymerase, kindly provided by Steffen Frey, Max-Planck-Institute for biophysical chemistry, Göttingen

dNTPs: dATP $\mathrm{Na}_{4} \times 3 \mathrm{H}_{2} \mathrm{O}$, dCTP $\mathrm{Na}_{4} \times 3 \mathrm{H}_{2} \mathrm{O}$, dGTP $\mathrm{Na}_{4} \times 3 \mathrm{H}_{2} \mathrm{O}$, dTTP $\mathrm{Na}_{4} \times$ $3 \mathrm{H}_{2} \mathrm{O}$, Genaxxon bioscience, Ulm

Power SYBR ${ }^{\circledR}$ green, Applied Biosystems, Foster City, California, USA

96-well Optical Reaction Plates, Applied Biosystems, Foster City, California, USA

Optical Adhesive Covers, Applied Biosystems, Foster City, California, USA

7500 Real Time PCR System, Applied Biosystems, Foster City, California, USA

7500 System SDS Software version 1.4.0.25, Applied Biosystems, Foster City, California, USA

Orange G in 30\% glycerine, SIGMA-Aldrich, Taufkirchen

\subsection{Temperature and blood glucose}

Thermometer BIO-TK9882, Bioseb, Vitrolles, France

Rectal Probe, BIO-BRET-3, Bioseb, Vitrolles, France

Ascensia Blood Glucose Meter CONTOUR ${ }^{\circledR}$, Bayer HealthCare AG, Leverkusen CONTOUR $\circledast$ Test Strips, Bayer, Bayer HealthCare AG, Leverkusen 


\subsection{Cell lines}

L929 mouse fibroblast cell line, kindly provided by Anna Kleyman, Tuckermann lab, Leibniz Institute for Age Research, Jena 


\section{Methods}

\subsection{Mice}

Mice were kept under specific pathogen-free conditions (SPF) in individually ventilated cages (IVC). They were supplied with food and water ad libitum and maintained in a standard 12 hour light-dark cycle.

The experimental approach is based on the bone marrow transplantation between two MHC-disparate mouse strains, C57BI/6 $\left(H 2^{b}\right)$ and BALB/C $\left(H 2^{d}\right)$. Several transgenic mouse strains on these backgrounds were employed.

Most strains were bred in our own facilities in Göttingen. Next to wild type BALB/C and $\mathrm{C} 57 \mathrm{BI} / 6$ mice this includes Ick-Cre GR ${ }^{\text {floxfllox }}$ mice (Baumann et al., 2005; Wüst et al., 2008), that were backcrossed to $\mathrm{C} 57 \mathrm{~B} / / 6$ for $>10$ generations. Ick-Cre $\mathrm{GR}^{\text {floxflox }}$

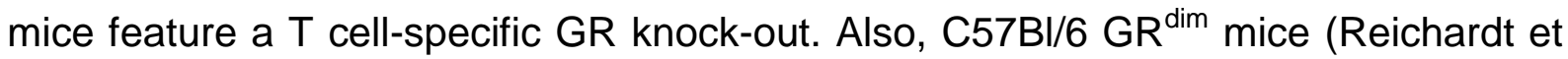
al., 1998) were used and $G^{\text {dim }}$ mice, which had been backcrossed to BALB/c for $>10$ generations. These mice express a dimerisation-deficient GR. I also used bone marrow from $\beta$-ActGFP mice (Okabe et al., 1997) and T cells from B6.SJLPtprcaPepcb/BoyJ (CD45.1-congenic C57BL/6J) mice (Uhmann et al., 2011).

Occasionally, BALB/c wild type mice were obtained from Charles River (Sulzfeld). BALB/c LysM-Cre GR ${ }^{\text {floxfllox }}$ mice (Tuckermann et al., 2007) were supplied by our cooperation partner in Jena (Jan Tuckermann, Leibniz Institute for Age Research, Jena). LysM-Cre $G R^{\text {floxfllox }}$ mice have a tissue-specific knock-out of the GR confined to myeloid cells.

All experiments were approved by the appropriate authorities in Lower Saxony (LAVES) and conducted in accordance with the ethical standards of humane animal care.

\subsection{Preparation of lymphocyte single cell suspensions}

Lymphocytes were isolated from lymph nodes (lymphnodi madibulares, axillares accessorii, inguinales superficiales, mesenteriales) and/or spleens. Mice were sacrificed in a carbon dioxide atmosphere and tissues were removed and placed in ice cold PBS with $0,1 \%$ BSA. Single cell suspensions were produced by passing the tissue through cell strainers with a $40 \mu \mathrm{m}$ nylon mesh. 


\subsection{Preparation of bone marrow}

Mice were sacrificed as described above. Tibia and femur were removed, cleaned from skin, flesh and tendons and placed in ice cold PBS with 0,1\% BSA. The ends of the bones were opened under sterile conditions and bone marrow was flushed out using a $30 \mathrm{G}$ needle. Afterwards the cells were passed through a $40 \mu \mathrm{m}$ cell strainer.

\subsection{Determination of cell number}

Cells were counted using a Neubauer haemocytometer.

\subsection{T cell purification}

T cells were purified from lymph node and/or spleen single cell suspensions using MACS-technology. The Pan T Cell Isolation Kit II mouse was used according to manufacturer's instructions. In brief, cells were resuspended in $40 \mu \mathrm{l}$ MACS buffer $/ 10^{7}$ cells and incubated with $10 \mu$ Biotin-Antibody Cocktail/ $10^{7}$ cells for $10 \mathrm{~min}$ at $4^{\circ} \mathrm{C}$. They were then washed with $4 \mathrm{ml}$ MACS buffer and resuspended in $30 \mu \mathrm{l}$ MACS buffer $/ 10^{7}$ cells, before they were incubated for $20 \mathrm{~min}$ at $4^{\circ} \mathrm{C}$ with $20 \mu \mathrm{l}$ of Anti-Biotin MicroBeads $/ 10^{7}$ cells and washed again. The cell suspension was filtered using a $30 \mu \mathrm{m}$ Pre-Separation Filter and then separated using an autoMACS Separator (programme "deplete"). Purified cells were stained for $\beta T C R$, B220, CD4 and CD8 and analysed by FACS. T cell purity was usually $>95 \%$ and CD4/CD8-Ratio remained constant before and after separation (Figure 4). 

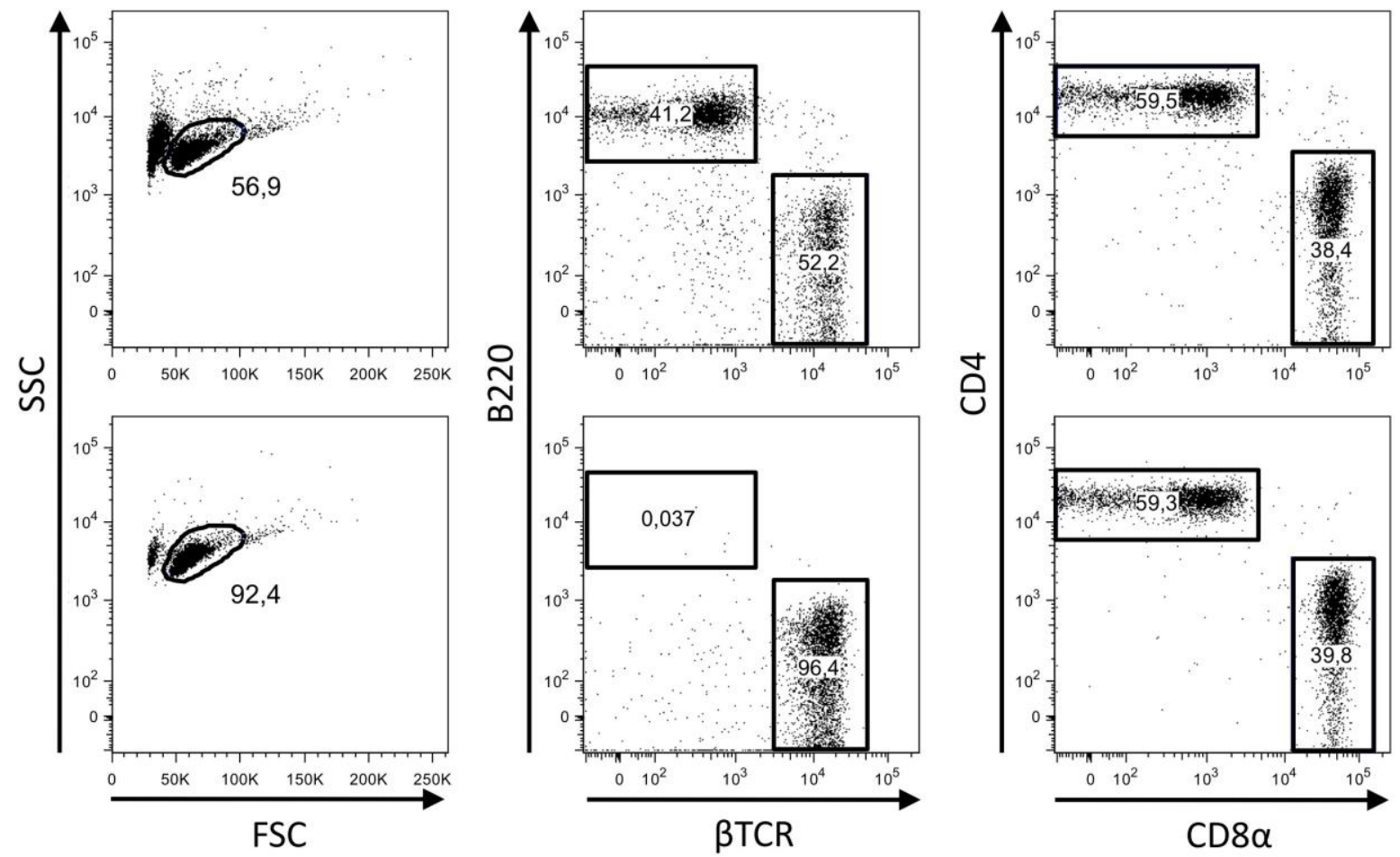

Figure 4: FACS analysis of purified $\mathrm{T}$ cells. top panel: $\mathrm{T}$ cells before purification, lower panel: $\mathrm{T}$ cells after purification with the Pan T Cell Isolation Kit II mouse.

\subsection{T cell depletion of bone marrow}

Bone marrow was depleted of $T$ cells using CD90.2 MicroBeads according to manufacturer's instructions. Bone marrow cells were resuspended in $90 \mu \mathrm{l}$ MACS buffer $/ 10^{7}$ cells and incubated with $10 \mu \mathrm{CD} 90.2$ MicroBeads $/ 10^{7}$ cells for $15 \mathrm{~min}$ at $4^{\circ} \mathrm{C}$. After passing the cells through a $30 \mu \mathrm{m}$ Pre-Separation Filter, the cells were separated using an autoMACS Separator (programme: "depletes"). Cells were stained for $\beta$ TCR and CD3 and analysed by FACS. Purity was $<1 \%$ T cells (Figure $5)$. 


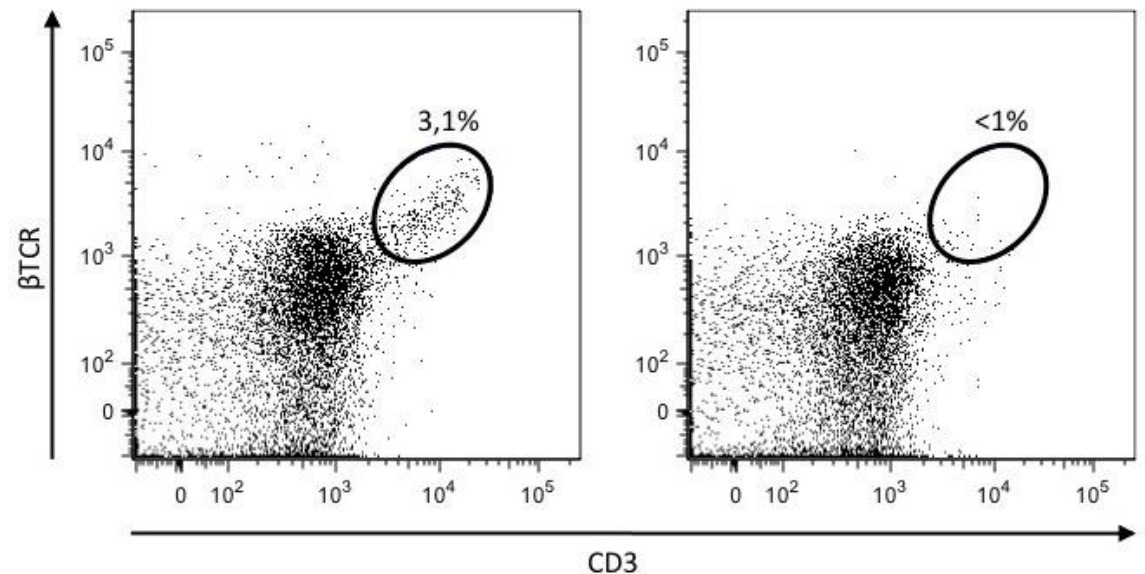

Figure 5: T cell depletion of bone marrow. left: bone marrow before T cell depletion, right: bone marrow after T cell depletion with CD90.2 MicroBeads

\subsection{Bone Marrow Derived Macrophages (BMDMs)}

\subsubsection{Production of L929-cell conditioned medium (LCCM)}

LCCM was produced as described by Ladner et al.. In brief, L929 mouse fibroblasts were grown in DMEM until confluent. Then the supernatant was collected and replaced every other day. The resulting medium was filtered sterile and stored at $-20^{\circ} \mathrm{C}$. For use, it was diluted 1:5 with DMEM (Ladner et al., 1988).

\subsubsection{Cultivation of Bone Marrow Derived Macrophages (BMDMs)}

Bone marrow was isolated as described above (3.3). Cells were resuspended in $30 \mathrm{ml} \mathrm{LCCM}$ and incubated overnight in a $175 \mathrm{ccm}$ cell culture flask per mouse $\left(37^{\circ} \mathrm{C}, 5 \% \mathrm{CO}_{2}\right)$. Adherent cells were discarded and non-adherent cells were transferred to suspension culture plates $(\varnothing 10 \mathrm{~cm}, 4 \mathrm{ml}$ cell suspension/plate). $6 \mathrm{ml}$ of LCCM were added. After 5 days, another $5 \mathrm{ml}$ of fresh LCCM were added. On day 10, the cells were washed with PBS and removed using $1 \mathrm{ml}$ enzyme free dissociation buffer/plate. A cell scraper was used to assist detachment, cells were washed off using PBS+0.1\% BSA. The suspension was centrifuged at $300 \times \mathrm{g}, 7 \mathrm{~min}$, $4^{\circ} \mathrm{C}$, the pellet resuspended in $2 \mathrm{ml}$ DMEM. Cells were checked for expression of macrophage markers and viability by flow cytometry. 


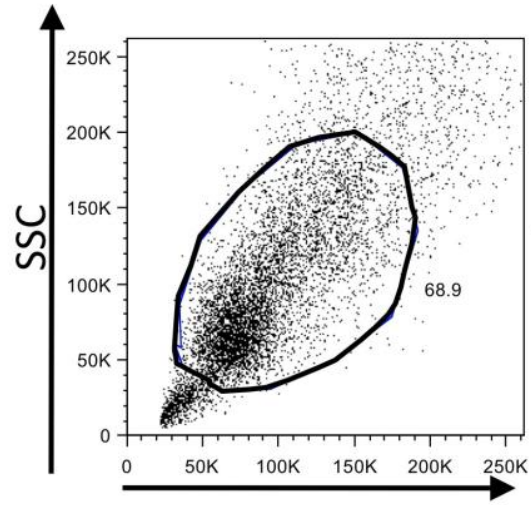

FSC

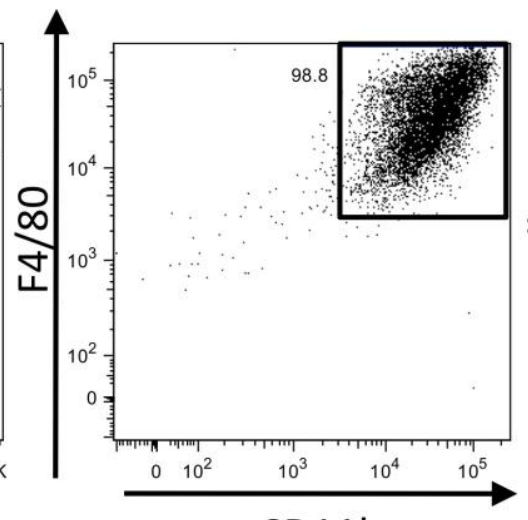

$\mathrm{CD} 11 \mathrm{~b}$

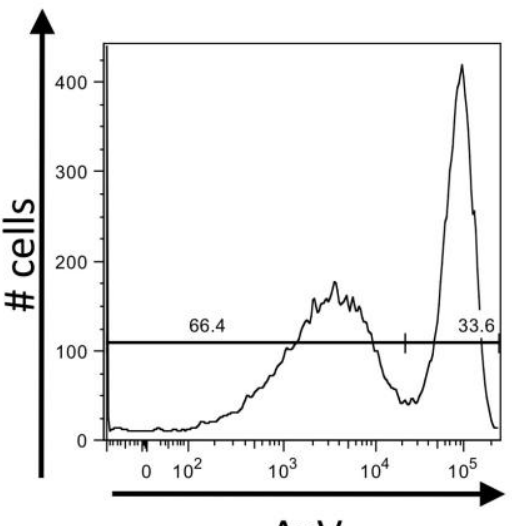

$\mathrm{AxV}$

Figure 6: Bone Marrow Derived Macrophages. left: SSC-FSC, middle: macrophage markers, right: viability

\subsection{Induction of aGvHD}

Male BALB/c mice aged 8-10 weeks were exclusively used as recipients. They were kept in IVC cages under SPF conditions and provided with food and water ad libitum. The drinking water was supplied with neomycin $(25 \mu \mathrm{g} / \mathrm{ml})$ from one day prior to irradiation until three weeks after transplantation. One day prior to transplantation, BALB/c recipients were placed in a Perspex box and irradiated with 8,5 Gy total body irradiation using an X-Ray source operated at $200 \mathrm{kV}, 15 \mathrm{~mA}$ and with $0.5-\mathrm{mm} \mathrm{Cu}$ filtration. $1 \times 10^{7} \mathrm{~T}$ cell-depleted bone marrow cells with or without (control) $2 \times 10^{6}$ purified T cells in $200 \mu \mathrm{l}$ PBS were injected into the tail vein.

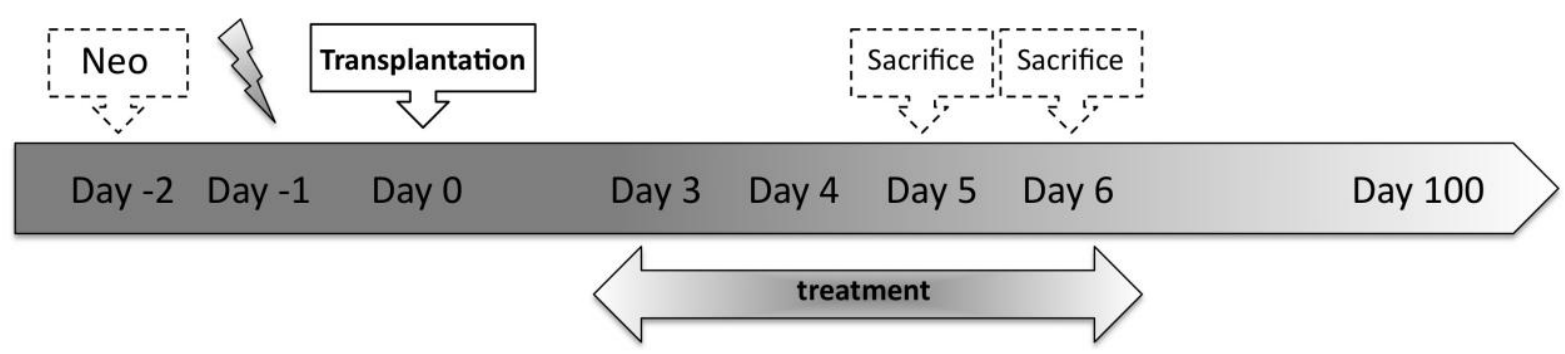

Figure 7: Scheme of aGvHD induction, therapy and analysis.

\subsection{Treatment with dex}

In our MHC-mismatched model mice usually started to develop first mild symptoms on day 3. Because of the rapid progression of the disease, treatment was therefore initiated on day 3 with $100 \mathrm{mg} / \mathrm{kg}$ dex (ratiopharm), injected intraperitoneally (i.p.), and was continued until day 6 . 


\subsection{Monitoring of disease progression}

Mice were monitored daily for signs of aGvHD. They were evaluated on the basis of a widely established (e.g. Cooke et al., 1996) clinical scoring system that features five parameters: posture, activity, fur ruffling, diarrhoea and weight loss. Each of those parameters is assigned a score from 0 (no symptoms) to 2 (severe symptoms), which results in a total score from 0 to 10 . For ethical reasons, mice with a score of 7 or greater or weight loss above $25 \%$ for more than $24 \mathrm{~h}$ were euthanised.

Table 6: aGvHD clinical score

\begin{tabular}{|c|c|c|c|}
\hline Parameter & 0 & 1 & 2 \\
\hline Posture & Normal & $\begin{array}{l}\text { Slight hunched when } \\
\text { resting }\end{array}$ & Severe hunched \\
\hline Activity & Normal & Slightly reduced & $\begin{array}{c}\text { Motionless unless } \\
\text { stimulated }\end{array}$ \\
\hline Fur ruffling & Healthy fur & Slight ruffling & $\begin{array}{l}\text { Absent grooming and } \\
\text { ruffled fur }\end{array}$ \\
\hline Diarrhoea & None & Mild & Severe \\
\hline Weight loss & $<10 \%$ & $10-25 \%$ & $>25 \%$ \\
\hline
\end{tabular}

\subsection{Blood sugar}

The tail vein was punctured using a needle and a drop of blood was obtained. Blood sugar was then measured with an Ascensia Blood Glucose Meter and CONTOUR ${ }^{\circledR}$ Test Strips.

\subsection{Body temperature}

The mouse was placed in a restrainer tube and the probe was inserted rectally. Temperature was measured.

\subsection{Serum collection}

Mice were sacrificed using carbon dioxide and a blood sample was obtained via cardiac puncture with a $24 \mathrm{G}$ needle. The blood was transferred into a BD Microtainer SST tube and left to coagulate for $30 \mathrm{~min}$ at $4^{\circ} \mathrm{C}$, before it was centrifuged at $14000 \times \mathrm{g}$ for $5 \mathrm{~min}$. Serum was stored at $-20^{\circ} \mathrm{C}$. 


\subsection{Mixed Leukocyte Reaction (MLR)}

For the in vitro mixed leukocyte reaction $4 \times 10^{5} \mathrm{~T}$ cells and an equal number of BMDMs were mixed in $200 \mu \mathrm{l}$ DMEM. Dex was added at the concentration of $10^{-7}$ or $10^{-8} \mathrm{M}$. Cells were incubated in 96 -well round bottom plates for 4 days at $37^{\circ} \mathrm{C}$, $5 \% \mathrm{CO}_{2}$. The plate was centrifuged $(300 \times \mathrm{g}, 10 \mathrm{~min}$, room temperature). Supernatant was collected and stored at $-20^{\circ} \mathrm{C}$, cells were resuspended in $200 \mu \mathrm{l}$ FACS Buffer for analysis.

\subsection{Enzyme Linked Immunosorbant Assay (ELISA)}

Cytokines were analysed via ELISA in serum samples and MLR supernatants. Samples were diluted with assay diluent and ELISA was performed according to manufacturer's instructions.

BD Biosciences kits. In brief, 96-well plates were coated with capture Antibody overnight at $4^{\circ} \mathrm{C}$ using the appropriate coating buffer. Subsequent steps were performed at room temperature. After washing with wash buffer, plates were blocked with assay diluent for $1 \mathrm{~h}$. Washing was repeated and plates were incubated with samples/standards for $2 \mathrm{~h}$. After another wash step, wells were incubated for $1 \mathrm{~h}$ with detection antibody and enzyme reagent diluted in assay diluent. Washing was then performed leaving the wells to soak for $30 \mathrm{~s}$ and finally the plate was incubated for 20 min with substrate solution. The reaction was stopped with stop solution and then measured at $450 \mathrm{~nm}$ and $570 \mathrm{~nm}$.

BioLegend kits. The procedure for BioLegend kits was similar, only all incubation steps were performed on a shaker at $200 \mathrm{rpm}$. Incubation with detection antibody and enzyme reagent was performed separately for $1 \mathrm{~h}$ and $30 \mathrm{~min}$, respectively.

\subsection{Cytokine Bead Array (CBA)}

CBA was performed according to manufacturer's instructions. Briefly, standards were prepared according to protocol. A 96-well V-bottom microtiter plate was pre-wetted with wash buffer. Capture beads were appropriately diluted in capture bead diluent and dispensed onto the plate. Serum samples were diluted 1:5 in assay diluent and added to the beads. The plate was incubated for $1 \mathrm{~h}$ at RT. Then PE-detection antibodies diluted in detection reagent diluent were added and the plate was again incubated for $1 \mathrm{~h}$ at RT. The plate was then centrifuged ( $200 \times \mathrm{g}, 3 \mathrm{~min}$ ) and the supernatant discarded. wash buffer was added to each sample and the samples 
were measured using a FACS Cantoll. Data analysis was done using FCAP array software.

\subsection{Radio Immuno Assay (RIA)}

The corticosterone-specific RIA with serum samples was performed in the Department of Internal Medicine I at the University Hospital in Würzburg by the lab of Martin Fassnacht. The MP Biomedicals Corticosterone Double Antibody - ${ }^{125}$ I RIA kit was used according to the manufacturer's instructions.

\subsection{8. qRT-PCR analysis of spleen}

For quantitative real time PCR, a spleen biopsy was collected from sacrificed mice and frozen in liquid nitrogen. Samples were stored at $-80^{\circ} \mathrm{C}$.

\subsubsection{RNA-isolation}

RNA was isolated using the Qiagen RNeasy® Plus Universal Kit according to manufacturer's instructions. Briefly, the tissue was homogenized with a highperformance disperser in $900 \mu \mathrm{l}$ Quiazol and incubated at room temperature for $5 \mathrm{~min}$. The solution was then vortexed with $100 \mu \mathrm{lgDNA}$ eliminator solution for $15 \mathrm{~s}$. $180 \mu \mathrm{l}$ of chloroform were added, the solution was vortexed for $15 \mathrm{~s}$ and then incubated for $3 \mathrm{~min}$. It was then centrifuged $\left(20000 \times \mathrm{g}, 15 \mathrm{~min}, 4^{\circ} \mathrm{C}\right)$. The upper phase was transferred to a new tube and mixed with $600 \mu \mathrm{l} 70 \%$ ethanol. The sample was then transferred to a RNeasy mini-column and centrifuged (20000 x g, $15 \mathrm{~s}$, room temperature). This step was repeated. The column was then washed using $700 \mu \mathrm{l}$ buffer RWT (10 $000 \times \mathrm{g}, 15 \mathrm{~s}$, room temperature) and afterwards $500 \mu \mathrm{l}$ buffer RPE. It was then dried (10 $000 \times \mathrm{g}, 1 \mathrm{~min}$, room temperature) and subsequently eluted with 2x35 $\mu \mathrm{l}$ RNase free water (10 $000 \times \mathrm{g}, 1 \mathrm{~min}$, room temperature).

The sample was diluted (1:50) and absorption was measured at $260 \mathrm{~nm}$ using a photometer. Contamination with protein was measured at $280 \mathrm{~nm}$ and organic compounds at $230 \mathrm{~nm}$. Quality was accepted at 260/280 >1.7 and 260/230 $\approx 2$.

$1 \mu \mathrm{g}$ of sample was run diluted in Orange $\mathrm{G}$ on a $1 \%$ agarose gel $(120 \mathrm{~V}, 230 \mathrm{~mA}$, $15 \mathrm{~min}$ ) to confirm quality.

RNA was stored at $-20^{\circ} \mathrm{C}$. 


\subsection{2. cDNA synthesis}

For cDNA synthesis the iScript cDNA Synthesis Kit was used according to manufacturer's instructions.

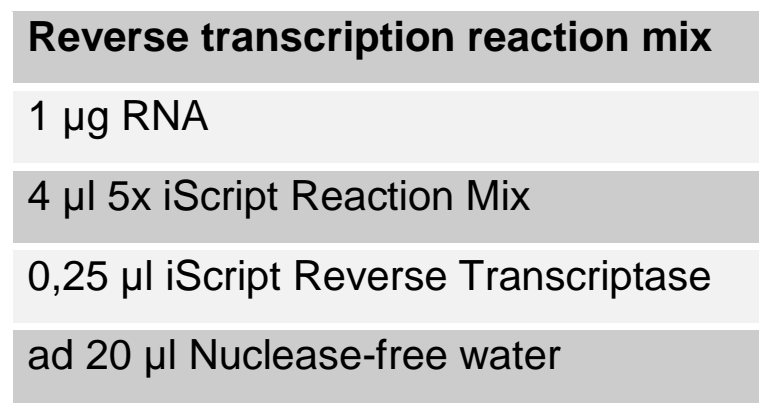

\begin{tabular}{|lll}
\multicolumn{3}{l}{ Reverse transcription programme } \\
\hline 5 min & $25^{\circ} \mathrm{C}$ & annealing \\
\hline 30 min & $42^{\circ} \mathrm{C}$ & reverse transcription \\
\hline 5 min & $85^{\circ} \mathrm{C}$ & denaturation
\end{tabular}

A PCR specific for HPRT was performed to test CDNA quality.

\begin{tabular}{|c|}
\hline PCR reaction mix \\
\hline $12,7 \mu \mathrm{ldd} \mathrm{H}_{2} \mathrm{O}$ \\
\hline $1 \mu \mathrm{ldNTPs}(5 \mathrm{mM})$ \\
\hline $1 \mu \mathrm{l} \mathrm{HPRT}$ primer mix $(10 \mathrm{p}$ \\
\hline $4 \mu \mathrm{l} 5 \mathrm{x}$ Phusion Reaction $\mathrm{B}$ \\
\hline $0,3 \mu \mathrm{l}$ PhuS \\
\hline The PCR product was run \\
\hline 3.18.3. $q R T-P C R$ \\
\hline qRT-PCR reaction mix \\
\hline $1 \mu \mathrm{l}$ cDNA \\
\hline $12,5 \mu$ I SYBR green \\
\hline $0,5 \mu \mathrm{l}$ primer mix \\
\hline $11 \mu \mathrm{lddH} \mathrm{H}_{2} \mathrm{O}$ \\
\hline
\end{tabular}

The reaction was conducted in a 96-Well Optical Reaction Plate and sealed with an Optical Adhesive Cover. qRT-PCR was run with the Applied Biosystems 7500 Real Time PCR System using 7500 System SDS Software.

The $\Delta \Delta$ ct was calculated.

\subsection{Isolation of lymphocytes from lung and liver for FACS analysis}

Liver was perfused with PBS via the vena portae, lung via the ventriculus dexter. The organs were removed. In case of liver, the vesica biliaris was carefully removed. The 
organs were passed through a metal mesh, centrifuged $\left(300 \times \mathrm{g}, 10 \mathrm{~min}, 4^{\circ} \mathrm{C}\right)$ and then resuspended in $8 \mathrm{ml} 40 \%$ Percoll. The cell suspension was then applied to a layer of $4 \mathrm{ml} 80 \%$ Percoll and centrifuged for $25 \mathrm{~min}$ at $950 \times \mathrm{g}$ with slow acceleration and stopped without brakes. The lymphocytes were collected from the interface between the two layers using a $20 \mathrm{G} \times 23 / 4$ " needle with a $2 \mathrm{ml}$ syringe.

\subsection{Flow cytometry}

For standard FACS-analysis $4 \times 10^{5}$ cells were used. All samples were analysed using a FACS Cantoll and FlowJo.

\subsubsection{Standard staining}

Samples were incubated for 20 min with primary antibodies, washed with $4 \mathrm{ml}$ FACS Buffer, and, if applicable, were incubated with secondary antibodies in the same fashion.

\subsubsection{Apoptosis assay}

To evaluate the viability of cells, they were stained with Annexin $V$ and 7-AAD. After regular staining, cells were incubated for $15 \mathrm{~min}$ at room temperature with $1 \mu \mathrm{l} \mathrm{Cy5}$ Annexin $V$ and $3 \mu \mathrm{l}$ 7-AAD in $100 \mu \mathrm{l}$ Annexin V Binding Buffer.

\subsubsection{Erythrolysis of blood samples}

Blood samples were stained according to the standard procedure and afterwards incubated for $12 \mathrm{~min}$ with $100 \mu \mathrm{l}$ Optilyse B Lysing Solution. $1 \mathrm{ml}$ of $\mathrm{ddH}_{2} \mathrm{O}$ was added and incubated for another $1.5 \mathrm{~h}$. Cells were then washed with $3 \mathrm{ml}$ FACS Buffer.

\subsection{Histology}

Liver was removed and placed in $4 \%$ formaldehyde. A section of jejunum was also removed and cleaned with $4 \%$ formaldehyde using a $25 \mathrm{G}$ needle and then placed in $4 \%$ fomaldehyde.

The slicing and staining was performed in the Department of Cellular and Molecular Pathology at the DKFZ in Heidelberg by the lab of Hermann-Josef Gröne. Following stainings were prepared:

liver. hematoxylin/eosin stain (HE), T cells ( $\alpha-C D 3)$, macrophages ( $\alpha-F 4 / 80)$ 
jejunum: hematoxylin/eosin stain ( $\mathrm{HE})$, periodic acid-Schiff stain (PAS), T cells ( $\alpha-C D 3)$, macrophages ( $\alpha-H R 3)$, proliferating cells ( $\alpha-\mathrm{Ki} 67)$

\subsection{Statistical analysis}

Statistical analysis was performed using Prism for Macintosh version 4.0c, GraphPad Software, Inc., San Diego, California, USA. For all analyses student's unpaired t-test was used, except for survival curves, where the logrank test was used. Measures of significance: n.s. $=$ not significant: $p>0.05 ;{ }^{*}: p<0.05 ;{ }^{* *}: p<0.01 ;{ }^{* \star *}: p<0.001$. 


\section{Results}

\subsection{Characterisation of the aGvHD in vivo model}

Despite the fact that the aGvHD in vivo model is in general well-established, it can vary in its characteristics between different laboratories and is greatly dependent on factors such as general health status of the mouse colony. Since the model had not been previously used in our laboratory, I optimised it to suit our needs. Irradiation of BALB/c mice with 8.5 Gy generally lead to haematopoietic failure within 14 days. I also tested different numbers of bone marrow cells and purified allogeneic $T$ cells or, alternatively, whole spleen preparations. The optimal disease progression was achieved at $10^{7}$ bone marrow cells and $2 \times 10^{6}$ purified T cells. In $\mathrm{GR}^{\text {wt }}$ mice receiving $\mathrm{GR}^{\mathrm{wt}} \mathrm{T}$ cells this generally lead to a survival rate of around $70-100 \%$ during the first phase of the disease (an example is shown in Figure 8A). Mice were treated with $100 \mathrm{mg} / \mathrm{kg}$ dex from days 3 to 6 . Since there was already no/low mortality during the acute phase, the effect of dex therapy cannot be illustrated by improved survival. Morbidity during the acute phase around day 5 to 7 , however, was decreased by dex treatment (Figure 8B).

A

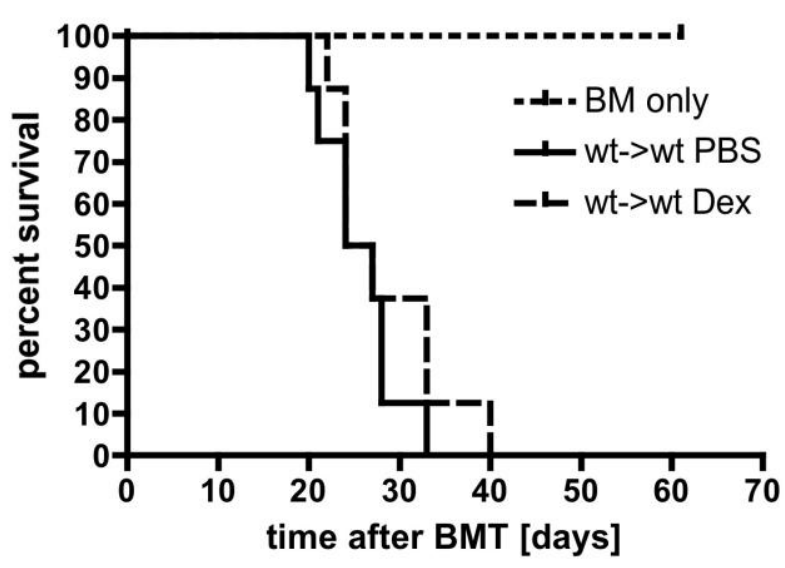

B

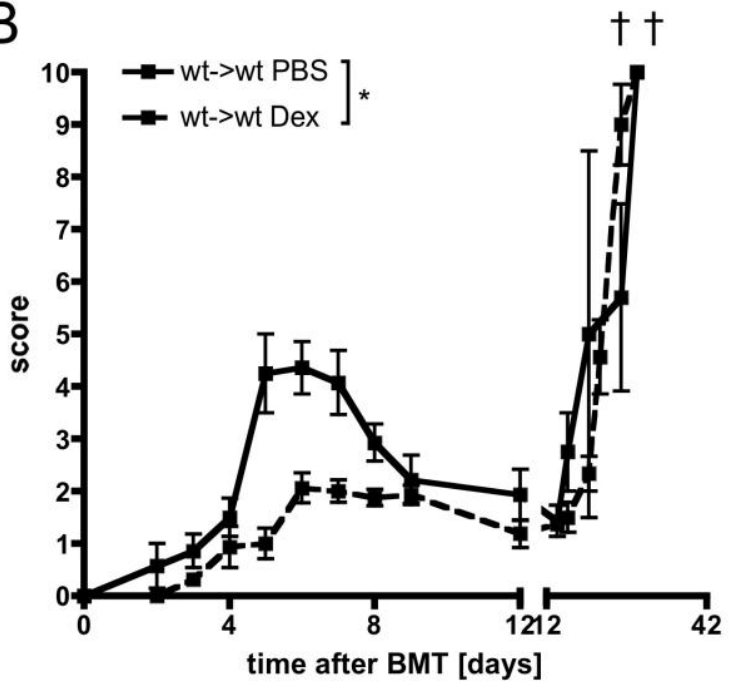

Figure 8: Mortality and morbidity after aGvHD induction in $\mathrm{GR}^{\mathrm{wt}}$ mice using $\mathrm{GR}^{\mathrm{wt}} \mathrm{T}$ cells and dex treatment with $100 \mathrm{mg} / \mathrm{kg}$ from day 3 to day 6 or PBS (control). (A) Mortality (B) Morbidity; ( $=7-8$ ); Experimental groups were as follows: $\mathrm{BM}$ only $=$ no $\mathrm{T}$ cells transplanted, $\mathrm{wt} \rightarrow \mathrm{wt}=\mathrm{GR}^{\mathrm{wt}} \mathrm{T}$ cells transplanted into $\mathrm{GR}^{\mathrm{wt}}$ recipient mice. (Adopted from Tischner et al., 2011).

Since the use of GR modified mice was anticipated to cause exacerbated aGvHD, this setting, characterised by relatively late death, was chosen for all further 
experiments and $10^{7} \mathrm{GR}^{\mathrm{wt}}$ bone marrow cells were transplanted with $2 \times 10^{6}$ of the desired T cells.

To establish the best read out parameters, the model was further characterised. A cohort of mice was transplanted with $\mathrm{GFP}^{+}$bone marrow cells and CD45.1 ${ }^{+} \mathrm{T}$ cells and each day animals were sacrificed to analyse $T$ cell expansion and infiltration. No $\mathrm{GFP}^{+}$cells were found in the early transplantation phase, so a role of newly differentiated cells arising from the bone marrow can be excluded. CD45. $1^{+} \mathrm{T}$ cells started expanding in secondary lymphoid organs on day 5, peaked at day 6 and then started to decline again (Figure 9A). Few $T$ cells could be found at later time points as represented by hypoplasia of the spleen on day 46 (Figure 9B).

A

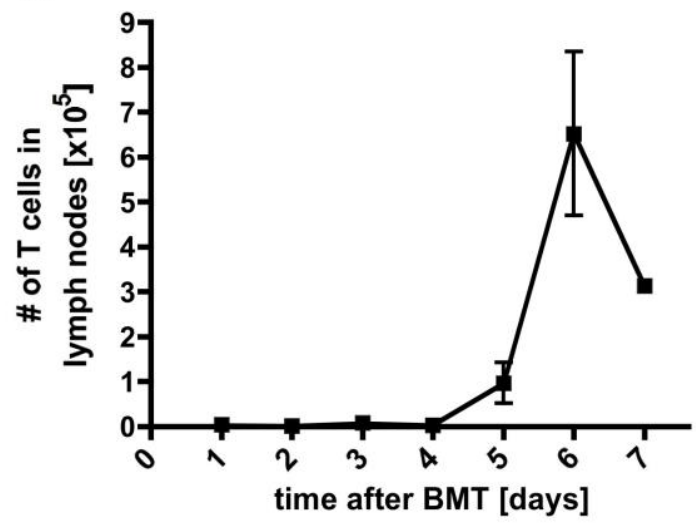

B

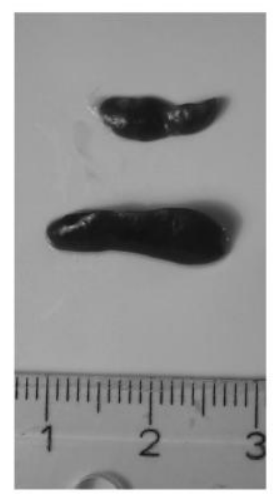

Figure 9: $T$ cell expansion after transplantation of $\mathrm{GR}^{\mathrm{wt}} \mathrm{T}$ cells. (A) Total number of $\beta \mathrm{TCR}^{+} \mathrm{T}$ cells in the lymph nodes $(n=1-2)$. (B) Spleens on day 46 after BMT from a mouse transplanted with bone marrow plus GR ${ }^{\mathrm{wt}}$ $\mathrm{T}$ cells (top) or with bone marrow only (bottom).

Almost at the same time, when increasing numbers of $T$ cells could be found in lymphoid tissues, they could also be found in target organs. In jejunum and liver antiCD3 staining revealed T cell infiltration on day 6 (Figure 10A+B). When perfused liver and lung were homogenised and lymphocytes were isolated by Percoll gradient separation, FACS analysis revealed increasing numbers of $\beta \mathrm{TCR}^{+}$cells starting on day 5 (Figure 10C). 

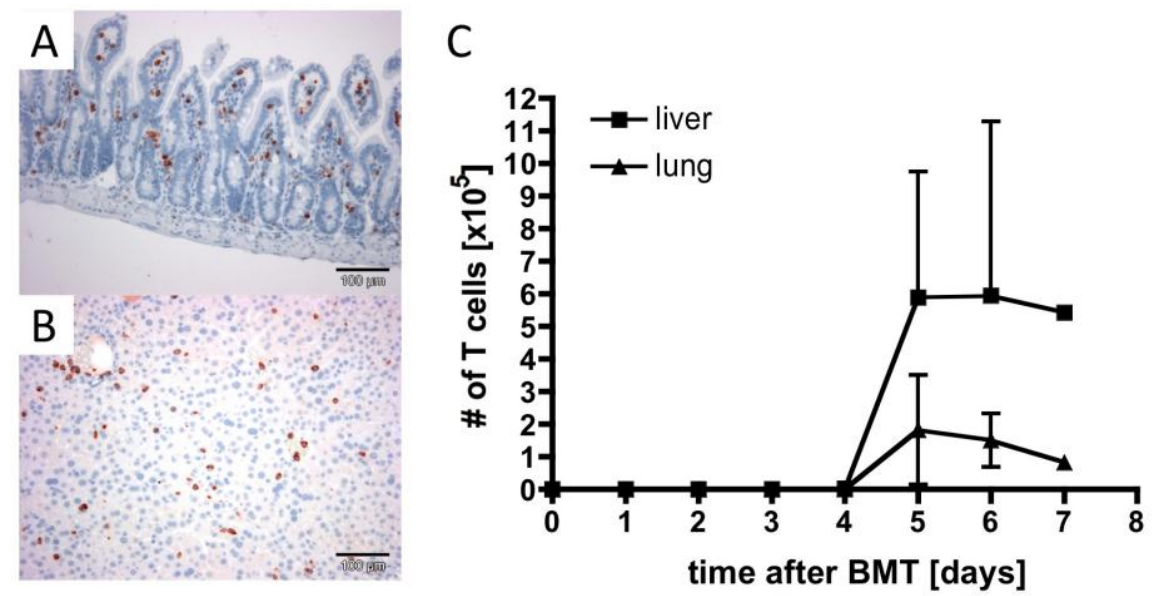

Figure 10: $T$ cell infiltration in target organs in the early post-transplantation phase. (A) $T$ cell infiltration in jejunum on day 6 after BMT (CD3 ${ }^{+}$stain, 10x magnification) (B) T cell infiltration in liver on day 6 after BMT (CD3 stain, 10x magnification) (C) Infiltration of $\beta T_{C R}^{+}$cells in liver and lung, analysed by FACS.

\subsection{Mortality}

Mice that received $G^{\text {lckCre }} T$ cells developed stronger disease than mice receiving $\mathrm{GR}^{\mathrm{wt}} \mathrm{T}$ cells. They died, almost without exception, within a week (Figure 11A). Disease onset and death often occurred suddenly and within 24 hours.

Like the transplantation of $\mathrm{GR}^{\mathrm{lck} C \mathrm{re}} \mathrm{T}$ cells, the transplantation of $\mathrm{GR}^{\mathrm{dim}} \mathrm{T}$ cells also resulted in a disease course more fulminant than in case of the transplantation of $\mathrm{GR}^{\mathrm{wt}} \mathrm{T}$ cells (Figure 11B).

$\mathrm{GR}^{\text {lysMCre }}$ mice were obtained from our co-operation partner in Jena and, unfortunately, not only the knock-out mice, but also the $\mathrm{GR}^{\text {floxflox }}$ control mice from Jena exhibited a more severe disease course than mice bred in our own facilities or supplied by Charles River. This was the case in two independent experiments and may be attributed to a generally poorer health status of the mice, different microbial status or the stress associated with the transfer to our facilities. Although the survival of $\mathrm{GR}^{\text {lysMCre }}$ mice was significantly reduced compared to $\mathrm{GR}^{\text {floxflox }}$ control mice, the difference in median survival was only two days. Therefore, because of the poor survival of controls, it remains uncertain whether a GR knock-out in myeloid cells has an influence on survival, although tendency may indicate that it does (Figure 11C). When $\mathrm{GR}^{\mathrm{dim}}$ recipients were transplanted with $\mathrm{GR}^{\mathrm{wt}} \mathrm{T}$ cells, they also developed more potent aGvHD than $\mathrm{GR}^{\mathrm{wt}}$ littermates (Figure 11D). 

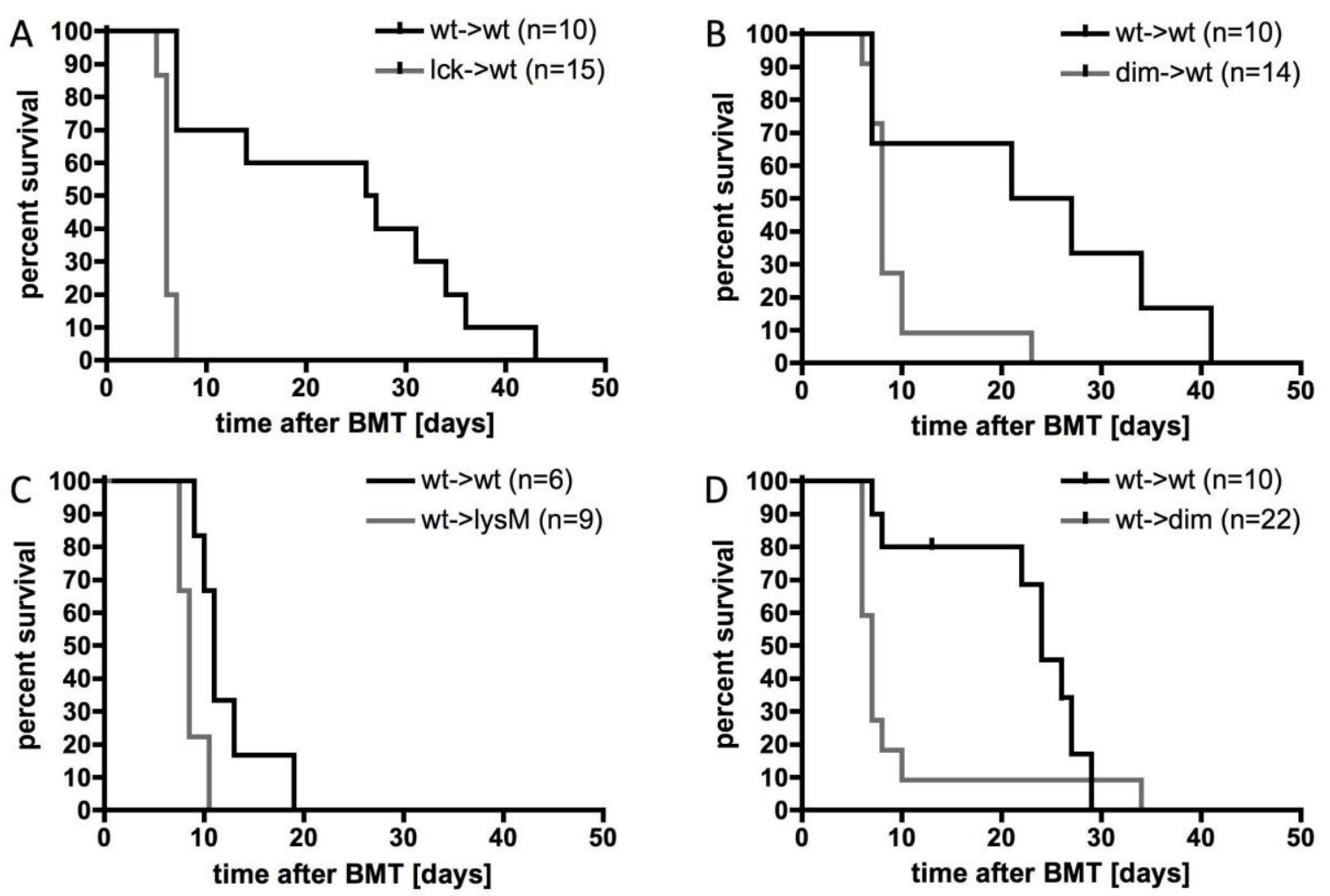

Figure 11: Survival after aGvHD induction. (A) $\mathrm{lck} \rightarrow \mathrm{wt}: \mathrm{GR}^{\mathrm{wt}}$ mice receiving $\mathrm{T}$ cells without GR compared to $\mathrm{wt} \rightarrow \mathrm{wt}: \mathrm{GR}^{\mathrm{wt}}$ mice receiving $\mathrm{GR}^{\mathrm{wt}} \mathrm{T}$ cells $(\mathrm{p}<0,0001)(\mathrm{B}) \mathrm{dim} \rightarrow \mathrm{wt}: \mathrm{GR}^{\mathrm{wt}}$ mice receiving $\mathrm{T}$ cells deficient for GR-dimerisation compared to $\mathrm{GR}^{\mathrm{wt}}$ mice receiving $\mathrm{GR}^{\mathrm{wt}} \mathrm{T}$ cells $(\mathrm{p}=0,0398)(\mathrm{C}) \mathrm{wt} \rightarrow \mathrm{lsyM}$ : mice without GR in myeloid cells receiving $G^{\mathrm{wt}} \mathrm{T}$ cells compared to $\mathrm{GR}^{\text {flox/flox }}$ littermates receiving $\mathrm{GR}^{\mathrm{wt}} \mathrm{T}$ cells $(\mathrm{p}=0,0282)(\mathrm{D})$ $\mathrm{wt} \rightarrow$ dim: recipients deficient for GR-dimerisation receiving $\mathrm{GR}^{\mathrm{wt}} \mathrm{T}$ cells compared to $\mathrm{GR}^{\mathrm{wt}}$ littermates receiving wild type $\mathrm{T}$ cells $(\mathrm{p}=0,0198)$.

Treatment with dex did not improve survival in mice receiving GR $^{\mathrm{lckCre}} \mathrm{T}$ cells (Figure 12A). If at all, it appeared as though sometimes disease onset and death were delayed for a day. Unlike recipients of $\mathrm{GR}^{\text {lckcre }} \mathrm{T}$ cells, however, recipients of $\mathrm{GR}^{\text {dim }}$ T cells were to some extend treatable with dex (Figure 12B).

Despite the fact that the mice from Jena showed an aggravated disease severity not only for $\mathrm{GR}^{\text {lysMCre }}$ but also for control mice, $\mathrm{GR}^{\text {lysMCre }}$ mice were, by trend, still treatable with dex and at least some animals survived the first phase after treatment (Figure 12C). The difference was not significant, probably due to low numbers of animals. In $\mathrm{GR}^{\text {dim }}$ recipients, dex treatment was able to alleviate mortality in the acute phase completely (Figure 12D). 

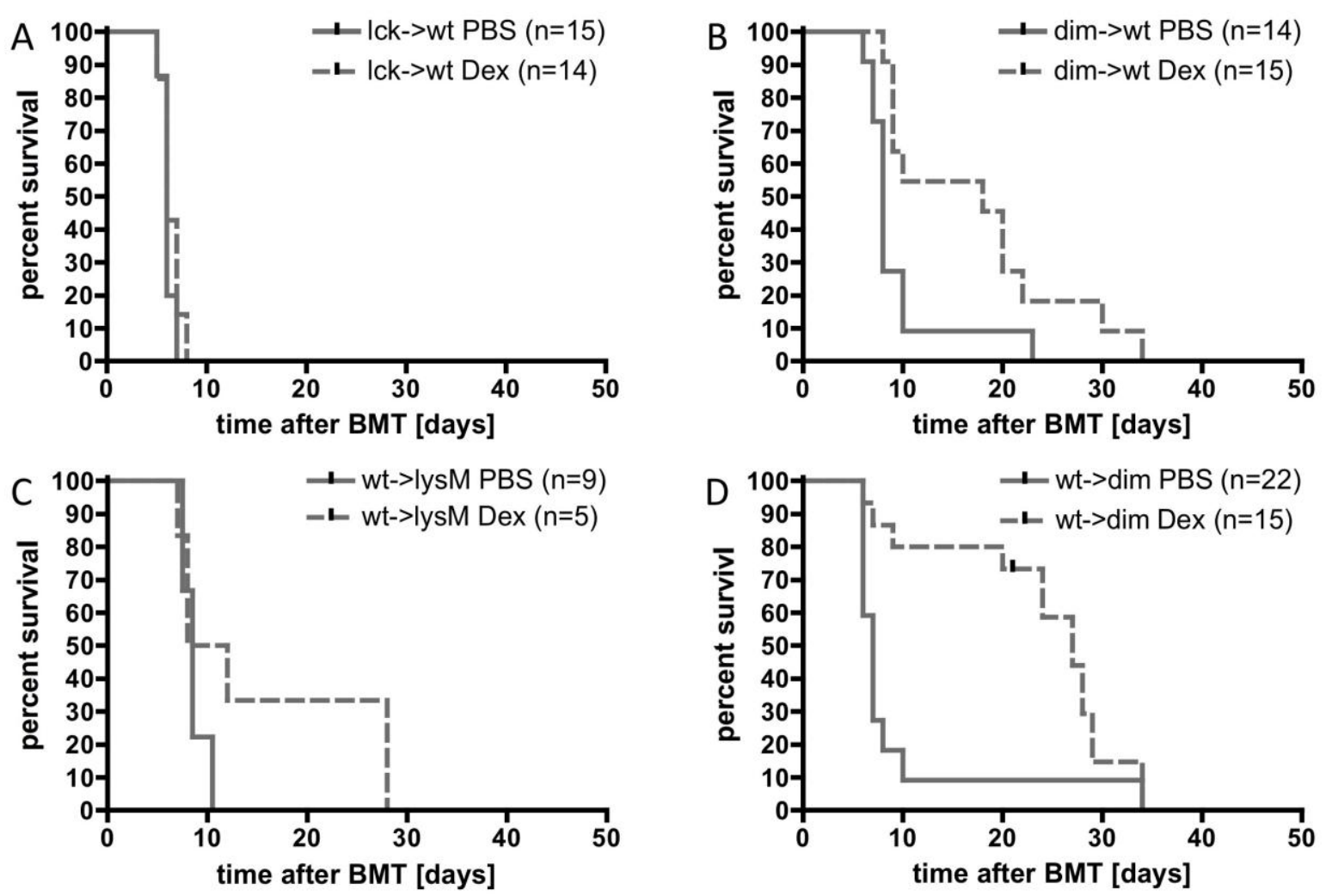

Figure 12: Survival after aGvHD induction in mice treated with $100 \mathrm{mg} / \mathrm{kg}$ dex from day 3 to 6 compared to mice treated with PBS (control). (A) lck $\rightarrow$ wt: $G^{w t}$ mice receiving T cells without $G R(p=0.1718)(B) d i m \rightarrow w t:$ $\mathrm{GR}^{\mathrm{wt}}$ mice receiving $\mathrm{T}$ cells deficient for GR-dimerisation $(\mathrm{p}=0.0190)(\mathrm{C}) \mathrm{wt} \rightarrow 1$ syM: mice without $\mathrm{GR}$ in myeloid cells receiving $\mathrm{GR}^{\mathrm{wt}} \mathrm{T}$ cells $(\mathrm{p}=0.0637)$ (D) $\mathrm{wt} \rightarrow \mathrm{dim}$ : recipients deficient for GR-dimerisation receiving $\mathrm{GR}^{\mathrm{wt}} \mathrm{T}$ cells $(\mathrm{p}=0.0017)$.

\subsection{FACS analysis}

\subsubsection{T cells in blood}

Blood was collected from aGvHD mice on day 6 after transplantation and analysed after lysis of erythrocytes (Figure 13). 

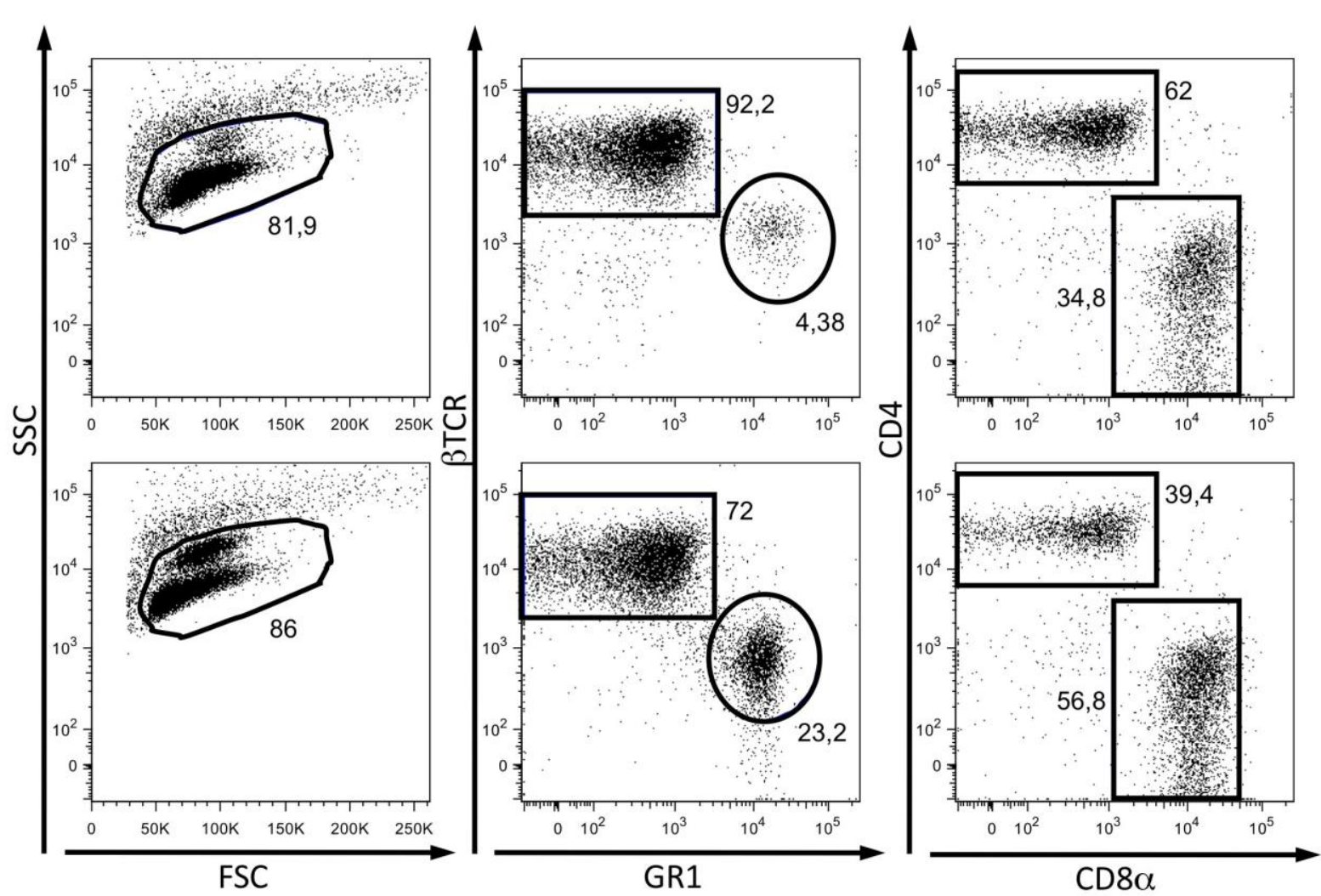

Figure 13: Blood of aGvHD mice. (A) Blood was collected by heart puncture on day 6 after transplantation, followed by lysis of erythrocytes; sideward scatter (SSC) against forward scatter (FSC). (B) Live cells were analysed for expression of $\mathrm{T}$ cell $(\beta \mathrm{TCR})$ and granulocyte (GR1) markers. (C) T cells were analysed for expression of CD4 and CD8 $\alpha$.

There was no change in $T$ cell/granulocyte ratio in mice receiving $G^{1 c k C r e}$ or $G^{\text {dim }}$ $T$ cells compared to mice receiving $G^{\text {wt }} T$ cells or in $G^{\text {dim }}$ recipients compared to $\mathrm{GR}^{\mathrm{wt}}$ littermates. Treatment with dex reduced the amount of $\mathrm{T}$ cells and selectively enriched $\mathrm{GR}^{+}$cells in $\mathrm{GR}^{\mathrm{wt}}$ and $\mathrm{GR}^{\mathrm{dim}}$ mice transplanted with $\mathrm{GR}^{\mathrm{wt}} \mathrm{T}$ cells. This change was significant. In $\mathrm{GR}^{\text {wt }}$ mice transplated with $\mathrm{GR}^{\text {lckCre }}$ or $\mathrm{GR}^{\text {dim }} \mathrm{T}$ cells, tendency showed that $\mathrm{T}$ cells were reduced and $\mathrm{GR} 1^{+}$cells were enriched, but the change was not significant and the ratio was still higher than for treated $G R^{\text {wt }}$ mice receiving $G^{w t} T$ cells ( $p=0.0001$ and $p=0.0066$, respectively) (Figure 14). 


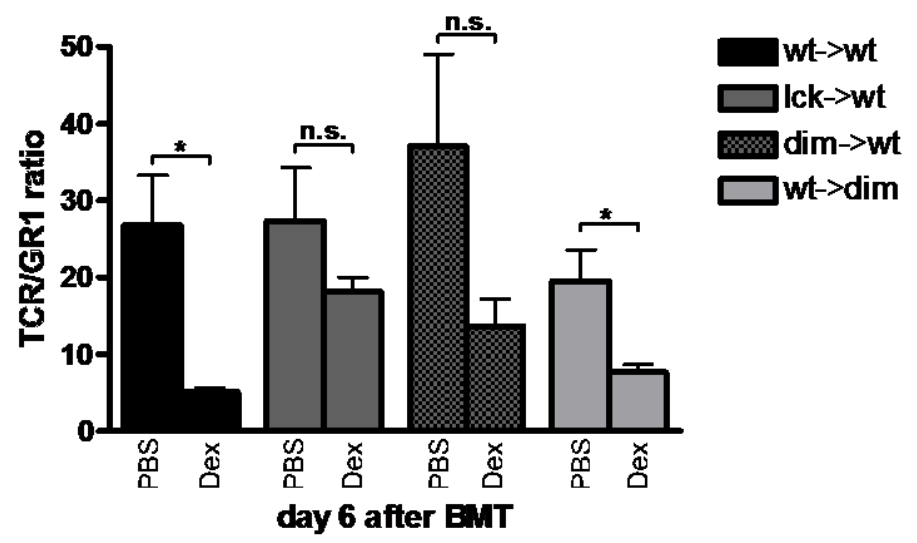

Figure 14: Ratio of cells positive for $\boldsymbol{\beta T C R}$ and GR1 in blood of aGvHD mice on day 6 after transplantation following treatment with dex from day 3 to 6 compared to untreated control. mean values + s.e.m., $(n=5-23)$ Experimental groups were as follows: $\mathrm{wt} \rightarrow \mathrm{wt}=\mathrm{GR}^{\mathrm{wt}} \mathrm{T}$ cells transplanted into $\mathrm{GR}^{\mathrm{wt}}$ recipient mice, lck $\rightarrow \mathrm{wt}=$ $\mathrm{GR}^{\text {lckCre }} \mathrm{T}$ cells transplanted into $\mathrm{GR}^{\mathrm{wt}}$ recipient mice, $\mathrm{dim} \rightarrow \mathrm{wt}=\mathrm{GR}^{\mathrm{dim}} \mathrm{T}$ cells transplanted into $\mathrm{GR}^{\mathrm{wt}}$ recipient mice, $\mathrm{wt} \rightarrow \mathrm{dim}=\mathrm{GR}^{\mathrm{wt}} \mathrm{T}$ cells transplanted into $\mathrm{GR}^{\mathrm{dim}}$ recipient mice.

\subsubsection{T cell count in lymph nodes, markers of $T$ cells activation}

Lymph nodes (lymphnodi madibulares, axillares accessorii, inguinales superficiales, mesenteriales) from mice were analysed by FACS on day 6 (Figure 15).
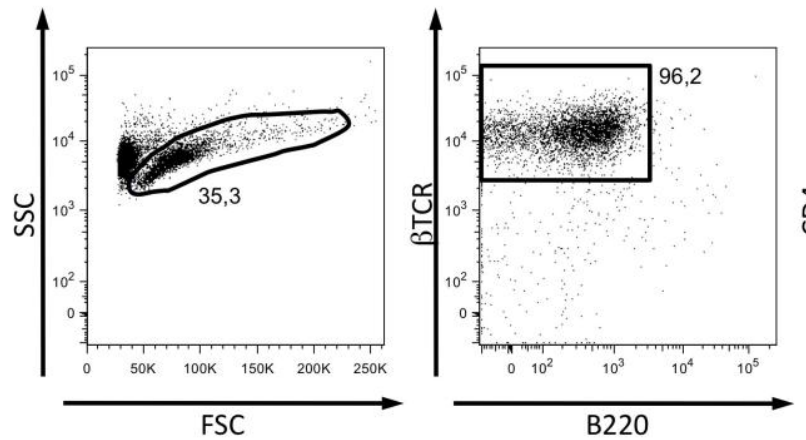
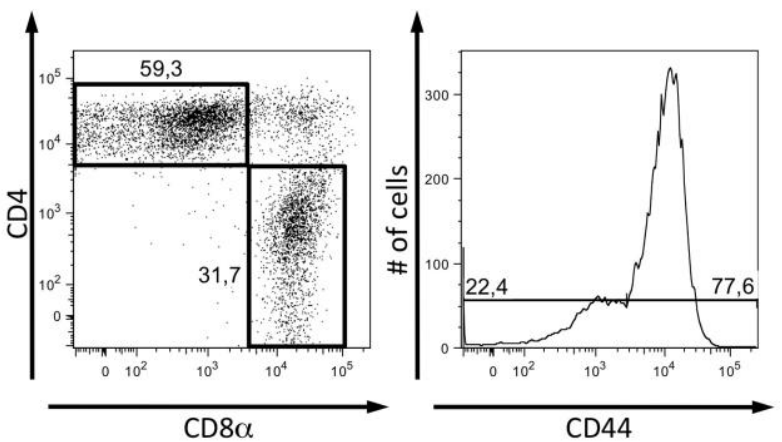

Figure 15: Lymph nodes of aGvHD mice. (A) Cells were isolated on day 6 after transplantation; sideward scatter (SSC) against forward scatter (FSC). (B) Live cells were analysed for expression of T cell ( $\beta$ TCR) and $\mathrm{B}$ cell markers (B220). (C) $\mathrm{T}$ cells were analysed for expression of CD4 and CD8 $\alpha$. (D) CD4 ${ }^{+}$cells were analysed for expression of CD44.

There was no difference in total T cell number in the lymph nodes on day 6 of $G^{\text {wt }}$ mice receiving $\mathrm{GR}^{\mathrm{wt}}, \mathrm{GR}^{\mathrm{lckCre}}$ or $\mathrm{GR}^{\mathrm{dim}} \mathrm{T}$ cells, or $\mathrm{GR}^{\text {dim }}$ recipients receiving $\mathrm{GR}^{\mathrm{wt}}$ T cells (Figure 16A). However, total $T$ cell number is reduced after treatment in all groups except recipients of $\mathrm{GR}^{\text {lckCre }} \mathrm{T}$ cells (Figure 16B). 

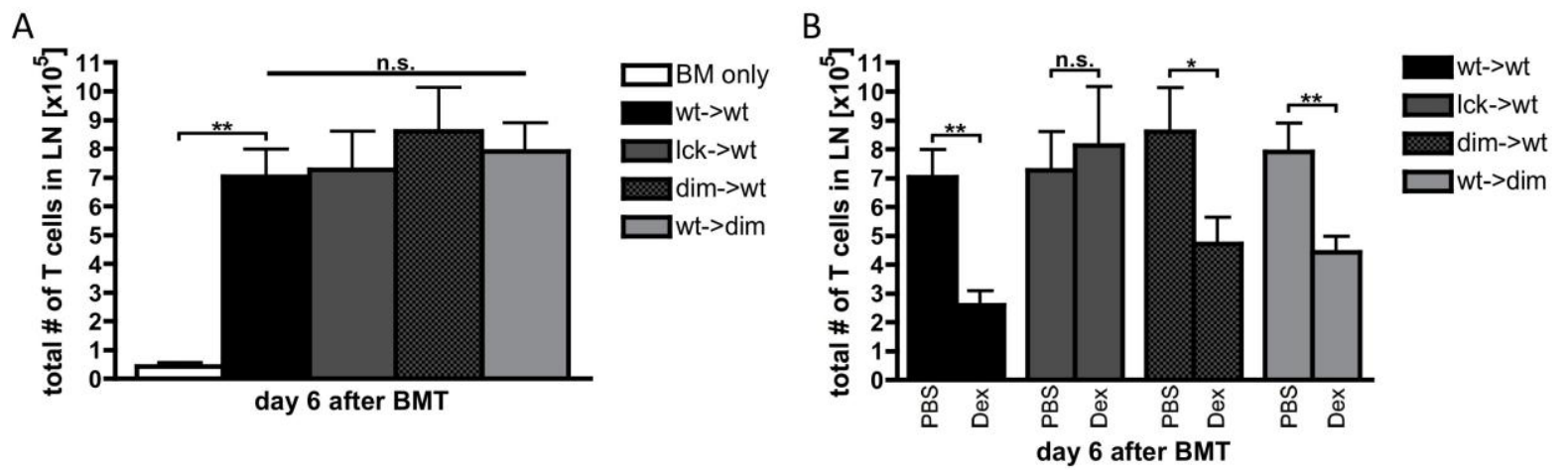

Figure 16: Total number of live $\beta \operatorname{TCR}^{+}$cells isolated from lymph nodes. (A) Total number of $\beta \mathrm{TCR}^{+}$cells in the lymph nodes of animals on day 6 after BMT (B) Total number of $\beta \mathrm{TCR}^{+}$cells in the lymph nodes of animals on day 6 after BMT after treatment with dex from day 3 to 6 compared to control; mean values + s.e.m., $(\mathrm{n}=5$ 23); Experimental groups were as follows: $\mathrm{BM}$ only $=$ no $\mathrm{T}$ cells transplanted; $\mathrm{wt} \rightarrow \mathrm{wt}=\mathrm{GR}^{\mathrm{wt}} \mathrm{T}$ cells transplanted into $\mathrm{GR}^{\mathrm{wt}}$ recipient mice, $\mathrm{lck} \rightarrow \mathrm{wt}=\mathrm{GR}^{\mathrm{lckCre}} \mathrm{T}$ cells transplanted into $\mathrm{GR}^{\mathrm{wt}}$ recipient mice; $\mathrm{dim} \rightarrow \mathrm{wt}$ $=\mathrm{GR}^{\mathrm{dim}} \mathrm{T}$ cells transplanted into $\mathrm{GR}^{\mathrm{wt}}$ recipient mice; $\mathrm{wt} \rightarrow \mathrm{dim}=\mathrm{GR}^{\mathrm{wt}} \mathrm{T}$ cells transplanted into $\mathrm{GR}^{\mathrm{dim}}$ recipient mice.

In $\mathrm{GR}^{\text {wt }}$ mice transplanted with $\mathrm{GR}^{\text {wt }} \mathrm{T}$ cells, a higher percentage of activated CD44 ${ }^{+}$ cells amongst $\mathrm{CD}^{+} \mathrm{T}$ cells was observed compared to the transplantation of $\mathrm{GR}^{\text {lckCre }}$ or $\mathrm{GR}^{\mathrm{dim}} \mathrm{T}$ cells, or the transplantation of $\mathrm{GR}^{\mathrm{wt}} \mathrm{T}$ cells into $\mathrm{GR}^{\mathrm{dim}}$ recipients. Dex treatment did not change the percentage of activated cells, except for $\mathrm{GR}^{\mathrm{lckCre}} \mathrm{T}$ cells transplanted into $\mathrm{GR}^{\mathrm{wt}}$ mice (Figure 17).
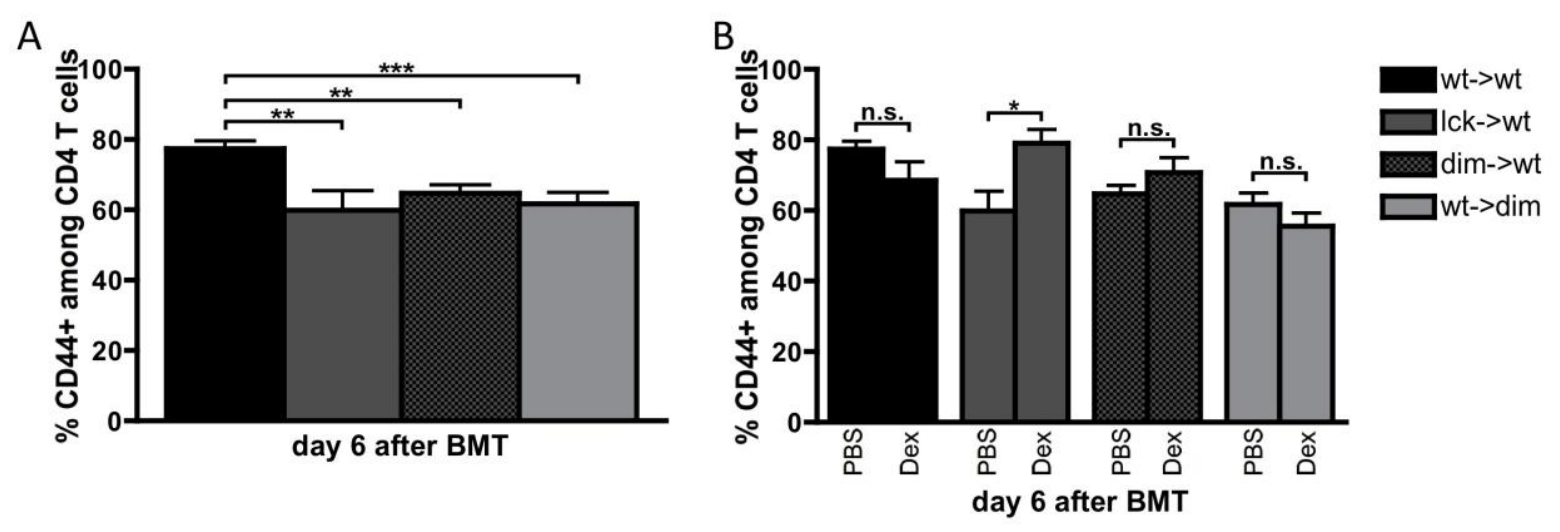

Figure 17: Percentage of activated $\mathrm{CD44}^{+}$cells amongst $\mathrm{CD4}^{+} \mathbf{T}$ cells in lymph nodes of aGvHD mice on day 6 after transplantation. (A) Activated cells in different GR knock-outs compared to wild type. (B) Activated cells after treatment with dex from day 3 to 6 compared to control; mean values + s.e.m., $(n=5-23)$; Experimental groups were as follows: $\mathrm{wt} \rightarrow \mathrm{wt}=\mathrm{GR}^{\mathrm{wt}} \mathrm{T}$ cells transplanted into $\mathrm{GR}^{\mathrm{wt}}$ recipient mice, $\mathrm{lck} \rightarrow \mathrm{wt}=\mathrm{GR}^{\mathrm{lckCre}} \mathrm{T}$ cells transplanted into $\mathrm{GR}^{\mathrm{wt}}$ recipient mice, $\mathrm{dim} \rightarrow \mathrm{wt}=\mathrm{GR}^{\mathrm{dim}} \mathrm{T}$ cells transplanted into $\mathrm{GR}^{\mathrm{wt}}$ recipient mice, wt $\rightarrow \mathrm{dim}$ $=\mathrm{GR}^{\mathrm{wt}} \mathrm{T}$ cells transplanted into GR ${ }^{\mathrm{dim}}$ recipient mice.

\subsection{3. $C D 4 / C D 8$ ratio in blood and target organs}

FACS analysis of blood showed that the CD4/CD8 ration in mice suffering from aGvHD was greatly skewed towards CD8 compared to healthy balb/c mice. There was no difference between $\mathrm{GR}^{\text {lck }}$ or $\mathrm{GR}^{\text {dim }} \mathrm{T}$ cells compared to transplantation of 
$\mathrm{GR}^{\mathrm{wt}} \mathrm{T}$ cells or in $\mathrm{GR}^{\mathrm{dim}}$ recipients compared to $\mathrm{GR}^{\mathrm{wt}}$ littermates. In the perfused liver, the proportion of $\mathrm{CD}^{+} \mathrm{T}$ cells is even higher than in blood (Figure 18). Unperfused liver shows a composition similar to blood, because of the high amount of blood it contains (not shown).

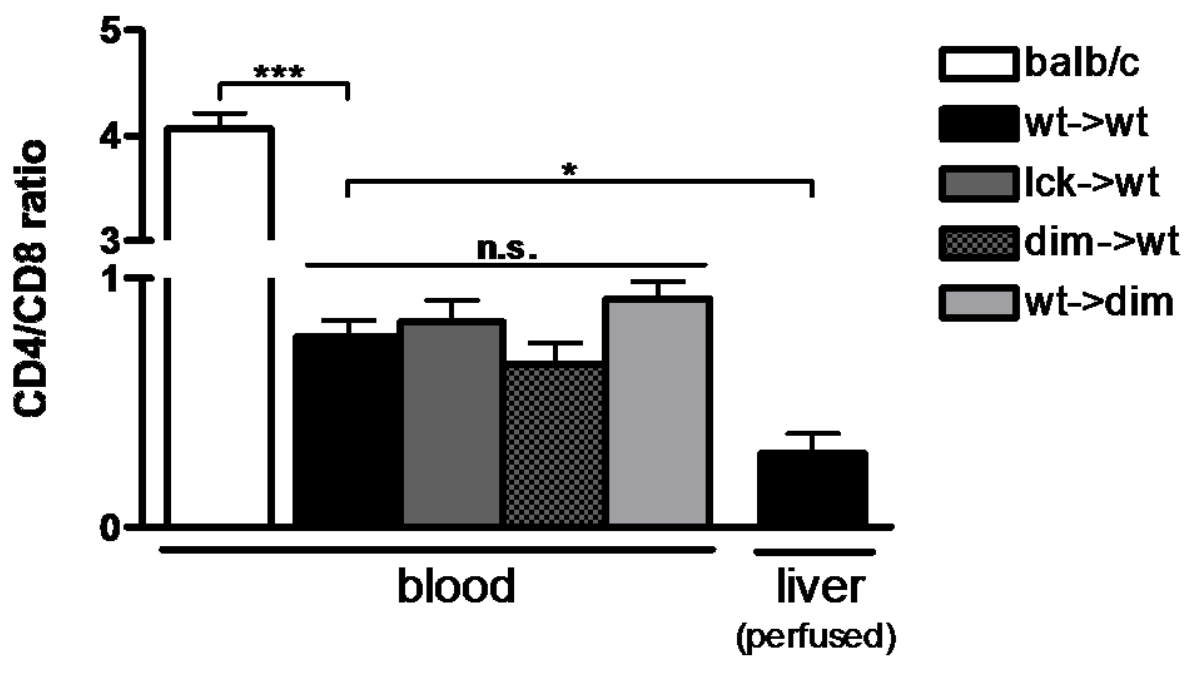

Figure 18: CD4/CD8 ratio on day 6 after transplatation in different organs. Ratio was determined in blood and liver (perfused) by FACS-analysis; mean values + s.e.m., (blood: $n=8-23$, liver: $n=2$ ).

\subsection{Histological analysis}

\subsubsection{T cell infiltration in jejunum and liver}

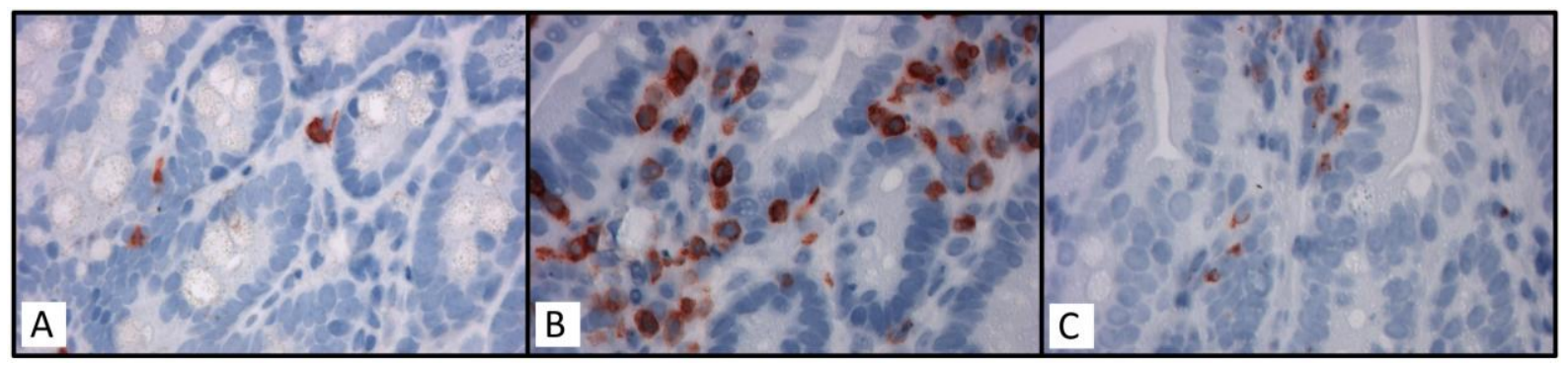

Figure 19: $T$ cells in jejunum on day 6 after transplantation (CD3 stain, 40x magnification). (A) A healthy mouse receiving only bone marrow; only sporadic $T$ cells can be seen (B) A mouse receiving GR $^{\mathrm{wt}} \mathrm{T}$ cells without treatment; $\mathrm{T}$ cell infiltration is high $(\mathrm{C}) \mathrm{A}$ mouse receiving $\mathrm{GR}^{\mathrm{wt}} \mathrm{T}$ cells and treatment with dex from day 3 to $6 ; \mathrm{T}$ cell infiltration is greatly reduced.

Mice that received $G^{\mathrm{wt}} \mathrm{T}$ cells showed increased $\mathrm{T}$ cell infiltration in jejunum, compared to mice receiving only $T$ cell-depleted bone marrow. The infiltration in mice receiving $G^{\text {lckcre }}$ or $G^{\text {dim }} T$ cells was comparable to those receiving $G^{\text {wt }} T$ cells. $G^{\text {dim }}$ mice receiving $G^{\text {wt }} T$ cells even had slightly less infiltration than $G^{\text {wt }}$ littermates, but this was not statistically significant. 
Upon treatment with dex, $T$ cell infiltration in mice receiving $G^{\text {wt }} T$ cells was significantly reduced. In mice receiving $\mathrm{GR}^{\mathrm{lck} C \mathrm{re}} \mathrm{T}$ cells, infiltration was not reduced. Mice receiving $G^{\text {dim }} T$ cells showed by trend reduced infiltration, but this was not significant. $G R^{\text {dim }}$ mice receiving $G R^{\text {wt }} T$ cells had no reduced infiltration, but the generally lower infiltration in untreated mice has to be taken into account.

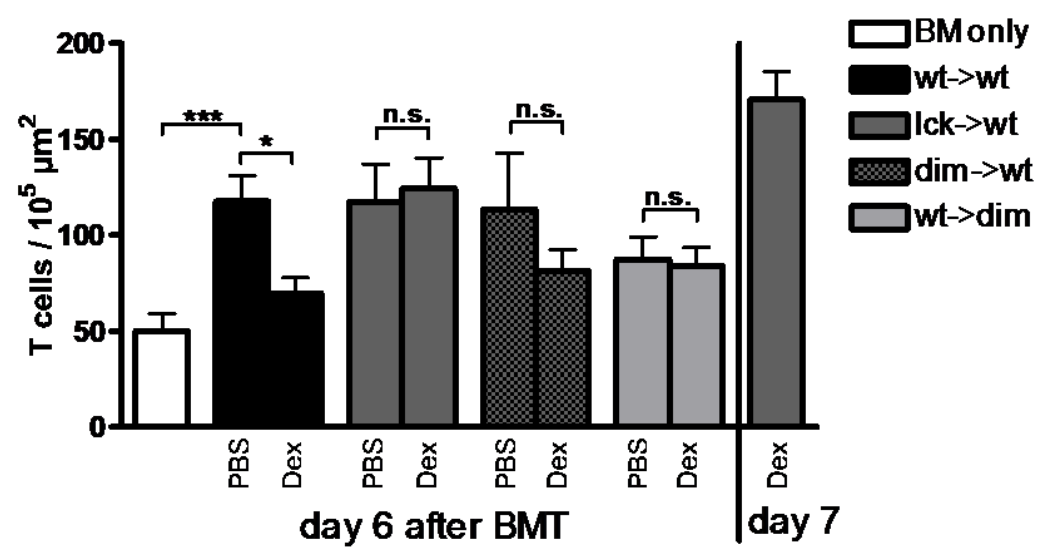

Figure 20: Number of $T$ cells in jejunum (CD3 stain, 40x) per section in untreated animals and in animals treated with dex $(100 \mathrm{mg} / \mathrm{kg})$ from day 3 to 6.5 sections were counted per animal and the average was taken, mean values + s.e.m., $(\mathrm{n}=5-10)$; Experimental groups were as follows: $\mathrm{BM}$ only $=$ no $\mathrm{T}$ cells transplanted; $\mathrm{wt} \rightarrow \mathrm{wt}=\mathrm{GR}^{\mathrm{wt}} \mathrm{T}$ cells transplanted into $\mathrm{GR}^{\mathrm{wt}}$ recipient mice, lck $\rightarrow \mathrm{wt}=\mathrm{GR}^{\text {lckCre }} \mathrm{T}$ cells transplanted into $\mathrm{GR}^{\mathrm{wt}}$ recipient mice, $\operatorname{dim} \rightarrow \mathrm{wt}=\mathrm{GR}^{\mathrm{dim}} \mathrm{T}$ cells transplanted into $\mathrm{GR}^{\mathrm{wt}}$ recipient mice, $\mathrm{wt} \rightarrow \operatorname{dim}=\mathrm{GR}^{\mathrm{wt}} \mathrm{T}$ cells transplanted into $\mathrm{GR}^{\mathrm{dim}}$ recipient mice.

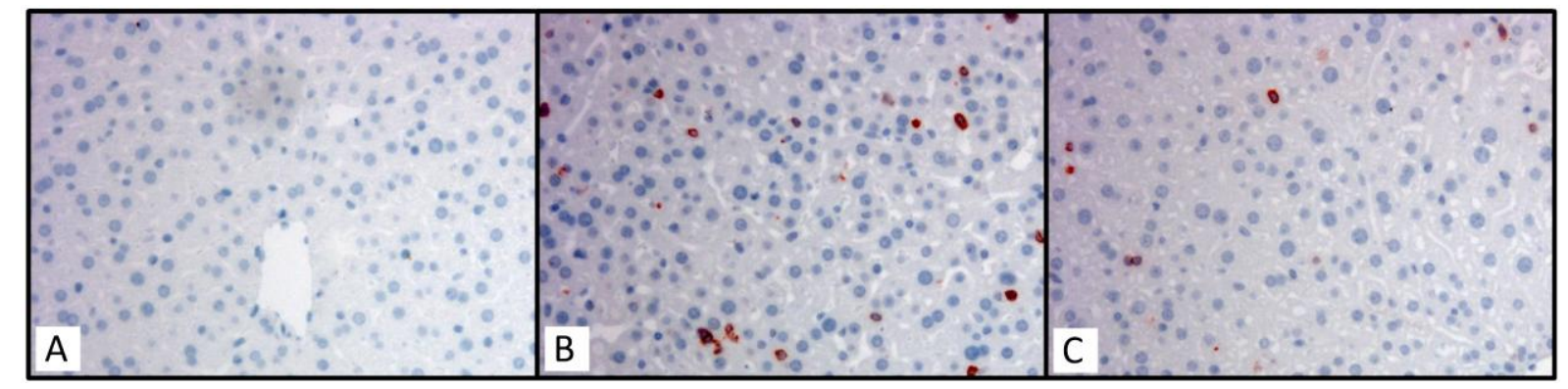

Figure 21: T cells in liver on day 6 after transplantation (CD3 stain, 10x magnification). (A) A healthy mouse receiving only bone marrow; only sporadic $\mathrm{T}$ cells can be seen (B) A mouse receiving $\mathrm{GR}^{\mathrm{wt}} \mathrm{T}$ cells without treatment; $T$ cell infiltration is high $(C) A$ mouse receiving $\mathrm{GR}^{\mathrm{wt}} \mathrm{T}$ cells and treatment with dex from day 3 to 6 ; $\mathrm{T}$ cell infiltration is reduced.

In the liver, basically the same situation can be found. $\mathrm{GR}^{\mathrm{wt}}$ mice receiving $\mathrm{GR}^{\mathrm{wt}}$, $\mathrm{GR}^{\mathrm{lckCre}}$ or $\mathrm{GR}^{\mathrm{dim}} \mathrm{T}$ cells have significantly higher infiltation than mice receiving only $T$ cell-depleted bone marrow. $G R^{\text {dim }}$ mice receiving $G^{\text {wt }} T$ cells, like for jejunum, show a surprisingly low infiltration. Dex treatment decreases $T$ cell infiltration in $G^{\text {wt }}$ recipients of $\mathrm{GR}^{\mathrm{wt}}, \mathrm{GR}^{\mathrm{lckCre}}$ and $\mathrm{GR}^{\mathrm{dim}} \mathrm{T}$ cells, although the reduction $\mathrm{GR}^{\text {lckCre }}$ and $G^{\text {dim }}$ receiving cells is not significant (presumably due to low numbers). In recipients of $\mathrm{GR}^{\text {lckCre }} \mathrm{T}$ cells on day 7 , infiltration is high despite dex treatment. In $\mathrm{GR}^{\text {dim }}$ 
recipients dex treatment does not reduce infiltration, but again the low infiltration in the first place has to be kept in mind.

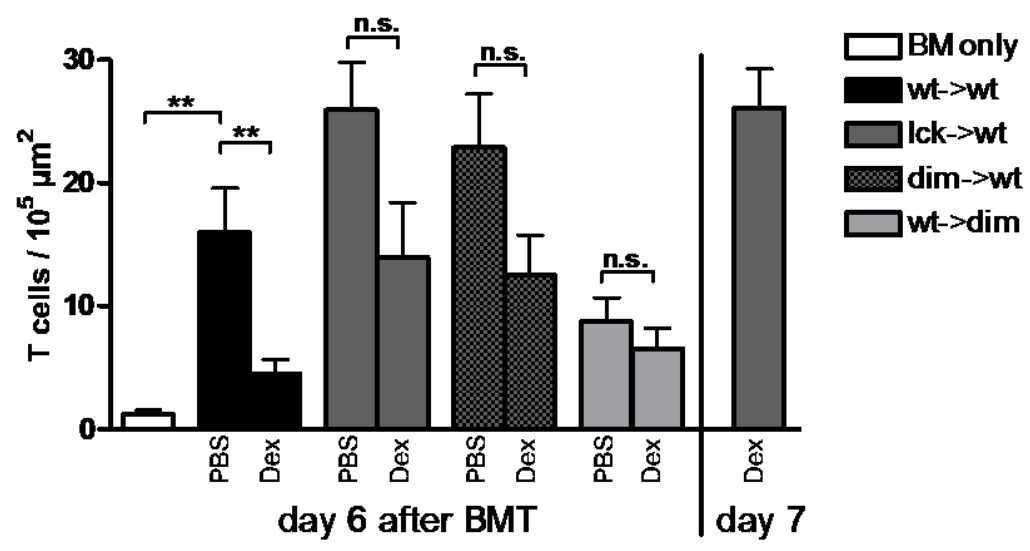

Figure 22: Number of $\mathrm{T}$ cells in liver (CD3 stain, 40x) per section in untreated animals and in animals treated with dex $(100 \mathrm{mg} / \mathrm{kg})$ from day 3 to 6.5 sections were counted per animal and the average was taken, mean values + s.e.m., $(\mathrm{n}=5-10)$; Experimental groups were as follows: $\mathrm{BM}$ only $=$ no $\mathrm{T}$ cells transplanted; $\mathrm{wt} \rightarrow \mathrm{wt}=\mathrm{GR}^{\mathrm{wt}} \mathrm{T}$ cells transplanted into $\mathrm{GR}^{\mathrm{wt}}$ recipient mice, $\mathrm{lck} \rightarrow \mathrm{wt}=\mathrm{GR}^{\mathrm{lckCre}} \mathrm{T}$ cells transplanted into $\mathrm{GR}^{\mathrm{wt}}$ recipient mice, $\operatorname{dim} \rightarrow \mathrm{wt}=\mathrm{GR}^{\mathrm{dim}} \mathrm{T}$ cells transplanted into $\mathrm{GR}^{\mathrm{wt}}$ recipient mice, $\mathrm{wt} \rightarrow \operatorname{dim}=\mathrm{GR}^{\mathrm{wt}} \mathrm{T}$ cells transplanted into $\mathrm{GR}^{\mathrm{dim}}$ recipient mice.

\subsubsection{Tissue destruction in jejunum}

In mice receiving $\mathrm{GR}^{\mathrm{wt}} \mathrm{T}$ cells the number of goblet cells in jejunum was significantly reduced compared to mice receiving only $\mathrm{T}$ cell-depleted bone marrow. Mice receiving $\mathrm{GR}^{\mathrm{lckCre}} \mathrm{T}$ cells also showed a significantly reduced number of goblet cells, which was even lower than in mice receiving $G^{\text {wt }} T$ cells. Mice receiving $G^{\text {dim }}$ $T$ cells had also slightly less goblet cells than mice receiving $G^{\text {wt }} T$ cells, but this was not significant. $G R^{\text {dim }}$ mice receiving $G^{\text {wt }} T$ cells showed a reduction of goblet cells comparable to $\mathrm{GR}^{\mathrm{wt}}$ littermates (Figure 23).
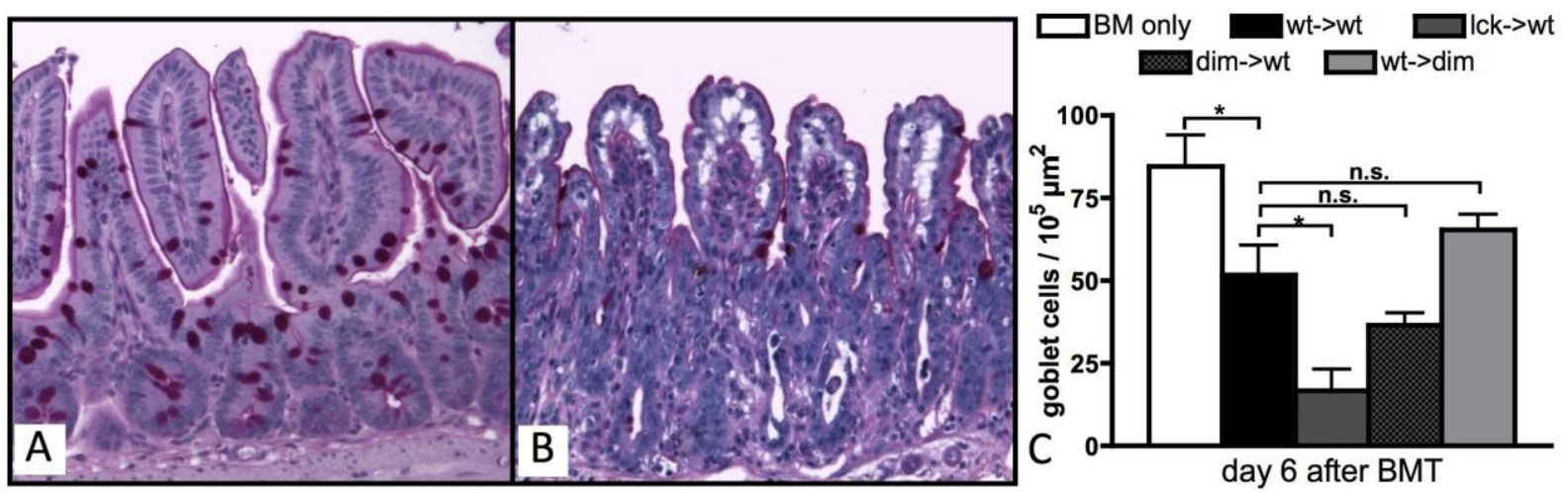

Figure 23: Goblet cells in jejunum (PAS stain). (A+B) Examples for PAS stain of jejunum (10x magnification) of (A) A healthy mouse receiving only bone marrow and (B) A mouse receiving $\mathrm{GR}^{\mathrm{wt}} \mathrm{T}$ cells suffering from aGvHD including severe diarrhoea. (C) Quantification of goblet cells in jejunum (40x magnification); 5 sections were counted per animal and the average was taken, mean values + s.e.m., (BM only: $n=8$. wt $\rightarrow$ wt: $n=10$, lck $\rightarrow$ wt: $n=4$, dim $\rightarrow$ wt: $n=4$, wt $\rightarrow \operatorname{dim}: n=7$ ); Experimental groups were as follows: BM only $=$ no $\mathrm{T}$ cells transplanted, $\mathrm{wt} \rightarrow \mathrm{wt}=\mathrm{GR}^{\mathrm{wt}} \mathrm{T}$ cells transplanted into $\mathrm{GR}^{\mathrm{wt}}$ recipient mice, $\mathrm{lck} \rightarrow \mathrm{wt}=\mathrm{GR}^{\mathrm{lckCre}}$ 
$\mathrm{T}$ cells transplanted into $\mathrm{GR}^{\mathrm{wt}}$ recipient mice, $\mathrm{dim} \rightarrow \mathrm{wt}=\mathrm{GR}^{\mathrm{dim}} \mathrm{T}$ cells transplanted into $\mathrm{GR}^{\mathrm{wt}}$ recipient mice, $\mathrm{wt} \rightarrow \mathrm{dim}=\mathrm{GR}^{\mathrm{wt}} \mathrm{T}$ cells transplanted into $\mathrm{GR}^{\mathrm{dim}}$ recipient mice.

Dex treatment could prevent the destruction of goblet cells in mice receiving $\mathrm{GR}^{\mathrm{wt}}$ T cells. In the treatment group, there were no mice with extremely low values. In mice receiving $\mathrm{GR}^{\text {lckCre }} \mathrm{T}$ cells, some mice seemed to respond to treatment, whereas others had a very low number of goblet cells. Since the survival curves implied that the disease course was delayed for $24 \mathrm{~h}$, mice were analysed on day 7 . In two independent experiments, treated mice that had received $\mathrm{GR}^{\text {lckCre }} \mathrm{T}$ cells, showed extremely low goblet cell numbers on day 7. In mice receiving $\mathrm{GR}^{\mathrm{dim}} \mathrm{T}$ cells, goblet cell number was increased after treatment. In $\mathrm{GR}^{\mathrm{dim}}$ recipients, goblet cell numbers were not greatly increased after treatment, but this can be attributed to the fact that the reduction of goblet cells in $\mathrm{GR}^{\mathrm{dim}}$ mice was not as strong as in the other groups (Figure 24).

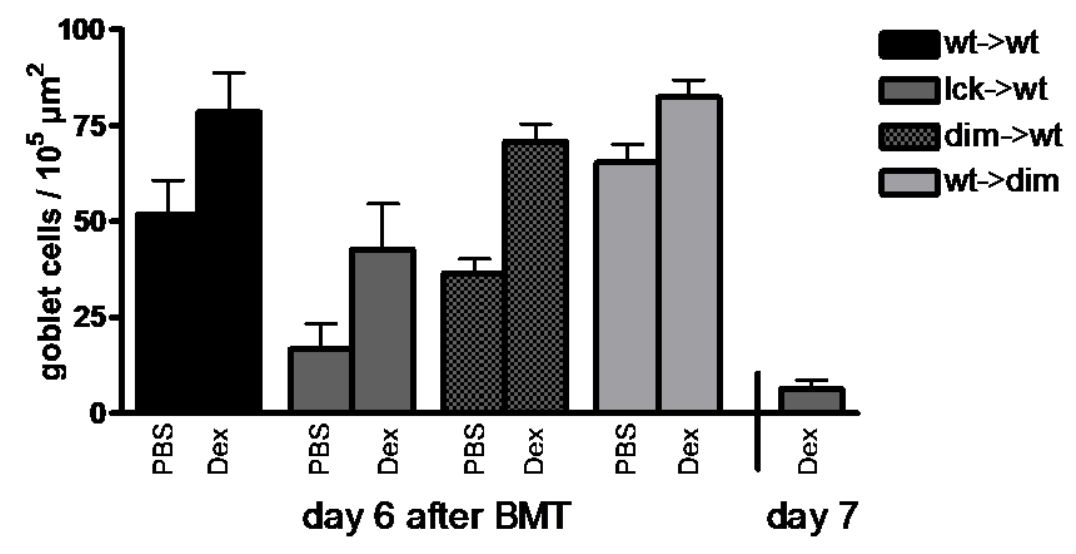

Figure 24: Number of goblet cells in jejunum (PAS stain, 40x) per section in untreated animals and in animals treated with $100 \mathrm{mg} / \mathrm{kg}$ dex from day 3 to 6.5 sections were counted per animal and the average was taken, mean values + s.e.m., $(n=4-10)$; Experimental groups were as follows: $w t \rightarrow w t=G^{\mathrm{wt}} \mathrm{T}$ cells transplanted into $\mathrm{GR}^{\mathrm{wt}}$ recipient mice, $\mathrm{lck} \rightarrow \mathrm{wt}=\mathrm{GR}^{\mathrm{lckCre}} \mathrm{T}$ cells transplanted into $\mathrm{GR}^{\mathrm{wt}}$ recipient mice, $\operatorname{dim} \rightarrow \mathrm{wt}=\mathrm{GR}^{\mathrm{dim}}$ $\mathrm{T}$ cells transplanted into $\mathrm{GR}^{\mathrm{wt}}$ recipient mice, $\mathrm{wt} \rightarrow \mathrm{dim}=\mathrm{GR}^{\mathrm{wt}} \mathrm{T}$ cells transplanted into $\mathrm{GR}^{\mathrm{dim}}$ recipient mice.

\subsubsection{Proliferation of epithelial cells in jejunum}

In jejunum, tissue destruction is compensated by hyperproliferation. Only when aGvHD progresses, complete destruction of the villi architecture with apoptosis of stem cells and cessation of proliferation occurs (Figure 25). 


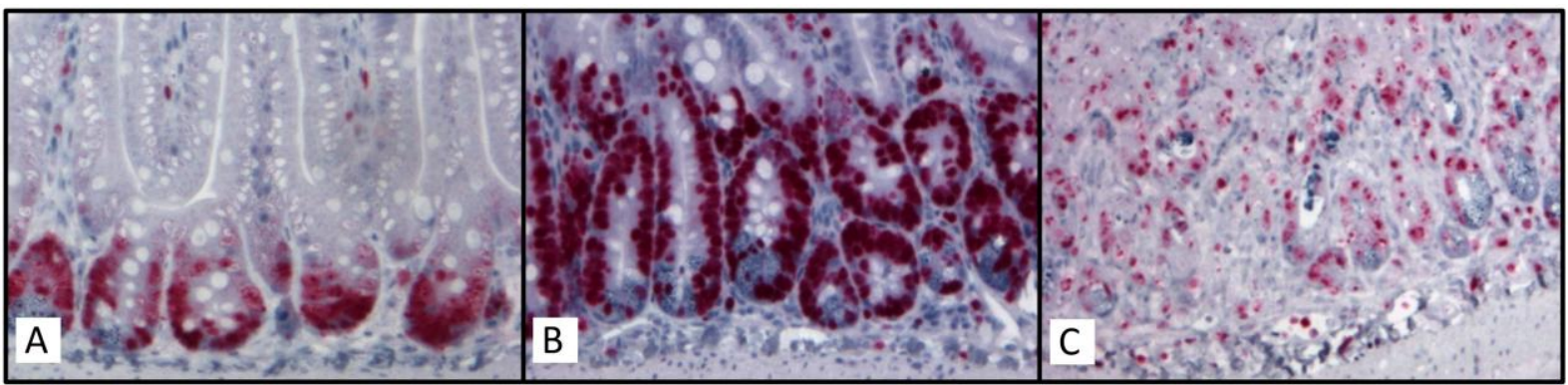

Figure 25: Proliferation of epithelial cells in jejunum on day 6 after transplantation (Ki67 stain, 20x magnification). (A) Normal proliferation $=0$ (B) Hyperproliferation $=1$ (C) Destruction of villi architecture $=2$.

In mice receiving $\mathrm{GR}^{\mathrm{wt}} \mathrm{T}$ cells, a hyperproliferative or destructive architecture can be observed compared to transplantation of only bone marrow, where proliferation is normal. Mice receiving $\mathrm{GR}^{\text {lckCre }}$ or $\mathrm{GR}^{\mathrm{dim}} \mathrm{T}$ cells, by trend, have an even worse architecture in comparison to mice receiving $\mathrm{GR}^{\mathrm{wt}} \mathrm{T}$ cells. $\mathrm{GR}^{\mathrm{dim}}$ recipients receiving $\mathrm{GR}^{\mathrm{wt}} \mathrm{T}$ cells do not seem to differ from $\mathrm{GR}^{\mathrm{wt}}$ littermates. Dex by trend improves jejunum towards a normal proliferative situation (Figure 26).

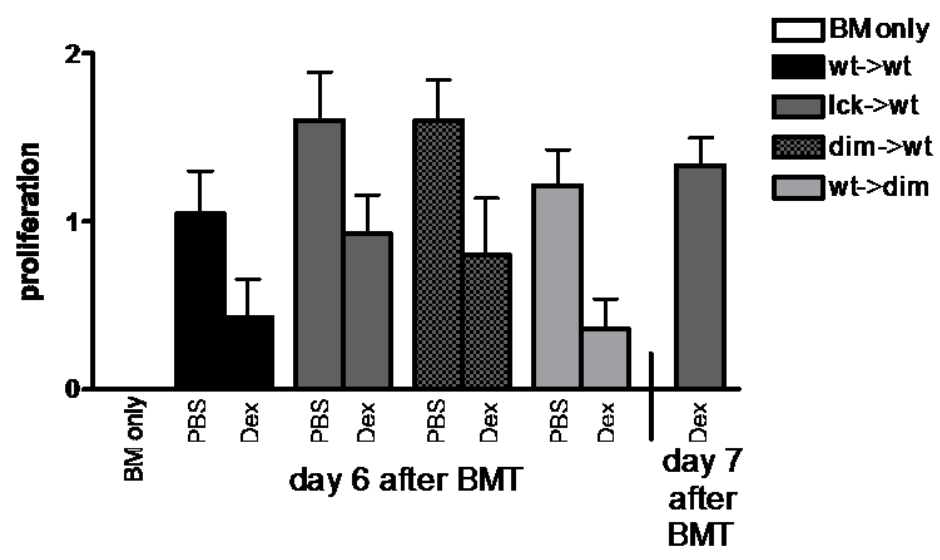

Figure 26: Proliferation in jejunum (Ki67 stain) in untreated animals and in animals treated with dex $(100 \mathrm{mg} / \mathrm{kg})$ from day 3 to $6 .(0=$ normal proliferation, $1=$ hyperproliferation, $2=$ cessation of proliferation due to destruction; mean values + s.e.m., $(n=5-10)$; Experimental groups were as follows: $\mathrm{BM}$ only $=$ no $\mathrm{T}$ cells transplanted; $\mathrm{wt} \rightarrow \mathrm{wt}=\mathrm{GR}^{\mathrm{wt}} \mathrm{T}$ cells transplanted into $\mathrm{GR}^{\mathrm{wt}}$ recipient mice, $1 \mathrm{ck} \rightarrow \mathrm{wt}=\mathrm{GR}^{\text {lckCre }} \mathrm{T}$ cells transplanted into $\mathrm{GR}^{\mathrm{wt}}$ recipient mice, $\mathrm{dim} \rightarrow \mathrm{wt}=\mathrm{GR}^{\mathrm{dim}} \mathrm{T}$ cells transplanted into $\mathrm{GR}^{\mathrm{wt}}$ recipient mice, wt $\rightarrow \mathrm{dim}$ $=\mathrm{GR}^{\mathrm{wt}} \mathrm{T}$ cells transplanted into GR ${ }^{\mathrm{dim}}$ recipient mice.

\subsubsection{Macrophages in jejunum and liver}

Dex does not generally cause apoptosis of macrophages, but rather morphological changes that reduce the spreading of the macrophages. In histological specimens, this results in a reduction of the area the macrophages take up. Therefore, to judge the influence of dex on macrophages, the area of macrophage-specific staining signal was measured. 

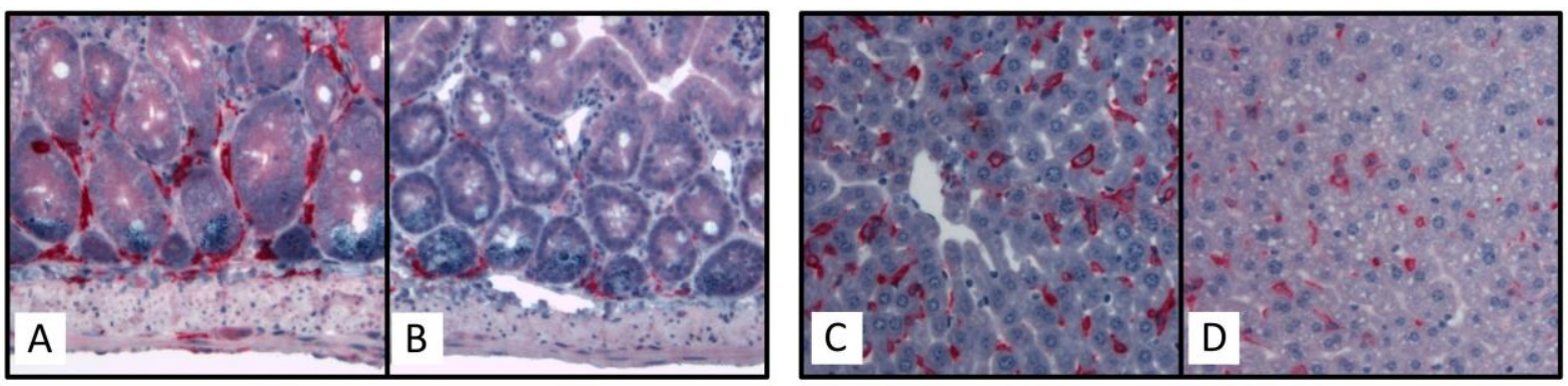

Figure 27: Macrophages in jejunum and liver on day 6 after transplantation (A\&B: HR3 stain, 10x magnification; C\&D: F4/80 stain, 10x magnification). (A) Jejunum of a mouse receiving $\mathrm{GR}^{\mathrm{wt}} \mathrm{T}$ cells without treatment (B) Jejunum of a mouse receiving GR $^{\mathrm{wt}} \mathrm{T}$ cells treatment with dex from day 3 to 6 (C) Liver of a mouse receiving $\mathrm{GR}^{\mathrm{wt}} \mathrm{T}$ cells without treatment (D) Liver of a mouse receiving $\mathrm{GR}^{\mathrm{wt}} \mathrm{T}$ cells treatment with dex from day 3 to 6 .

Generally, area of macrophages in jejunum was reduced after dex treatment. This is true for $\mathrm{GR}^{\mathrm{wt}}$ animals transplanted with $\mathrm{GR}^{\mathrm{wt}}, \mathrm{GR}^{\text {lckCre }}$ or $\mathrm{GR}^{\mathrm{dim}} \mathrm{T}$ cells, as well as for $\mathrm{GR}^{\mathrm{dim}}$ recipients transplanted with $\mathrm{GR}^{\mathrm{wt}} \mathrm{T}$ cells.

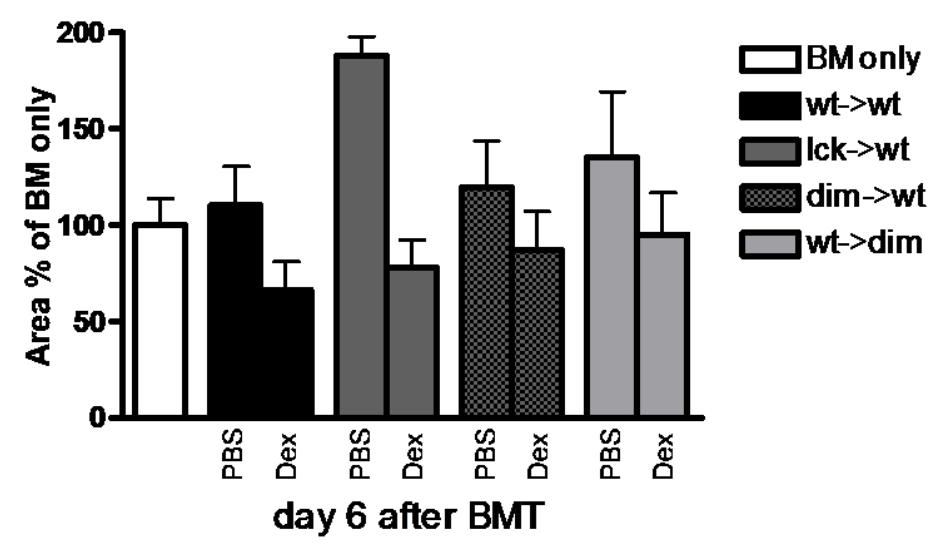

Figure 28: Area of macrophages in jejunum (HR3 stain, 10x) per section in untreated animals and in animals treated with $100 \mathrm{mg} / \mathrm{kg}$ dex from day 3 to 6. The area of macrophage spreading was selected and measured, mean values + s.e.m., $(\mathrm{n}=5-10)$; Experimental groups were as follows: $\mathrm{BM}$ only $=$ no $\mathrm{T}$ cells transplanted; $\mathrm{wt} \rightarrow \mathrm{wt}=\mathrm{GR}^{\mathrm{wt}} \mathrm{T}$ cells transplanted into $\mathrm{GR}^{\mathrm{wt}}$ recipient mice, lck $\rightarrow \mathrm{wt}=\mathrm{GR}^{\text {lckCre }} \mathrm{T}$ cells transplanted into $\mathrm{GR}^{\mathrm{wt}}$ recipient mice, $\mathrm{dim} \rightarrow \mathrm{wt}=\mathrm{GR}^{\mathrm{dim}} \mathrm{T}$ cells transplanted into $\mathrm{GR}^{\mathrm{wt}}$ recipient mice, wt $\rightarrow \mathrm{dim}$ $=\mathrm{GR}^{\mathrm{wt}} \mathrm{T}$ cells transplanted into $\mathrm{GR}^{\mathrm{dim}}$ recipient mice.

For $\mathrm{GR}^{\mathrm{wt}}$ animals transplanted with $\mathrm{GR}^{\mathrm{wt}}$ or $\mathrm{GR}^{\mathrm{lckCre}} \mathrm{T}$ cells the situation in liver is similar as for jejunum, dex treatment reduces macrophage area. In $\mathrm{GR}^{\mathrm{wt}}$ recipients receiving $\mathrm{GR}^{\text {dim }} \mathrm{T}$ cells, macrophage area was low without treatment and was not reduced after treatment. In $\mathrm{GR}^{\mathrm{dim}}$ recipients, macrophage area was also low, but was further reduced upon treatment. 


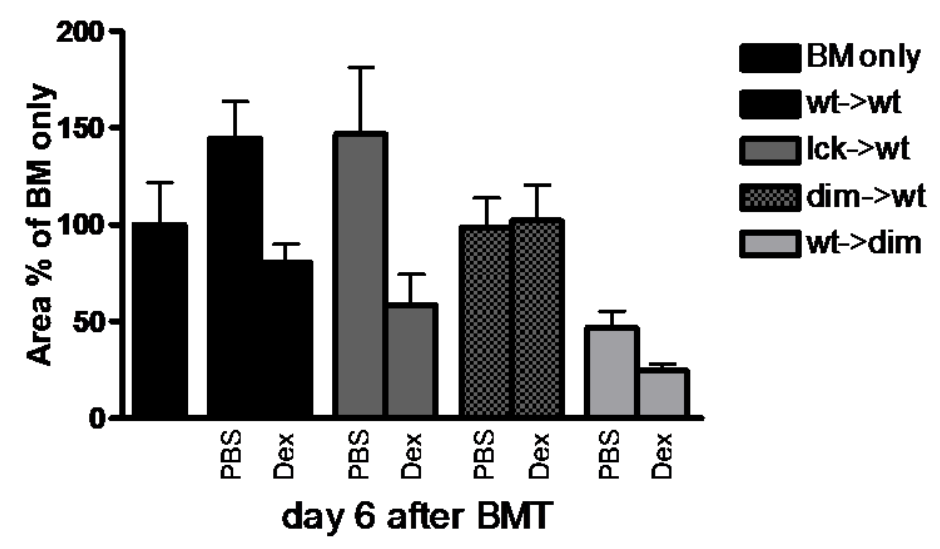

Figure 29: Area of macrophages in liver $\left(\mathbf{F 4 / 8 0 ^ { + }}\right.$ stain, 10x) per section in untreated animals and in animals treated with dex $(\mathbf{1 0 0} \mathbf{~ m g} / \mathbf{k g})$ from day 3 to 6 . The area of macrophage spreading was selected and measured, mean values + s.e.m., $(\mathrm{n}=5-10)$; Experimental groups were as follows: $\mathrm{BM}$ only $=$ no $\mathrm{T}$ cells transplanted; $\mathrm{wt} \rightarrow \mathrm{wt}=\mathrm{GR}^{\mathrm{wt}} \mathrm{T}$ cells transplanted into $\mathrm{GR}^{\mathrm{wt}}$ recipient mice, lck $\rightarrow \mathrm{wt}=\mathrm{GR}^{\text {lckCre }} \mathrm{T}$ cells transplanted into $\mathrm{GR}^{\mathrm{wt}}$ recipient mice; $\mathrm{dim} \rightarrow \mathrm{wt}=\mathrm{GR}^{\mathrm{dim}} \mathrm{T}$ cells transplanted into $\mathrm{GR}^{\mathrm{wt}}$ recipient mice; wt $\rightarrow \mathrm{dim}$ $=\mathrm{GR}^{\mathrm{wt}} \mathrm{T}$ cells transplanted into $\mathrm{GR}^{\mathrm{dim}}$ recipient mice.

\subsubsection{Changes in liver histology upon dex treatment}

Histological changes of the liver were observed after dex treatment. White spaces could be observed, which are likely fatty deposits. This effect could be observed in most dex treated animals, regardless of recipient or donor phenotype.

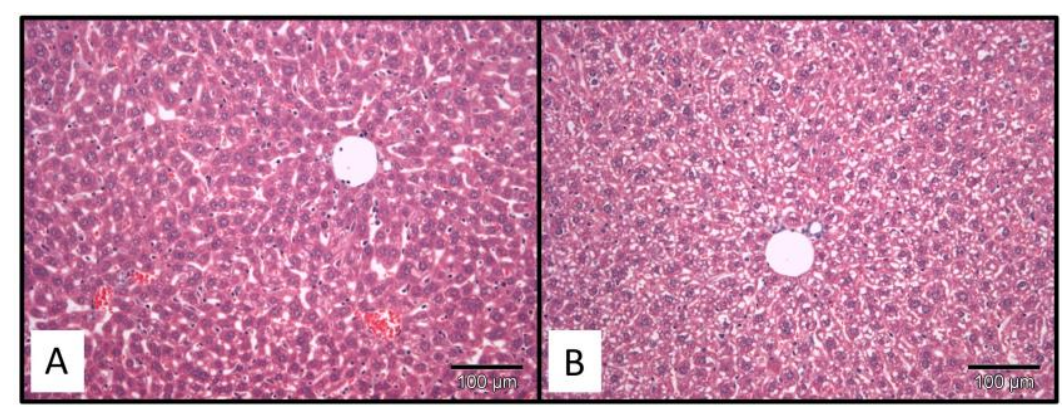

Figure 30: Liver histology on day 6 after transplantation (HE stain, 10x magnification). (A) Liver of a mouse receiving $\mathrm{GR}^{\mathrm{wt}} \mathrm{T}$ cells without treatment $(\mathrm{B})$ Liver of a mouse receiving $\mathrm{GR}^{\mathrm{wt}} \mathrm{T}$ cells treatment with dex from day 3 to 6 .

\subsection{Cytokines}

\subsubsection{Interleukin-2 (IL-2)}

On day 5 , recipients of $\mathrm{GR}^{\mathrm{wt}} \mathrm{T}$ cells had significantly elevated levels of IL-2 in the serum (sIL-2) compared to recipients receiving only $T$ cell-depleted bone marrow. On day 6 there was no increase. In case of GR ${ }^{\text {lckCre }} T$ cells, slL-2 was increased on both, day 5 and 6 , compared to the transplantation of $G^{\text {wt }} T$ cells. When $G^{\text {dim }} T$ cells 
were transplanted, no difference compared to $\mathrm{GR}^{\mathrm{wt}}$ transplantation could be found. If hosts were $\mathrm{GR}^{\mathrm{dim}}$, sIL-2 was significantly increased compared to $\mathrm{GR}^{\text {wt }}$ littermates on day 5 , but not on day 6 (Figure 31 ).

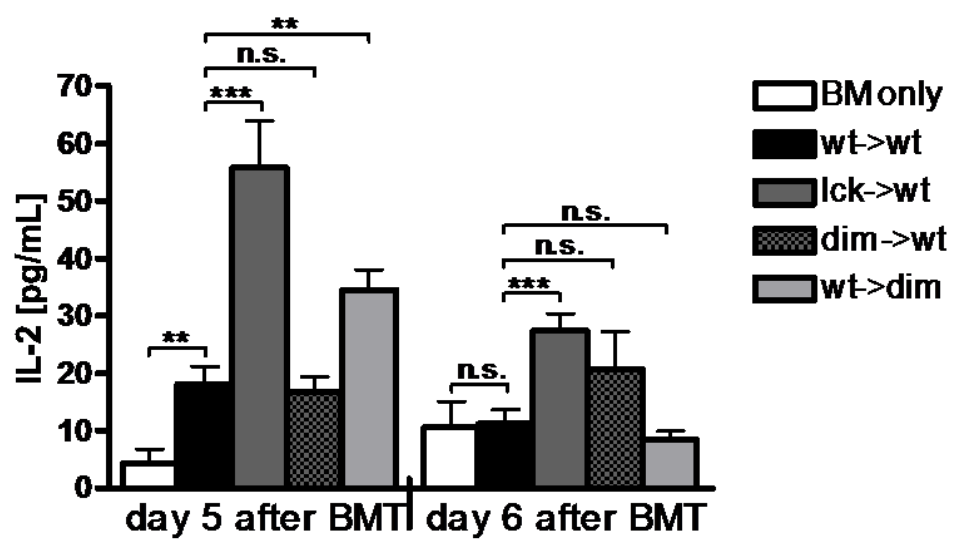

Figure 31: IL-2 serum levels after aGvHD induction. Blood was collected by heart puncture on days 5 or 6 after transplantation and IL-2 was measured by ELISA after preparation of serum; mean values + s.e.m., (day 5: $\mathrm{n}=7-15$, day 6: $\mathrm{n}=5-14$, BM only: $\mathrm{n}=4-8$ ); Experimental groups were as follows: $\mathrm{BM}$ only $=$ no $\mathrm{T}$ cells transplanted, $\mathrm{wt} \rightarrow \mathrm{wt}=\mathrm{GR}^{\mathrm{wt}} \mathrm{T}$ cells transplanted into $\mathrm{GR}^{\mathrm{wt}}$ recipient mice, lck $\rightarrow \mathrm{wt}=\mathrm{GR}^{\text {lckCre }} \mathrm{T}$ cells transplanted into $\mathrm{GR}^{\mathrm{wt}}$ recipient mice, $\mathrm{dim} \rightarrow \mathrm{wt}=\mathrm{GR}^{\mathrm{dim}} \mathrm{T}$ cells transplanted into $\mathrm{GR}^{\mathrm{wt}}$ recipient mice, $\mathrm{wt} \rightarrow \mathrm{dim}$ $=\mathrm{GR}^{\mathrm{wt}} \mathrm{T}$ cells transplanted into $\mathrm{GR}^{\mathrm{dim}}$ recipient mice.

When mice receiving $\mathrm{GR}^{\mathrm{wt}} \mathrm{T}$ cells were treated with dex, sIL-2 on day 5 could not be reduced. The significantly higher concentration in mice receiving $G^{1 \text { ckCre }} T$ cells, however, could be diminished by dex treatment on both days 5 and 6 . The sIL-2 concentration in mice receiving $\mathrm{GR}^{\mathrm{dim}} \mathrm{T}$ cells could also be reduced. In $\mathrm{GR}^{\mathrm{dim}}$ recipients, sIL-2 was not influenced by treatment (Figure 32).

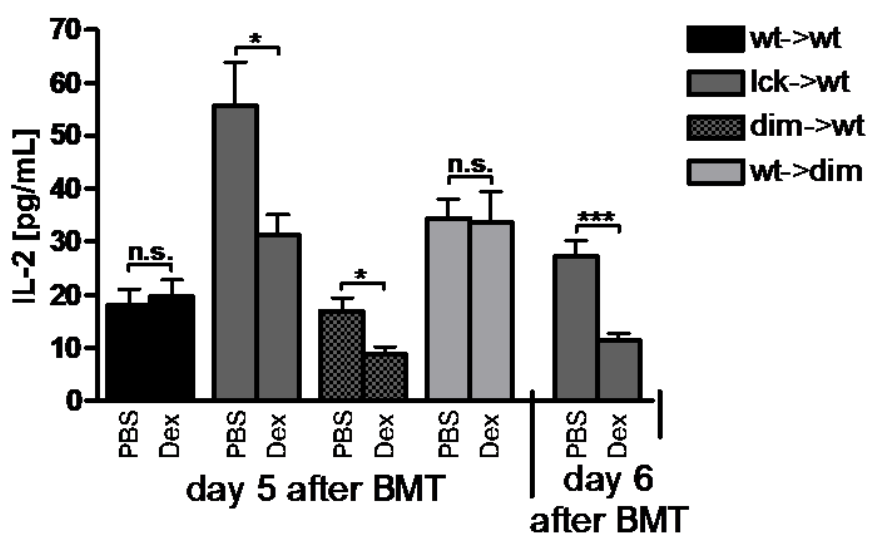

Figure 32: IL-2 serum levels after aGvHD induction and treatment with dex $(100 \mathrm{mg} / \mathrm{kg})$ from day 3 to 6 compared to treatment with PBS (control). Blood was collected by heart puncture on days 5 or 6 after transplantation and IL-2 was measured by ELISA after preparation of serum; mean values + s.e.m. (day 5: $\mathrm{n}=5$ 15, day 6: $n=5-13)$; Experimental groups were as follows: $w t \rightarrow w t=G^{w t} T$ cells transplanted into $\mathrm{GR}^{\mathrm{wt}}$ recipient mice, $1 \mathrm{ck} \rightarrow \mathrm{wt}=\mathrm{GR}^{\mathrm{lckCre}} \mathrm{T}$ cells transplanted into $\mathrm{GR}^{\mathrm{wt}}$ recipient mice, $\mathrm{dim} \rightarrow \mathrm{wt}=\mathrm{GR}^{\mathrm{dim}} \mathrm{T}$ cells transplanted into $\mathrm{GR}^{\mathrm{wt}}$ recipient mice, $\mathrm{wt} \rightarrow \mathrm{dim}=\mathrm{GR}^{\mathrm{wt}} \mathrm{T}$ cells transplanted into $\mathrm{GR}^{\mathrm{dim}}$ recipient mice. 
Of note, IL-2 serum levels were generally low and in the lower range of the standard curve of the ELISA kit (detection limit $=3.1 \mathrm{pg} / \mathrm{mL}$ ).

\subsubsection{Interferon- $\gamma(I N F \gamma)$}

Mice receiving $\mathrm{T}$ cell-depleted bone marrow had virtually no INF $\gamma$ in the serum (sINF $\gamma$ ) on days 5 and 6 after transplantation. If aGvHD was induced in $\mathrm{GR}^{\mathrm{wt}}$ recipients using $\mathrm{GR}^{\mathrm{wt}} \mathrm{T}$ cells, sIFN $\gamma$ was elevated. There was no difference on day 5 for $\mathrm{GR}^{\text {lckCre }}$ or $\mathrm{GR}^{\mathrm{dim}} \mathrm{T}$ cells, or for $\mathrm{GR}^{\mathrm{dim}}$ recipients compared to $\mathrm{GR}^{\mathrm{wt}} \mathrm{T}$ cells or $\mathrm{GR}^{\mathrm{wt}}$ recipients, respectively. On day 6 , however, animals that had received $G^{\text {lckCre }}$ T cells had significantly elevated sIFN $\gamma$ compared to those receiving GR $^{\text {wt }} \mathrm{T}$ cells. Mice receiving $\mathrm{GR}^{\mathrm{dim}} \mathrm{T}$ cells also showed elevated sIFN $\gamma$, although the increase was less pronounced compared to $\mathrm{GR}^{\text {lckCre }} T$ cells $(p=0.0293)$. $G R^{\text {dim }}$ recipients showed no difference compared to $\mathrm{GR}^{\mathrm{wt}}$ littermates (Figure 33).

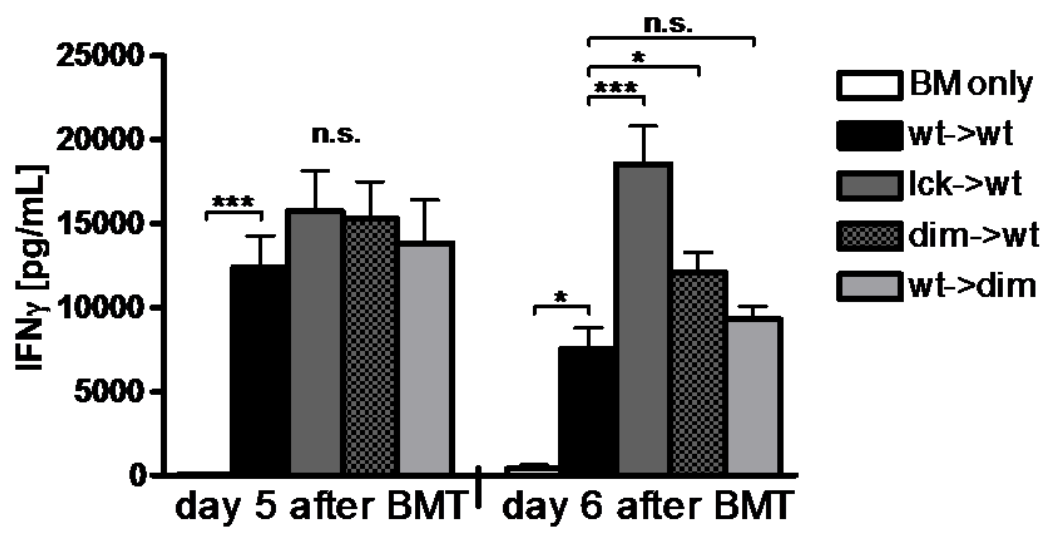

Figure 33: IFN $\gamma$ serum levels after aGvHD induction. Blood was collected by heart puncture on days 5 or 6 after transplantation and IFN $\gamma$ was measured by ELISA after preparation of serum; mean values + s.e.m., (day 5: $\mathrm{n}=8-16$, day $6: \mathrm{n}=9-24$, BM only: $\mathrm{n}=4-8$ ); Experimental groups were as follows: $\mathrm{BM}$ only = no $\mathrm{T}$ cells transplanted, $\mathrm{wt} \rightarrow \mathrm{wt}=\mathrm{GR}^{\mathrm{wt}} \mathrm{T}$ cells transplanted into $\mathrm{GR}^{\mathrm{wt}}$ recipient mice, lck $\rightarrow \mathrm{wt}=\mathrm{GR}^{\text {lckCre }} \mathrm{T}$ cells transplanted into $\mathrm{GR}^{\mathrm{wt}}$ recipient mice, $\mathrm{dim} \rightarrow \mathrm{wt}=\mathrm{GR}^{\mathrm{dim}} \mathrm{T}$ cells transplanted into $\mathrm{GR}^{\mathrm{wt}}$ recipient mice, wt $\rightarrow \mathrm{dim}$ $=\mathrm{GR}^{\mathrm{wt}} \mathrm{T}$ cells transplanted into $\mathrm{GR}^{\mathrm{dim}}$ recipient mice.

In all cases treatment with dex lead to significantly decreased sIFNy levels on day 5. On day 6 , the decrease was less pronounced. This was especially true for wt $\rightarrow$ wt and $w t \rightarrow \operatorname{dim}$ combinations, which can be attributed to the fact that sIFN $\gamma$ decreased from day 5 to day 6 in both $w t \rightarrow w t \quad(p=0.0290)$ and $w t \rightarrow \operatorname{dim}(p=0.0355)$ transplantations. In contrast, in mice transplanted with $\mathrm{GR}^{\text {lckCre }}$ or $\mathrm{GR}^{\mathrm{dim}} \mathrm{T}$ cells sIFN $\gamma$ did not abate from day 5 to day 6 (Figure 34). 


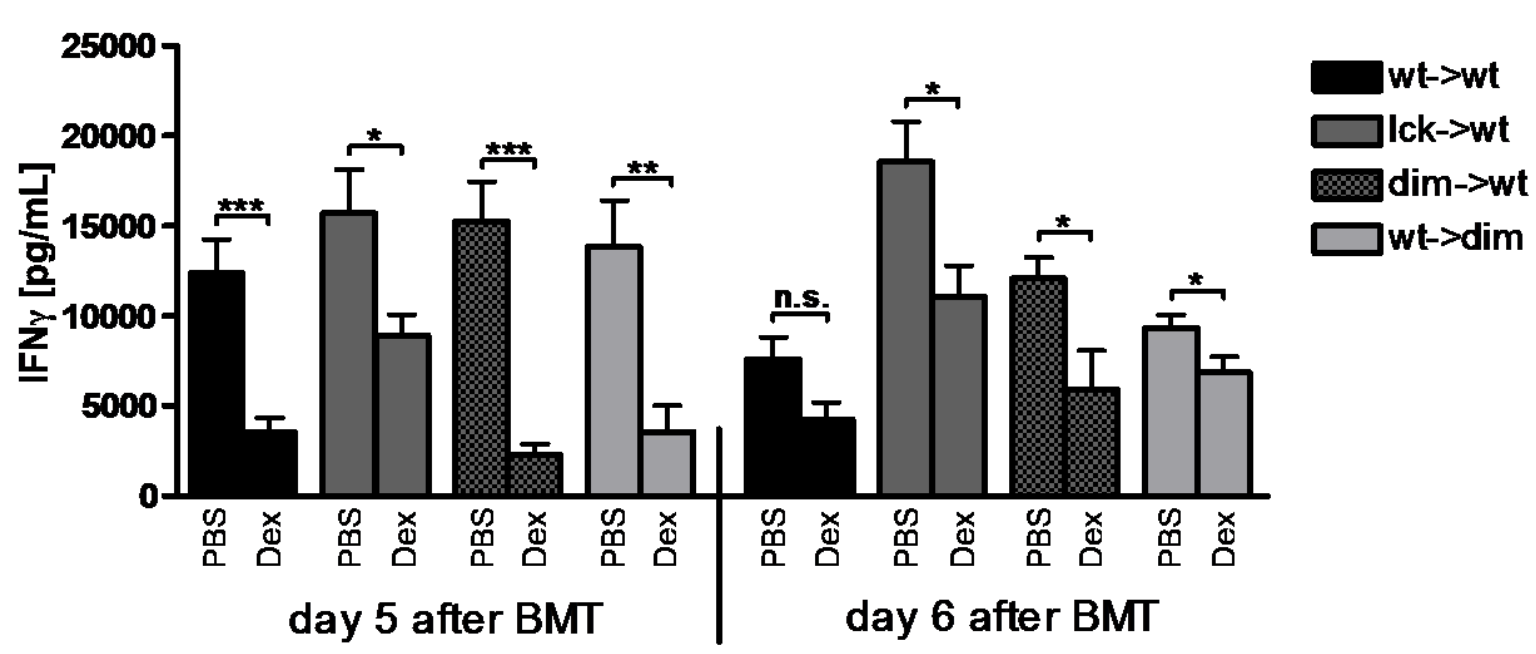

Figure 34: IFN $\gamma$ serum levels after aGvHD induction and treatment with dex $(100 \mathrm{mg} / \mathrm{kg})$ from day 3 to 6 compared to treatment with PBS (control). Blood was collected by heart puncture on days 5 or 6 after transplantation and IFN $\gamma$ was measured by ELISA after preparation of serum; mean values + s.e.m., (day 5: $n=6-$ 16, day 6: $\mathrm{n}=8-24)$; Experimental groups were as follows: $\mathrm{wt} \rightarrow \mathrm{wt}=\mathrm{GR}^{\mathrm{wt}} \mathrm{T}$ cells transplanted into $\mathrm{GR}^{\mathrm{wt}}$ recipient mice, $1 \mathrm{ck} \rightarrow \mathrm{wt}=\mathrm{GR}^{\mathrm{lckCr}} \mathrm{T}$ cells transplanted into $\mathrm{GR}^{\mathrm{wt}}$ recipient mice, $\operatorname{dim} \rightarrow \mathrm{wt}=\mathrm{GR}^{\mathrm{dim}} \mathrm{T}$ cells transplanted into $\mathrm{GR}^{\mathrm{wt}}$ recipient mice, $\mathrm{wt} \rightarrow \mathrm{dim}=\mathrm{GR}^{\mathrm{wt}} \mathrm{T}$ cells transplanted into $\mathrm{GR}^{\mathrm{dim}}$ recipient mice.

Despite the fact sIFN $\gamma$ could be reduced by dex treatment after transplantation of $\mathrm{GR}^{\mathrm{lckCre}} \mathrm{T}$ cells, its concentration remained significantly higher than after treatment of animals that had received $\mathrm{GR}^{\mathrm{wt}} \mathrm{T}$ cells. sIFN $\gamma$ after treatment in $\mathrm{GR}^{\mathrm{dim}}$ hosts or after transplantation of $\mathrm{GR}^{\mathrm{dim}} \mathrm{T}$ cells is comparable to $\mathrm{wt} \rightarrow \mathrm{wt}$ transplantations.

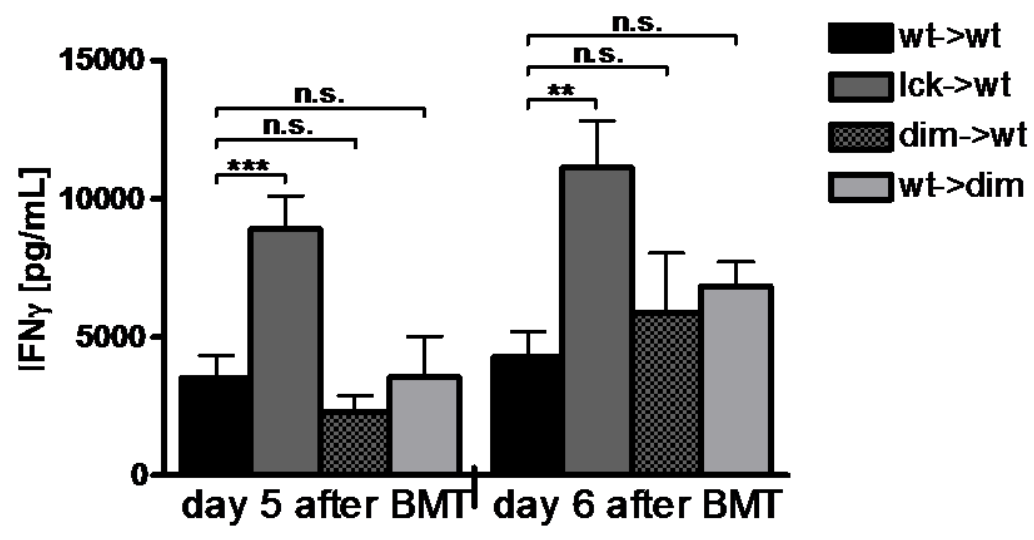

Figure 35: IFN $\gamma$ serum levels after aGvHD induction and treatment with dex $(100 \mathrm{mg} / \mathrm{kg})$ from day 3 to 6. Blood was collected by heart puncture on days 5 or 6 after transplantation and IFN $\gamma$ was measured by ELISA after preparation of serum; mean values + s.e.m., (day 5: $n=6-15$, day 6: $n=8-18$ ); Experimental groups were as follows: $\mathrm{wt} \rightarrow \mathrm{wt}=\mathrm{GR}^{\mathrm{wt}} \mathrm{T}$ cells transplanted into $\mathrm{GR}^{\mathrm{wt}}$ recipient mice, lck $\rightarrow \mathrm{wt}=\mathrm{GR}^{\text {lckCre }} \mathrm{T}$ cells transplanted into $\mathrm{GR}^{\mathrm{wt}}$ recipient mice, $\mathrm{dim} \rightarrow \mathrm{wt}=\mathrm{GR}^{\mathrm{dim}} \mathrm{T}$ cells transplanted into $\mathrm{GR}^{\mathrm{wt}}$ recipient mice, wt $\rightarrow \operatorname{dim}=\mathrm{GR}^{\mathrm{wt}}$ $\mathrm{T}$ cells transplanted into $\mathrm{GR}^{\mathrm{dim}}$ recipient mice.

Furthermore, the results for sIFN $\gamma$ are supported by qRT-PCR analysis of spleen. IFN $\gamma$ gene expression in the spleen was highest in mice receiving $\mathrm{GR}^{\mathrm{lckCre}} \mathrm{T}$ cells and 
slightly elevated in mice receiving $\mathrm{GR}^{\mathrm{dim}} \mathrm{T}$ cells. Dex treatment was able to reduce expression in all cases (Figure 36).

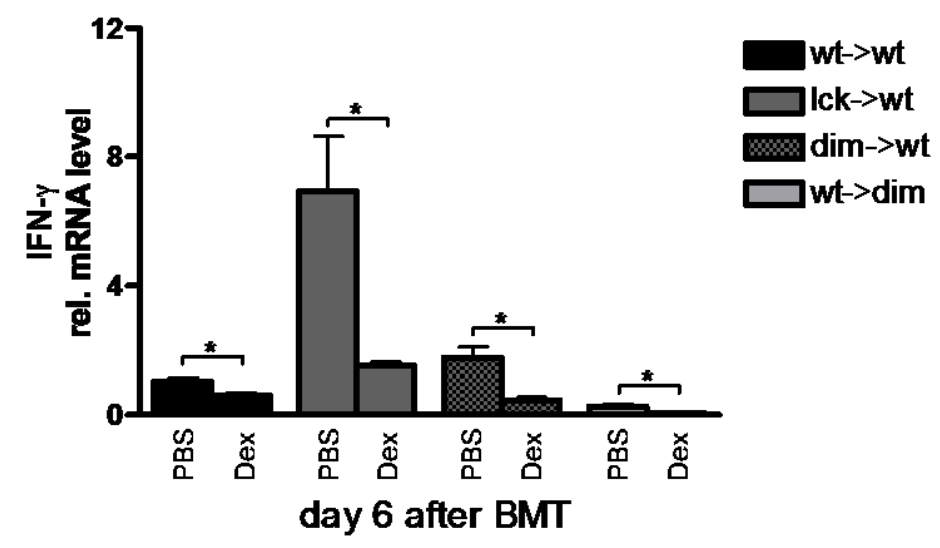

Figure 36: IFN $\gamma$ gene expression in the spleen after aGvHD induction and treatment with dex $(100 \mathrm{mg} / \mathrm{kg})$ from day 3 to 6 compared to treatment with PBS (control). Spleen was collected on day 6 after transplantation and IFN $\gamma$ expression was measured by qRT-PCT; relative mRNA expression levels were obtained by normalising to HPRT mRNA expression; relative expression in wt $\rightarrow \mathrm{wt}$ PBS mice was set equal to 1 ; mean values + s.e.m., $(\mathrm{n}=4-6)$; Experimental groups were as follows: $\mathrm{wt} \rightarrow \mathrm{wt}=\mathrm{GR}^{\mathrm{wt}} \mathrm{T}$ cells transplanted into $\mathrm{GR}^{\mathrm{wt}}$ recipient mice, $\mathrm{lck} \rightarrow \mathrm{wt}=\mathrm{GR}^{\mathrm{lckCre}} \mathrm{T}$ cells transplanted into $\mathrm{GR}^{\mathrm{wt}}$ recipient mice, $\mathrm{dim} \rightarrow \mathrm{wt}=\mathrm{GR}^{\mathrm{dim}} \mathrm{T}$ cells transplanted into $\mathrm{GR}^{\mathrm{wt}}$ recipient mice, $\mathrm{wt} \rightarrow \mathrm{dim}=\mathrm{GR}^{\mathrm{wt}} \mathrm{T}$ cells transplanted into $\mathrm{GR}^{\mathrm{dim}}$ recipient mice.

\subsubsection{Interleukin-17A (IL-17A)}

On day 5, IL-17A was elevated in the serum (sIL-17A) of mice receiving $\mathrm{GR}^{\mathrm{wt}} \mathrm{T}$ cells compared to mice receiving $T$ cell-depleted bone marrow only. On day 6, there was no elevation. Mice receiving $\mathrm{GR}^{\text {lckCre }}$ or $\mathrm{GR}^{\text {dim }} \mathrm{T}$ cells and $\mathrm{GR}^{\mathrm{dim}}$ recipients did not differ from the wt $\rightarrow$ wt transplantation setting on day 5 . On day 6 , slL-17A had declined in all groups like in the wt $\rightarrow$ wt transplantation, except for mice receiving $\mathrm{GR}^{\text {IckCre }} \mathrm{T}$ cells, in which it remained slightly elevated.

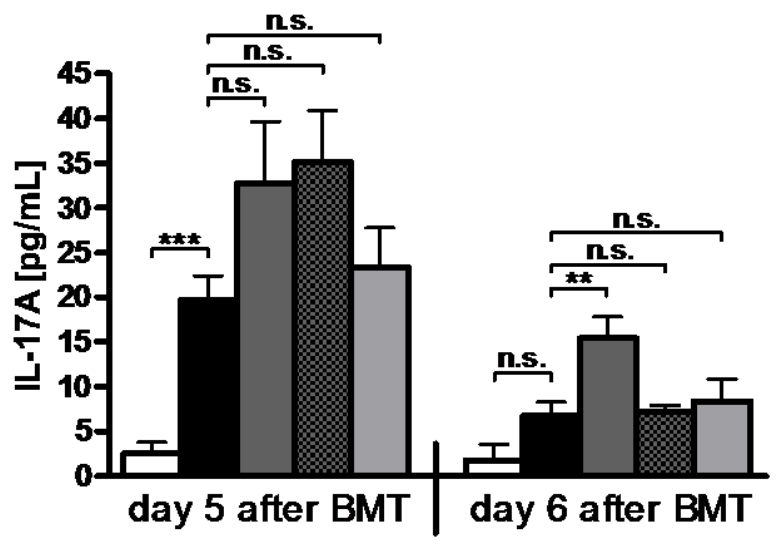

Figure 37: IL-17A serum levels after aGvHD induction. Blood was collected by heart puncture on days 5 or 6 after transplantation and IL-17A was measured by CBA after preparation of serum; mean values + s.e.m., (day 5: $\mathrm{n}=5-15$, day 6: $\mathrm{n}=6-13, \mathrm{BM}$ only: $\mathrm{n}=3-8$ ); Experimental groups were as follows: $\mathrm{BM}$ only $=$ no $\mathrm{T}$ cells transplanted, $\mathrm{wt} \rightarrow \mathrm{wt}=\mathrm{GR}^{\mathrm{wt}} \mathrm{T}$ cells transplanted into $\mathrm{GR}^{\mathrm{wt}}$ recipient mice, $\mathrm{lck} \rightarrow \mathrm{wt}=\mathrm{GR}^{\mathrm{lckCre}} \mathrm{T}$ cells 
transplanted into $\mathrm{GR}^{\mathrm{wt}}$ recipient mice, $\mathrm{dim} \rightarrow \mathrm{wt}=\mathrm{GR}^{\mathrm{dim}} \mathrm{T}$ cells transplanted into $\mathrm{GR}^{\mathrm{wt}}$ recipient mice, $\mathrm{wt} \rightarrow \mathrm{dim}$ $=\mathrm{GR}^{\mathrm{wt}} \mathrm{T}$ cells transplanted into $\mathrm{GR}^{\mathrm{dim}}$ recipient mice.

Treatment with dex was not able to significantly reduce slL-17 on day 5 in mice receiving $\mathrm{GR}^{\mathrm{wt}}, \mathrm{GR}^{\mathrm{lckCre}}$ or $\mathrm{GR}^{\text {dim }} \mathrm{T}$ cells. In $\mathrm{GR}^{\text {dim }}$ recipients on day 5 , slL-17A reduction was significant. The elevated sIL-17A concentration in recipients of $\mathrm{GR}^{\text {IckCre }}$ T cells on day 6 could also be significantly reduced by treatment with dex.

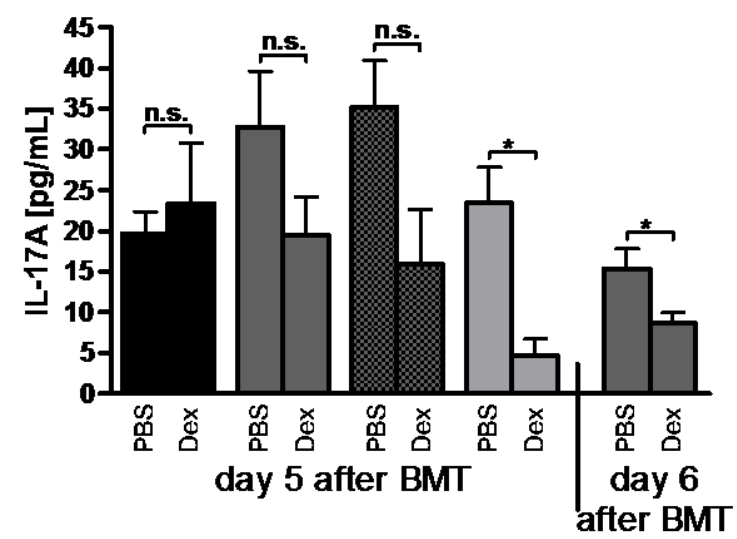

Figure 38: IL-17A serum levels after aGvHD induction and treatment with dex $(100 \mathrm{mg} / \mathrm{kg})$ from day 3 to 6 compared to treatment with PBS (control). Blood was collected by heart puncture on days 5 or 6 after transplantation and IL-17A was measured by CBA after preparation of serum; mean values + s.e.m., (day 5: $\mathrm{n}=4-15$, day 6: $\mathrm{n}=6-13$ ); Experimental groups were as follows: $\mathrm{wt} \rightarrow \mathrm{wt}=\mathrm{GR}^{\mathrm{wt}} \mathrm{T}$ cells transplanted into $\mathrm{GR}^{\mathrm{wt}}$ recipient mice, $1 \mathrm{ck} \rightarrow \mathrm{wt}=\mathrm{GR}^{\mathrm{lckCre}} \mathrm{T}$ cells transplanted into $\mathrm{GR}^{\mathrm{wt}}$ recipient mice, $\mathrm{dim} \rightarrow \mathrm{wt}=\mathrm{GR}^{\mathrm{dim}} \mathrm{T}$ cells transplanted into $\mathrm{GR}^{\mathrm{wt}}$ recipient mice, $\mathrm{wt} \rightarrow \mathrm{dim}=\mathrm{GR}^{\mathrm{wt}} \mathrm{T}$ cells transplanted into $\mathrm{GR}^{\mathrm{dim}}$ recipient mice.

In the spleen, IL-17A expression in mice receiving $\mathrm{GR}^{\mathrm{lckCre}} \mathrm{T}$ cells was also greatly increased on day 6 compared to all other groups. Dex treatment was able to decrease expression. 


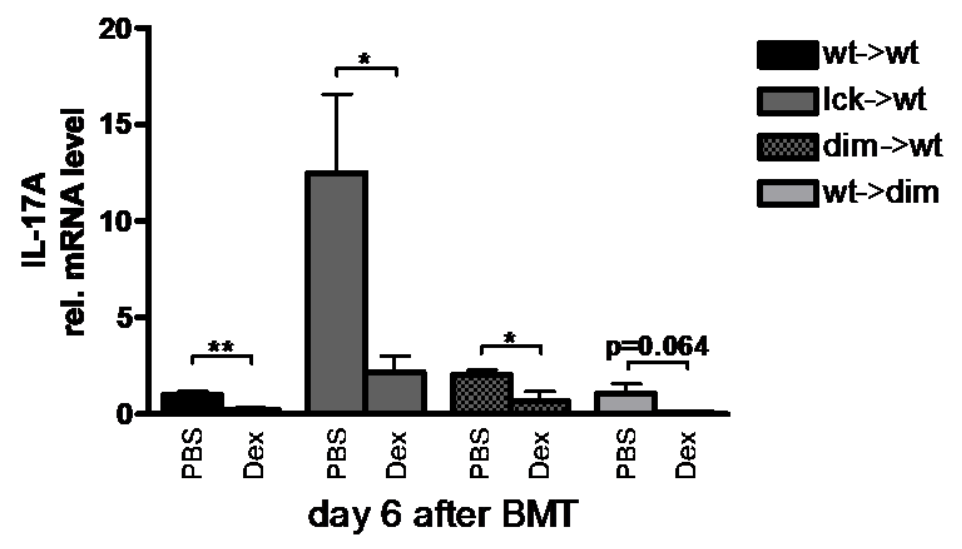

Figure 39: IL-17A gene expression in the spleen after aGvHD induction and treatment with dex $(100 \mathrm{mg} / \mathrm{kg}$ ) from day 3 to 6 compared to treatment with PBS (control). Spleen was collected on day 6 after transplantation and IL-17A expression was measured by qRT-PCT; relative mRNA expression levels were obtained by normalising to HPRT mRNA expression; relative expression in $\mathrm{wt} \rightarrow \mathrm{wt}$ PBS mice was set equal to 1 ; mean values + s.e.m., $(n=4-6)$; Experimental groups were as follows: $w t \rightarrow w t=\mathrm{GR}^{\mathrm{wt}} \mathrm{T}$ cells transplanted into $\mathrm{GR}^{\mathrm{wt}}$ recipient mice, $\mathrm{lck} \rightarrow \mathrm{wt}=\mathrm{GR}^{\text {lckCre }} \mathrm{T}$ cells transplanted into $\mathrm{GR}^{\mathrm{wt}}$ recipient mice, $\mathrm{dim} \rightarrow \mathrm{wt}=\mathrm{GR}^{\mathrm{dim}} \mathrm{T}$ cells transplanted into $\mathrm{GR}^{\mathrm{wt}}$ recipient mice, $\mathrm{wt} \rightarrow \mathrm{dim}=\mathrm{GR}^{\mathrm{wt}} \mathrm{T}$ cells transplanted into $\mathrm{GR}^{\mathrm{dim}}$ recipient mice.

\subsubsection{Interleukin-6 (IL-6) and monocyte chemotactic protein-1 (MCP-1)}

Although IL-6 in serum (sIL-6) on day 5 was elevated in mice receiving GR $^{\text {wt }}$ T cells compared to mice receiving only T cell-depleted bone marrow, no differences on day 5 could be observed between mice receiving $\mathrm{GR}^{\mathrm{wt}} \mathrm{T}$ cells and hosts of $\mathrm{T}$ cells with GR knock-outs. On day 6, sIL-6 was not elevated in mice receiving GR $^{\text {wt }} \mathrm{T}$ cells compared to mice receiving only T cell-depleted bone marrow. However, sIL-6 was significantly increased in $\mathrm{GR}^{\mathrm{dim}}$ hosts, but not in mice receiving $\mathrm{GR}^{\text {lckCre }}$ or $\mathrm{GR}^{\mathrm{dim}}$ T cells (Figure 40). 


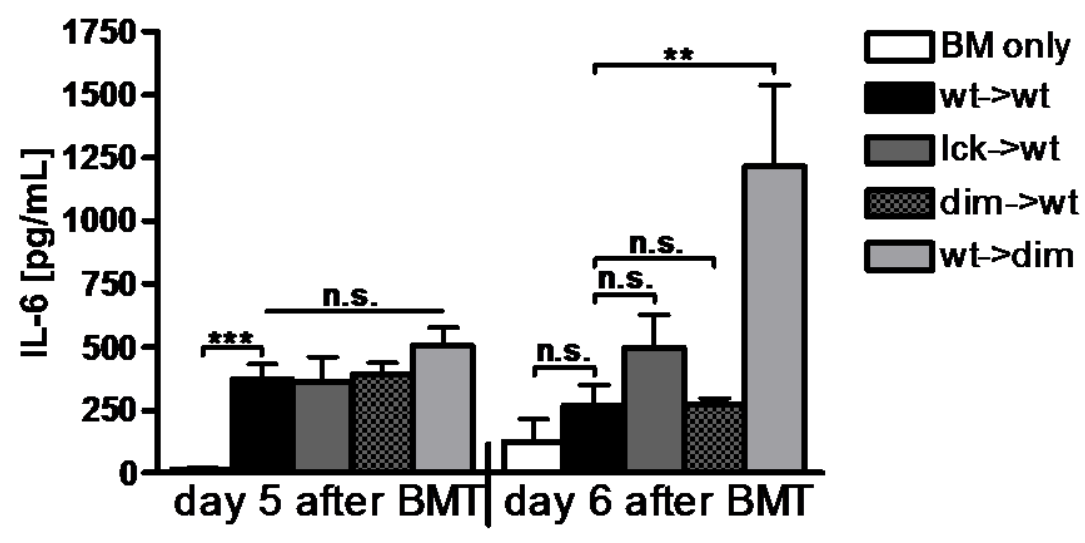

Figure 40: IL-6 serum levels after aGvHD induction. Blood was collected by heart puncture on days 5 or 6 after transplantation and IL-6 was measured by CBA after preparation of serum; mean values + s.e.m., (day 5: $\mathrm{n}=6-15$, day 6: $\mathrm{n}=6-13, \mathrm{BM}$ only: $\mathrm{n}=3-8)$; Experimental groups were as follows: $\mathrm{BM}$ only = no $\mathrm{T}$ cells transplanted, $\mathrm{wt} \rightarrow \mathrm{wt}=\mathrm{GR}^{\mathrm{wt}} \mathrm{T}$ cells transplanted into $\mathrm{GR}^{\mathrm{wt}}$ recipient mice, lck $\rightarrow \mathrm{wt}=\mathrm{GR}^{\text {lckCre }} \mathrm{T}$ cells transplanted into $\mathrm{GR}^{\mathrm{wt}}$ recipient mice; $\mathrm{dim} \rightarrow \mathrm{wt}=\mathrm{GR}^{\mathrm{dim}} \mathrm{T}$ cells transplanted into $\mathrm{GR}^{\mathrm{wt}}$ recipient mice; wt $\rightarrow \mathrm{dim}$ $=\mathrm{GR}^{\mathrm{wt}} \mathrm{T}$ cells transplanted into $\mathrm{GR}^{\mathrm{dim}}$ recipient mice.

Elevated sIL-6 on day 6 in GR ${ }^{\operatorname{dim}}$ recipients was treatable with dex (Figure 41).

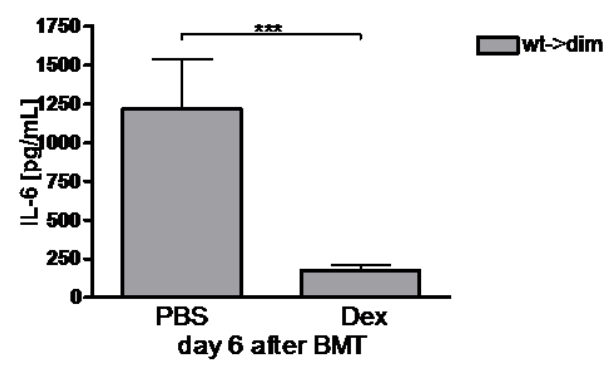

Figure 41: IL-6 serum levels after aGvHD induction and treatment with dex $(100 \mathrm{mg} / \mathrm{kg})$ from day 3 to 6 compared to treatment with PBS (control). Blood was collected by heart puncture on day 6 after transplantation and IL-6 was measured by CBA after preparation of serum; mean values + s.e.m., $(n=6-13)$; Experimental groups were as follows: $\mathrm{wt} \rightarrow \mathrm{dim}=\mathrm{GR}^{\mathrm{wt}} \mathrm{T}$ cells transplanted into $\mathrm{GR}^{\mathrm{dim}}$ recipient mice.

On day 5 but not on day 6, MCP-1 (CCL2) in serum (SMCP-1) was increased after the transplantation of $\mathrm{GR}^{\mathrm{wt}} \mathrm{T}$ cells compared to transplantation of $\mathrm{T}$ cell-depleted bone marrow only. In GR ${ }^{\operatorname{dim}}$ hosts SMCP-1 was highly increased on day 5, whereas recipients of $\mathrm{GR}^{\text {lckCre }}$ or $\mathrm{GR}^{\text {dim }} \mathrm{T}$ cells did not differ from $\mathrm{wt} \rightarrow \mathrm{wt}$ transplantation. On day 6, however, sMCP-1 in recipients of $\mathrm{GR}^{\text {lckCre }}$ or $\mathrm{GR}^{\mathrm{dim}} \mathrm{T}$ cells was also slightly but significantly increased compared to recipients of $\mathrm{GR}^{\mathrm{wt}} \mathrm{T}$ cells, but the increase in $\mathrm{GR}^{\mathrm{dim}}$ hosts was still much more pronounced (Figure 42). 


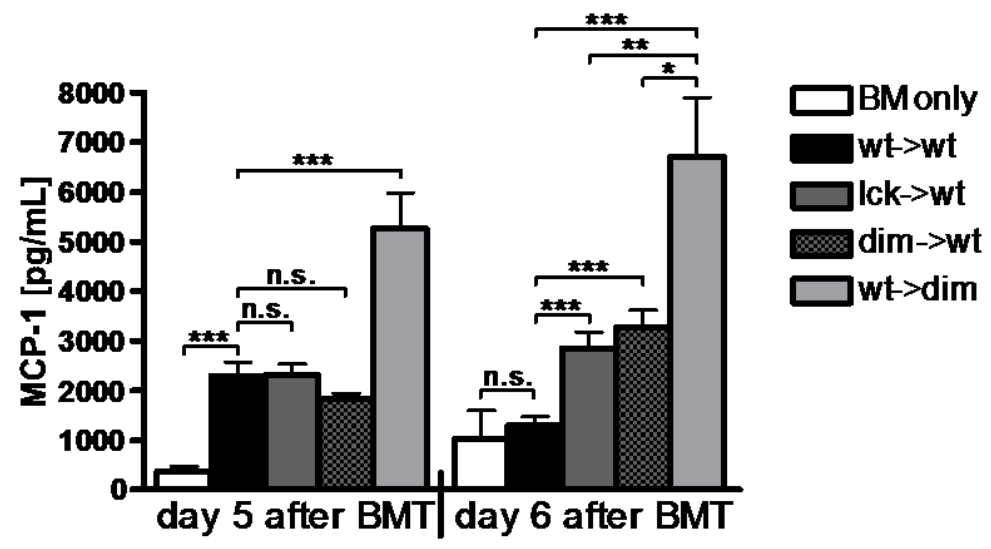

Figure 42: MCP-1 serum levels after aGvHD induction. Blood was collected by heart puncture on days 5 or 6 after transplantation and MCP-1 was measured by CBA after preparation of serum; mean values + s.e.m., (day 5: $\mathrm{n}=5-15$, day 6: $\mathrm{n}=6-13$, BM: only: $\mathrm{n}=4-8$ ); Experimental groups were as follows: $\mathrm{BM}$ only = no $\mathrm{T}$ cells transplanted, $\mathrm{wt} \rightarrow \mathrm{wt}=\mathrm{GR}^{\mathrm{wt}} \mathrm{T}$ cells transplanted into $\mathrm{GR}^{\mathrm{wt}}$ recipient mice, lck $\rightarrow \mathrm{wt}=\mathrm{GR}^{\text {lckCre }} \mathrm{T}$ cells transplanted into $\mathrm{GR}^{\mathrm{wt}}$ recipient mice, $\mathrm{dim} \rightarrow \mathrm{wt}=\mathrm{GR}^{\mathrm{dim}} \mathrm{T}$ cells transplanted into $\mathrm{GR}^{\mathrm{wt}}$ recipient mice, wt $\rightarrow \mathrm{dim}$ $=\mathrm{GR}^{\mathrm{wt}} \mathrm{T}$ cells transplanted into $\mathrm{GR}^{\mathrm{dim}}$ recipient mice.

After treatment with dex, SMCP-1 was significantly reduced in $\mathrm{GR}^{\text {dim }}$ recipients on both day 5 and 6 . In mice receiving $\mathrm{GR}^{\mathrm{dim}} \mathrm{T}$ cells, SMCP-1 was also reduced on day 6. In mice receiving $\mathrm{GR}^{\text {lckCre }} \mathrm{T}$ cells, however, SMCP-1 could not be reduced by treatment.

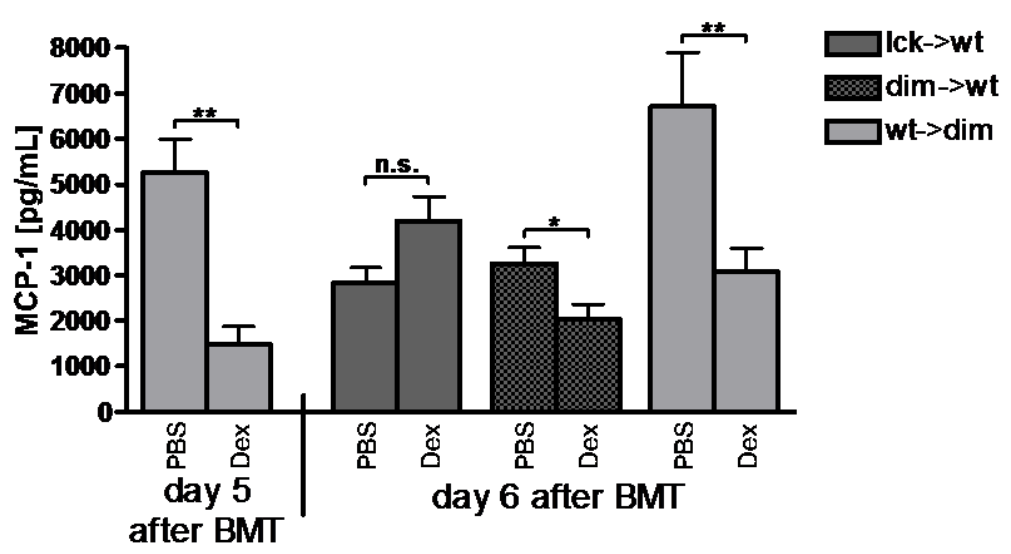

Figure 43: MCP-1 serum levels after aGvHD induction and treatment with dex $(100 \mathrm{mg} / \mathrm{kg})$ from day 3 to 6 compared to treatment with PBS (control). Blood was collected by heart puncture on days 5 or 6 after transplantation and MCP-1 was measured by CBA after preparation of serum; mean values + s.e.m., (day 5: $n=5$ 9, day 6: $\mathrm{n}=6$-13); Experimental groups were as follows: $\mathrm{wt} \rightarrow \mathrm{wt}=\mathrm{GR}^{\mathrm{wt}} \mathrm{T}$ cells transplanted into $\mathrm{GR}^{\mathrm{wt}}$ recipient mice, lck $\rightarrow \mathrm{wt}=\mathrm{GR}^{\text {lckCre }} \mathrm{T}$ cells transplanted into $\mathrm{GR}^{\mathrm{wt}}$ recipient mice, $\mathrm{dim} \rightarrow \mathrm{wt}=\mathrm{GR}^{\mathrm{dim}} \mathrm{T}$ cells transplanted into $\mathrm{GR}^{\mathrm{wt}}$ recipient mice, $\mathrm{wt} \rightarrow \mathrm{dim}=\mathrm{GR}^{\mathrm{wt}} \mathrm{T}$ cells transplanted into $\mathrm{GR}^{\mathrm{dim}}$ recipient mice.

\subsubsection{Other cytokines}

Analysis of IL-10 in serum (sIL-10) on days 5 and 6 revealed that only very low amounts were present (mean $20-60 \mathrm{pg} / \mathrm{mL}$ ) and that there were no differences between mice transplanted with $\mathrm{GR}^{\mathrm{wt}} \mathrm{T}$ cells and mice receiving $\mathrm{T}$ cell depleted bone 
marrow only. Furthermore, GR-deficiency in T cells or recipients made no difference compared to wt $\rightarrow$ wt transplantation. Treatment with dex also did not induce sIL-10 in any group.

IL-1b was not generally detectable in serum samples. Only a few samples contained some IL-1b and there was no correlation to genotype or treatment.

TNF- $\alpha$ was also not detectable in the serum at the analysed time points.

\subsection{Cytotoxic $T$ cell effector function}

Both perforin-1 and granzyme B expression of splenocytes was quantified to measure cytotoxic $T$ cell activity. Both are increased in mice receiving $G^{\text {lckcre }}$ or $G^{\text {dim }} T$ cells compared to mice receiving $G^{w t} T$ cells. $G R^{\text {dim }}$ recipients of $G^{\text {wt }}$ $T$ cells have an even lower expression than $G^{\text {wt }}$ littermates. Dex treatment decreases perforin-1 and granzyme $B$ expression in all groups except for mice receiving $\mathrm{GR}^{\mathrm{lckCre}} \mathrm{T}$ cells (Figure 44 and Figure 45 ).

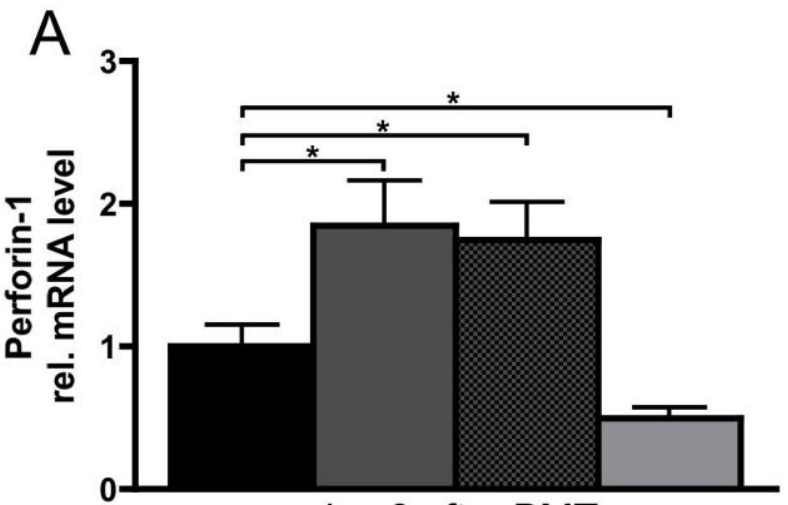

day 6 after BMT

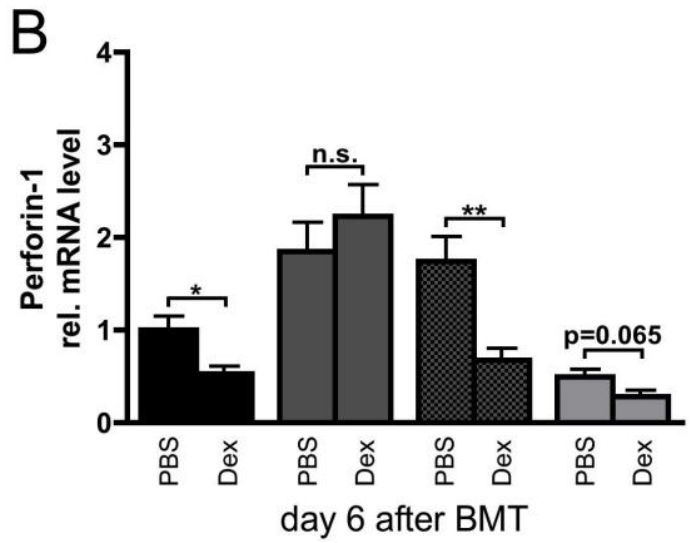

$\operatorname{dim}->$ wt $\square$ wt->dim

Figure 44: Perforin-1 gene expression in the spleen (A) After aGvHD induction and (B) After aGvHD induction and treatment with dex $(100 \mathrm{mg} / \mathrm{kg})$ from day 3 to 5 compared to treatment with PBS (control). Spleen was collected on day 6 after transplantation and perforin-1 expression was measured by qRT-PCT; relative mRNA expression levels were obtained by normalising to HPRT mRNA expression; relative expression in $w t \rightarrow$ wt PBS mice was set equal to 1 ; mean values + s.e.m., $(n=4-6)$; Experimental groups were as follows: $\mathrm{wt} \rightarrow \mathrm{wt}=\mathrm{GR}^{\mathrm{wt}} \mathrm{T}$ cells transplanted into $\mathrm{GR}^{\mathrm{wt}}$ recipient mice, lck $\rightarrow \mathrm{wt}=\mathrm{GR}^{\text {lckCre }} \mathrm{T}$ cells transplanted into $\mathrm{GR}^{\mathrm{wt}}$ recipient mice, $\operatorname{dim} \rightarrow \mathrm{wt}=\mathrm{GR}^{\mathrm{dim}} \mathrm{T}$ cells transplanted into $\mathrm{GR}^{\mathrm{wt}}$ recipient mice, $\mathrm{wt} \rightarrow \operatorname{dim}=\mathrm{GR}^{\mathrm{wt}} \mathrm{T}$ cells transplanted into $\mathrm{GR}^{\mathrm{dim}}$ recipient mice. 

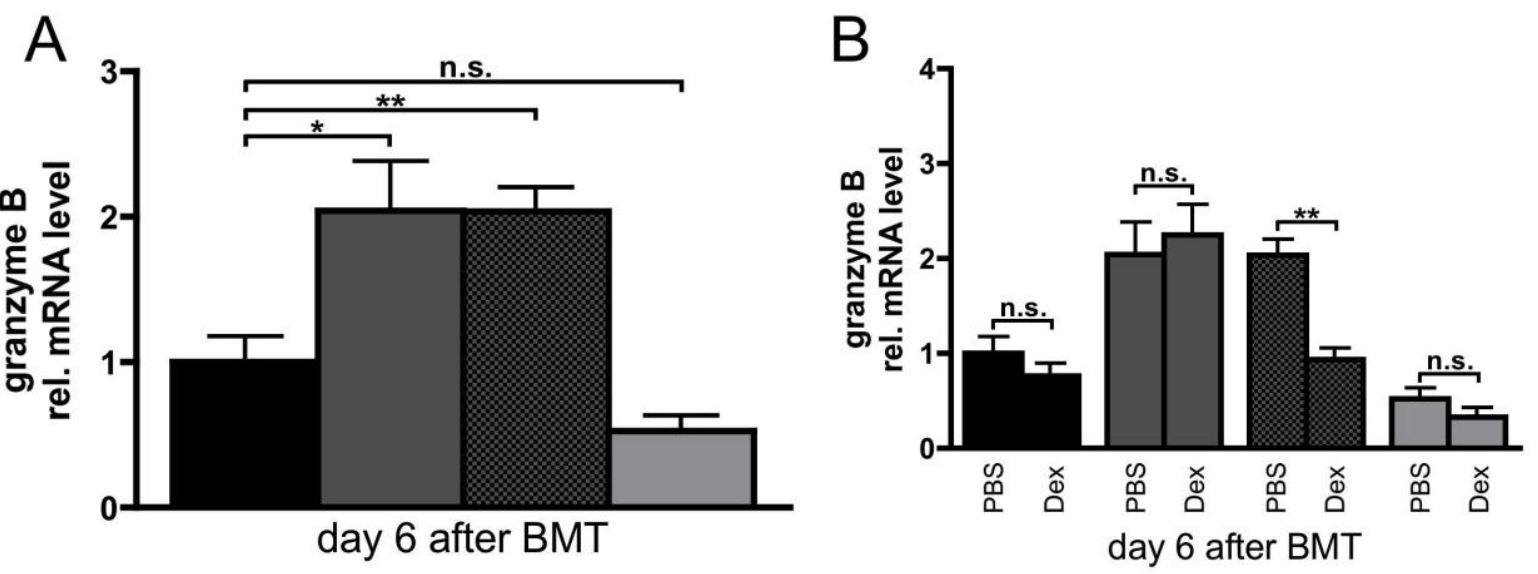

$\square$ wt->wt $\square$ lck->wt $\square$ dim->wt $\square$ wt->dim

Figure 45: Granzyme B gene expression in the spleen (A) After aGvHD induction and (B) After aGvHD induction and treatment with dex $(100 \mathrm{mg} / \mathrm{kg})$ from day 3 to 5 compared to treatment with PBS (control). Spleen was collected on day 6 after transplantation and Granzyme B expression was measured by qRT-PCT; relative mRNA expression levels were obtained by normalising to HPRT mRNA expression; relative expression in $\mathrm{wt} \rightarrow$ wt PBS mice was set equal to 1 ; mean values + s.e.m., $(\mathrm{n}=4-6)$; Experimental groups were as follows: $\mathrm{wt} \rightarrow \mathrm{wt}=\mathrm{GR}^{\mathrm{wt}} \mathrm{T}$ cells transplanted into $\mathrm{GR}^{\mathrm{wt}}$ recipient mice, lck $\rightarrow \mathrm{wt}=\mathrm{GR}^{\mathrm{lckCre}} \mathrm{T}$ cells transplanted into $\mathrm{GR}^{\mathrm{wt}}$ recipient mice, $\operatorname{dim} \rightarrow \mathrm{wt}=\mathrm{GR}^{\mathrm{dim}} \mathrm{T}$ cells transplanted into $\mathrm{GR}^{\mathrm{wt}}$ recipient mice, $\mathrm{wt} \rightarrow \operatorname{dim}=\mathrm{GR}^{\mathrm{wt}} \mathrm{T}$ cells transplanted into $\mathrm{GR}^{\mathrm{dim}}$ recipient mice.

\subsection{Endogenous glucocorticoids}

In $\mathrm{GR}^{\mathrm{wt}}$ animals receiving $\mathrm{GR}^{\mathrm{wt}} \mathrm{T}$ cells, corticosterone in serum was significantly elevated compared to animals receiving $T$ cell-depleted bone marrow only. There were no differences between recipients of $\mathrm{GR}^{\mathrm{lckCre}}$ or $\mathrm{GR}^{\mathrm{dim}} \mathrm{T}$ cells compared to recipients receiving $\mathrm{GR}^{\mathrm{wt}} \mathrm{T}$ cells, neither on day 5 nor on day $6 . \mathrm{GR}^{\mathrm{dim}}$ recipients, however, had significantly increased levels of serum corticosterone on day 5 compared to $\mathrm{GR}^{\mathrm{wt}}$ littermates, but not on day 6 (Figure 46).

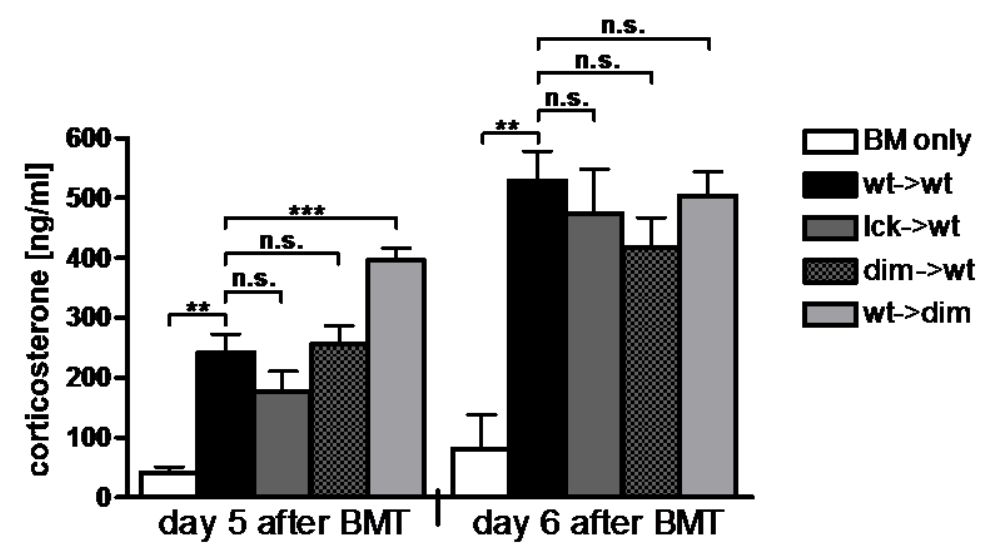

Figure 46: Corticosterone serum levels after aGvHD induction. Blood was collected by heart puncture on days 5 or 6 after transplantation and corticosterone was measured by RIA after preparation of serum; mean values + s.e.m., (day 5: $n=9-10$, day 6: $n=8-17$, BM only: $n=3$ ); Experimental groups were as follows: BM only $=$ no $\mathrm{T}$ cells transplanted, $\mathrm{wt} \rightarrow \mathrm{wt}=\mathrm{GR}^{\mathrm{wt}} \mathrm{T}$ cells transplanted into $\mathrm{GR}^{\mathrm{wt}}$ recipient mice, lck $\rightarrow \mathrm{wt}=\mathrm{GR}^{\mathrm{lckCre}}$ 
$\mathrm{T}$ cells transplanted into $\mathrm{GR}^{\mathrm{wt}}$ recipient mice, $\mathrm{dim} \rightarrow \mathrm{wt}=\mathrm{GR}^{\mathrm{dim}} \mathrm{T}$ cells transplanted into $\mathrm{GR}^{\mathrm{wt}}$ recipient mice, $\mathrm{wt} \rightarrow \mathrm{dim}=\mathrm{GR}^{\mathrm{wt}} \mathrm{T}$ cells transplanted into $\mathrm{GR}^{\mathrm{dim}}$ recipient mice.

After dex treatment, endogenous corticosterone in the serum was reduced in all cases. On day 6 , however, serum corticosterone in mice receiving $\mathrm{GR}^{\mathrm{lckCre}} \mathrm{T}$ cells $(p=0.0153)$ or in $G^{\text {dim }}$ hosts $(p=0.0020)$ remained elevated compared to treated mice in a wt $\rightarrow$ wt setting (Figure 47 ).

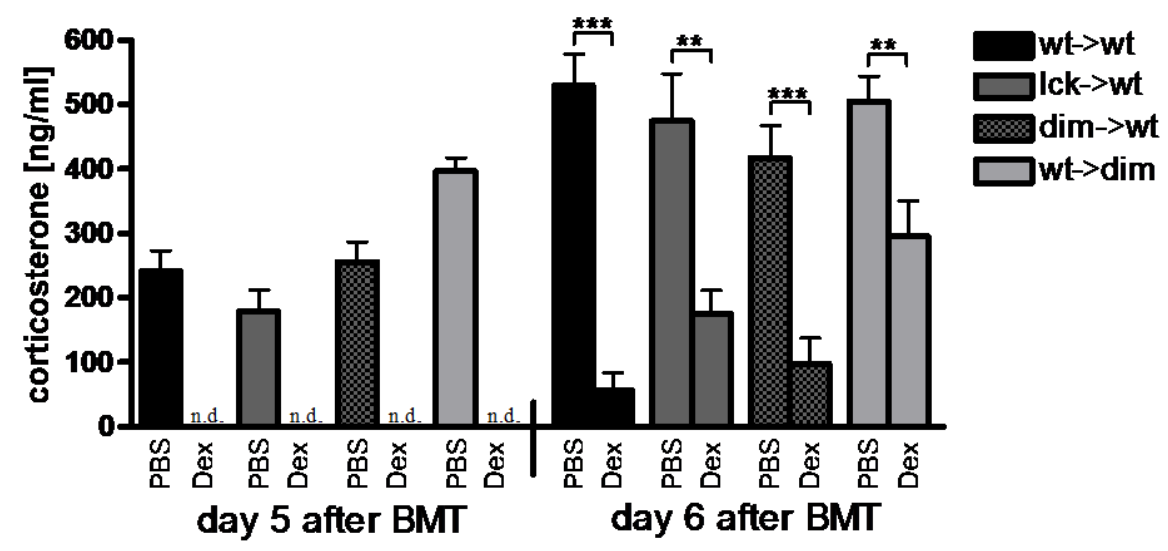

Figure 47: Corticosterone serum levels after aGvHD induction and treatment with Dex $(100 \mathrm{mg} / \mathrm{kg})$ compared to treatment with PBS (control). Blood was collected by heart puncture on days 5 or 6 after transplantation and corticosterone was measured by RIA after preparation of serum; mean values + s.e.m., (day 5: $\mathrm{n}=5-10$, day 6: $\mathrm{n}=8-13$ ); Experimental groups were as follows: $\mathrm{wt} \rightarrow \mathrm{wt}=\mathrm{GR}^{\mathrm{wt}} \mathrm{T}$ cells transplanted into $\mathrm{GR}^{\mathrm{wt}}$ recipient mice, $1 \mathrm{ck} \rightarrow \mathrm{wt}=\mathrm{GR}^{\mathrm{lckCre}} \mathrm{T}$ cells transplanted into $\mathrm{GR}^{\mathrm{wt}}$ recipient mice, $\mathrm{dim} \rightarrow \mathrm{wt}=\mathrm{GR}^{\mathrm{dim}} \mathrm{T}$ cells transplanted into $\mathrm{GR}^{\mathrm{wt}}$ recipient mice, $\mathrm{wt} \rightarrow \mathrm{dim}=\mathrm{GR}^{\mathrm{wt}} \mathrm{T}$ cells transplanted into $\mathrm{GR}^{\mathrm{dim}}$ recipient mice.

\subsection{Energy expenditure}

Mice suffering from aGvHD developed mild hypothermia on day 6 after transplantation compared to mice receiving only $\mathrm{T}$ cell-depleted bone marrow. Mice receiving $\mathrm{GR}^{\mathrm{lckCre}}$ or $\mathrm{GR}^{\text {dim }} \mathrm{T}$ cells showed no difference in body temperature compared to mice receiving $\mathrm{GR}^{\text {wt }} \mathrm{T}$ cells. $\mathrm{GR}^{\text {dim }}$ recipients, however, developed much more severe hypothermia than $\mathrm{GR}^{\mathrm{wt}}$ littermates (Figure 48A+B).
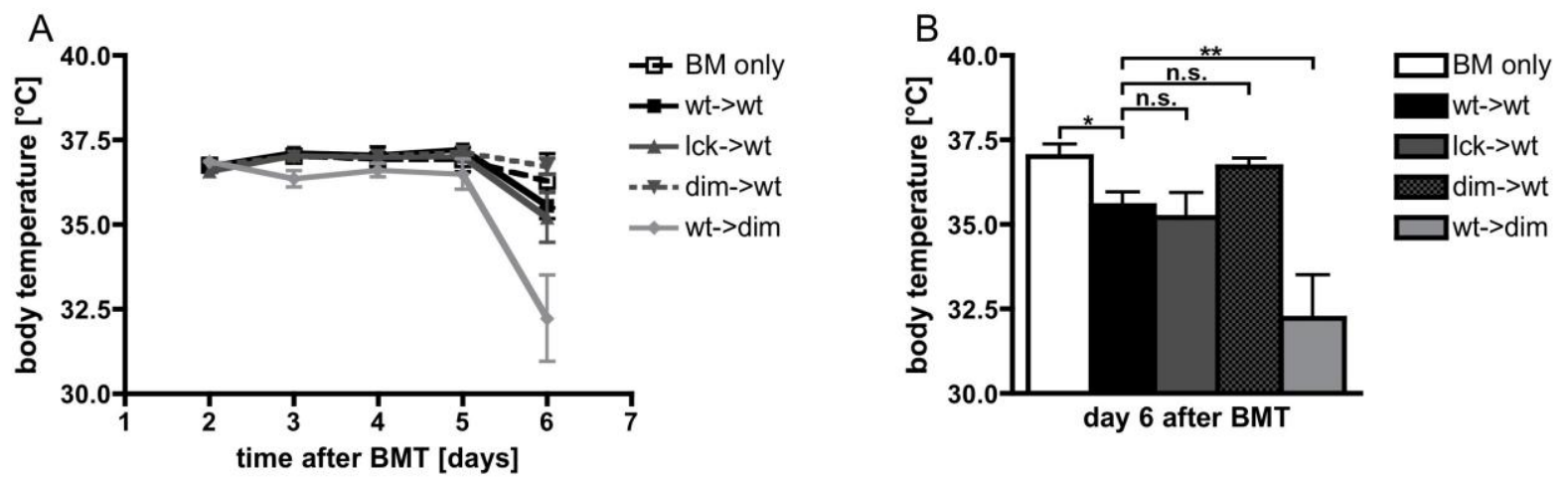

Figure 48: Body temperature in mice after aGvHD induction. (A) Body temperature was measured from day 2 to day 6 after transplantation using a rectal probe (B) Body temperature on day 6 after transplantation; 
mean values + s.e.m., $(\mathrm{n}=16-29, \mathrm{BM}$ only: $\mathrm{n}=11)$; Experimental groups were as follows: $\mathrm{BM}$ only $=$ no $\mathrm{T}$ cells transplanted, $\mathrm{wt} \rightarrow \mathrm{wt}=\mathrm{GR}^{\mathrm{wt}} \mathrm{T}$ cells transplanted into $\mathrm{GR}^{\mathrm{wt}}$ recipient mice, lck $\rightarrow \mathrm{wt}=\mathrm{GR}^{\text {lckCre }} \mathrm{T}$ cells transplanted into $\mathrm{GR}^{\mathrm{wt}}$ recipient mice, $\mathrm{dim} \rightarrow \mathrm{wt}=\mathrm{GR}^{\mathrm{dim}} \mathrm{T}$ cells transplanted into $\mathrm{GR}^{\mathrm{wt}}$ recipient mice, $\mathrm{wt} \rightarrow \mathrm{dim}$ $=\mathrm{GR}^{\mathrm{wt}} \mathrm{T}$ cells transplanted into GR ${ }^{\mathrm{dim}}$ recipient mice.

On day 6 after transplantation mice suffering from aGvHD also developed a marked hypoglycaemia compared to mice receiving only T cell-depleted bone marrow. Hypoglycaemia in mice receiving $\mathrm{GR}^{\text {lckCre }}$ or $\mathrm{GR}^{\text {dim }} \mathrm{T}$ cells was comparable to the one in mice receiving $\mathrm{GR}^{\mathrm{wt}} \mathrm{T}$ cells. $\mathrm{GR}^{\mathrm{dim}}$ recipients developed a stronger hypoglycaemia than any of the other groups (Figure 49A+B).
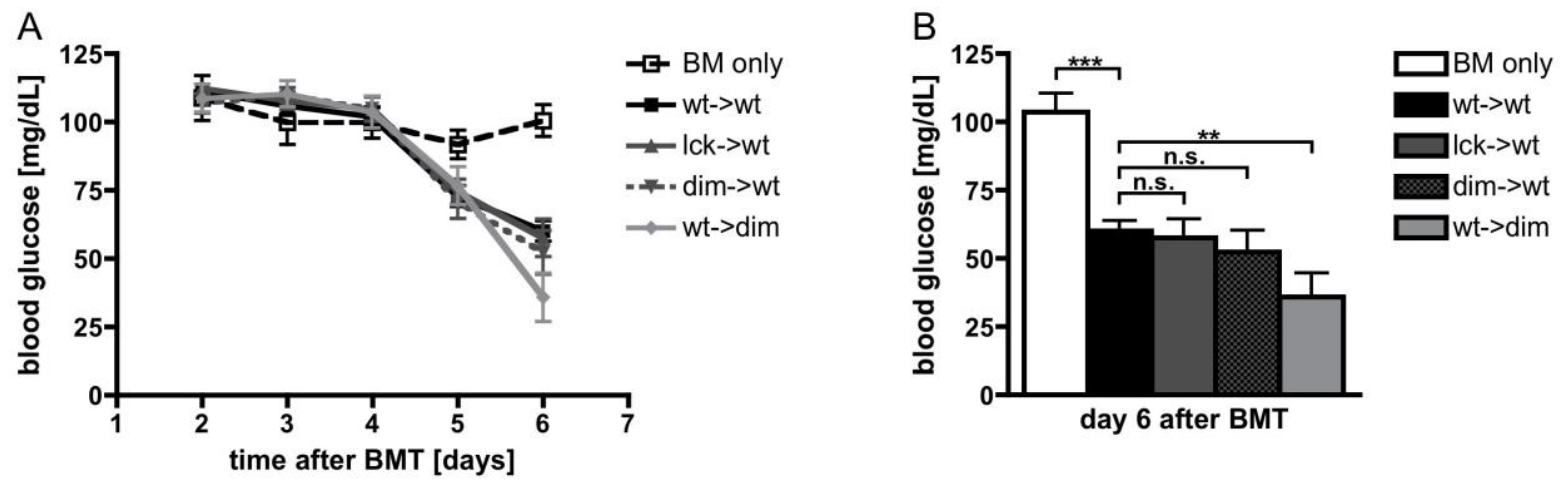

Figure 49: Blood glucose in mice after aGvHD induction. (A) Blood glucose was measured from day 2 to day 6 after transplantation; a drop of blood was obtained from the tail vein and blood glucose level was determined using test strips (B) Blood glucose level on day 6 after transplantation; mean values + s.e.m., $(n=16-$ 23, BM only: $\mathrm{n}=6$ ); Experimental groups were as follows: $\mathrm{BM}$ only $=$ no $\mathrm{T}$ cells transplanted, $\mathrm{wt} \rightarrow \mathrm{wt}=\mathrm{GR}^{\mathrm{wt}}$ $\mathrm{T}$ cells transplanted into $\mathrm{GR}^{\mathrm{wt}}$ recipient mice, $\mathrm{lck} \rightarrow \mathrm{wt}=\mathrm{GR}^{\mathrm{lckCre}} \mathrm{T}$ cells transplanted into $\mathrm{GR}^{\mathrm{wt}}$ recipient mice, $\mathrm{dim} \rightarrow \mathrm{wt}=\mathrm{GR}^{\mathrm{dim}} \mathrm{T}$ cells transplanted into $\mathrm{GR}^{\mathrm{wt}}$ recipient mice, $\mathrm{wt} \rightarrow \mathrm{dim}=\mathrm{GR}^{\mathrm{wt}} \mathrm{T}$ cells transplanted into $\mathrm{GR}^{\mathrm{dim}}$ recipient mice.

In mice receiving $\mathrm{GR}^{\mathrm{wt}} \mathrm{T}$ cells, hypoglycaemia was treatable with dex. In mice receiving $\mathrm{GR}^{\mathrm{lck} C r e}$ or $\mathrm{GR}^{\mathrm{dim}} \mathrm{T}$ cells, however, hypoglycaemia did not improve upon treatment (Figure 50A-C).

A

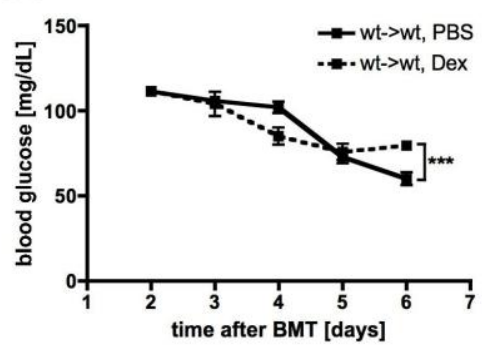

B

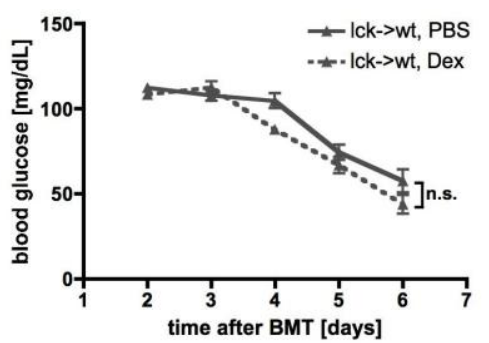

C

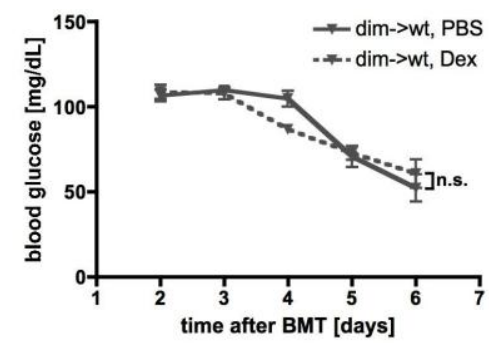

Figure 50: Blood glucose after aGvHD induction in mice treated with dex $(100 \mathrm{mg} / \mathrm{kg})$ from day 3 to 6 compared to mice treated with PBS (control). Blood glucose was measured from day 2 to day 6 after transplantation; mean values + s.e.m., t-test performed for values on day 6 . (A) $\mathrm{wt} \rightarrow \mathrm{wt}=\mathrm{GR}^{\mathrm{wt}}$ recipients transplanted with $\mathrm{GR}^{\mathrm{wt}} \mathrm{T}$ cells $(\mathrm{n}=17-34)(\mathrm{B}) \mathrm{lck} \rightarrow \mathrm{wt}=\mathrm{GR}^{\mathrm{wt}}$ recipient mice transplanted with $\mathrm{GR}^{\text {lckCre }} \mathrm{T}$ cells $(\mathrm{n}=12-17)(\mathrm{C}) \operatorname{dim} \rightarrow \mathrm{wt}=\mathrm{GR}^{\mathrm{wt}}$ recipient mice transplanted with $\mathrm{GR}^{\mathrm{dim}} \mathrm{T}$ cells $(\mathrm{n}=5-7)$. 
In $\mathrm{GR}^{\mathrm{dim}}$ recipients both hypothermia and hypoglycaemia were fully treatable with dex (Figure $51 \mathrm{~A}+\mathrm{B})$.
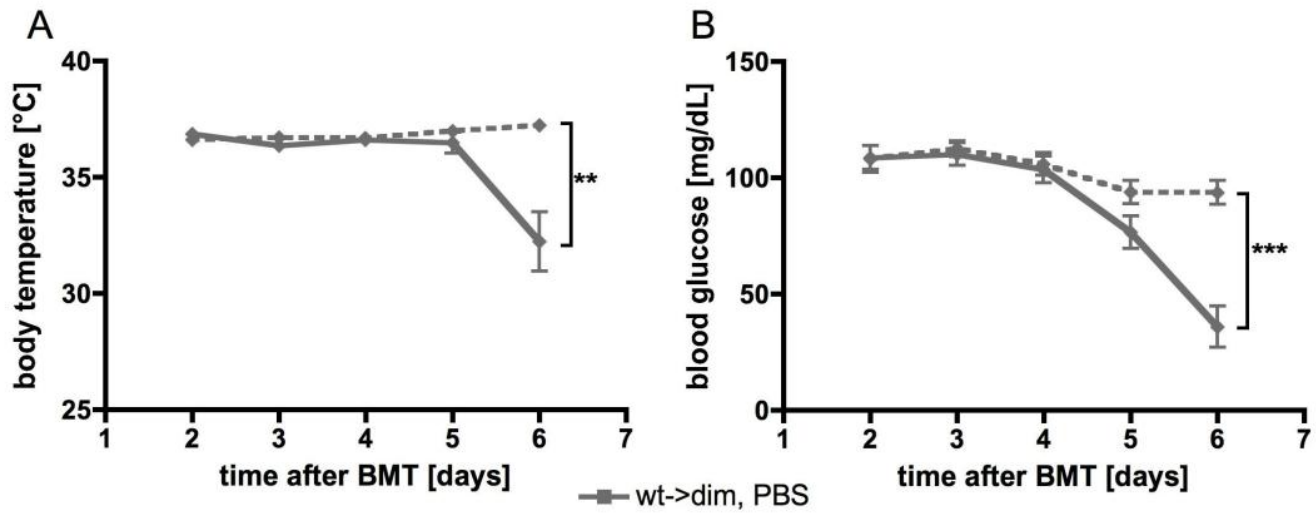

Figure 51: Blood glucose and body temperature after aGvHD induction in $\mathbf{G R}^{\mathrm{dim}}$ mice treated with dex $(100 \mathrm{mg} / \mathrm{kg}$ ) from day 3 to 6 compared to mice treated with PBS (control). (A) Blood glucose was measured from day 2 to 6 after transplantation (n=14-16) (B) Body temperature was measured from day 2 to day 6 after transplantation using a rectal probe $(n=16)$; mean values + s.e.m., t-test performed for values on day 6 .

\subsection{Mixed Leukocyte Reaction as an in vitro aGvHD model}

If dex was added to MLRs with $G R^{\text {wt }} T$ cells and $G R^{\text {wt }}$ macrophages, the percentage of live T cells after 4 days in FACS analysis was greatly reduced at both concentrations, $10^{-8} \mathrm{M}$ and $10^{-7} \mathrm{M}$. If $\mathrm{GR}^{\mathrm{lckCre}}$ or $\mathrm{GR}^{\mathrm{dim}} \mathrm{T}$ cells and $\mathrm{GR}^{\mathrm{wt}}$ macrophages were used, the percentage of live T cells was only slightly reduced (Figure 52). 
A
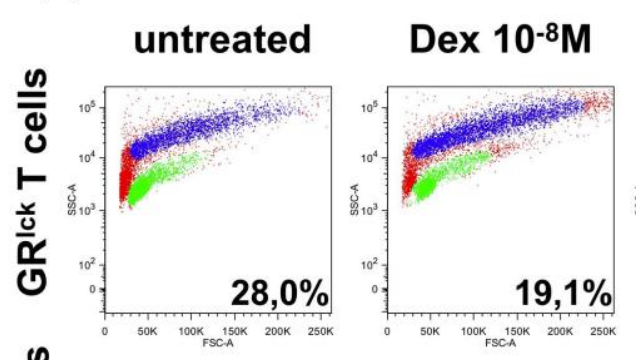

Dex $10^{-7} M$

B
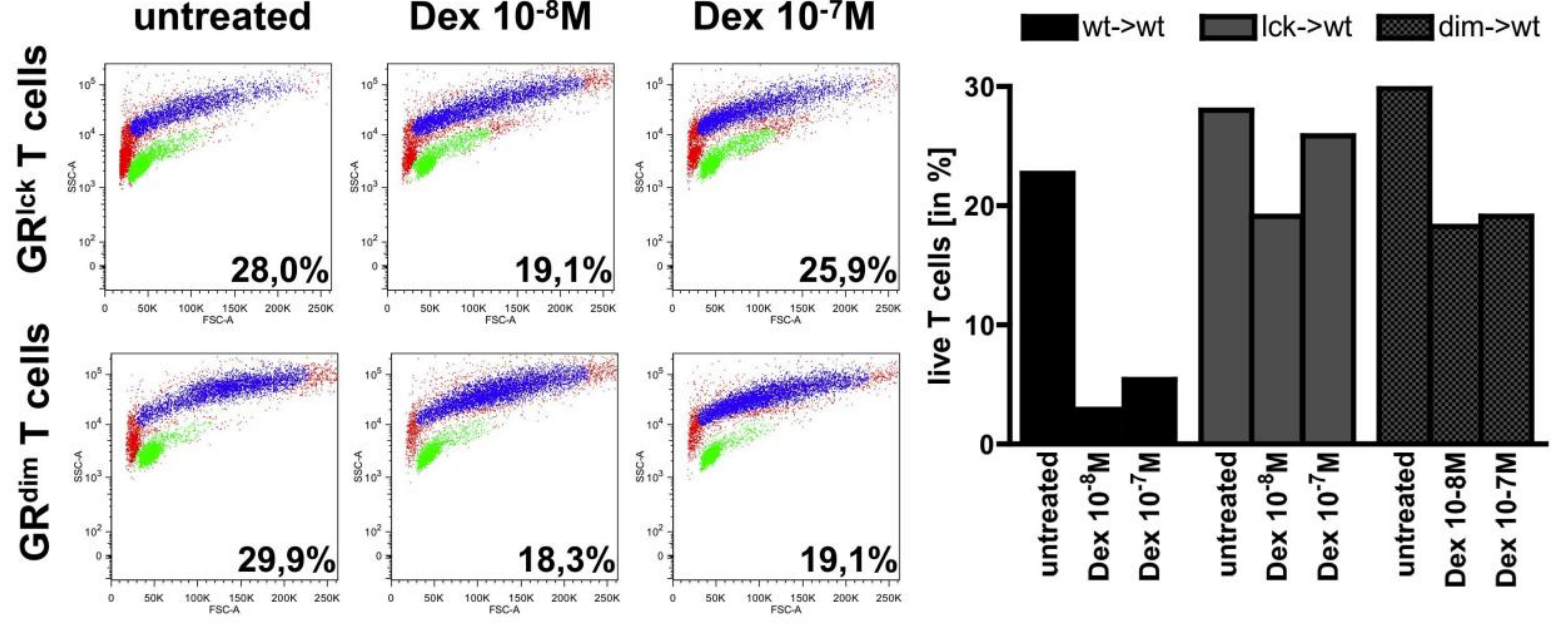

Figure 52: Mixed leukocyte reaction of $\mathbf{G R}^{\mathrm{wt}}$ macrophages with $\mathbf{G R}^{\mathrm{lckCre}}$ or $\mathbf{G R}^{\mathrm{dim}} \mathrm{T}$ cells treated with dex $\left(10^{-8} \mathrm{M}\right.$ or $\left.10^{-7} \mathrm{M}\right)$ compared to untreated cells. $10^{5} \mathrm{~T}$ cells and an equal number of BMDMs were mixed and incubated in medium with or without dex for 4 days. Cells were centrifuged and resuspended in FACS buffer. (A) FACS plot: green: T cells, blue: macrophages, red: debris. (B) Percentage of live T cells. A representative experiment of $n>3$ is shown; Experimental groups were as follows: $w t \rightarrow w t=G^{w t} T$ cells with $G^{w t}$ BMDMs, $\mathrm{lck} \rightarrow \mathrm{wt}=\mathrm{GR}^{\mathrm{lckCre}} \mathrm{T}$ cells with $\mathrm{GR}^{\mathrm{wt}} \mathrm{BMDMs}$, $\mathrm{dim} \rightarrow \mathrm{wt}=\mathrm{GR}^{\mathrm{dim}} \mathrm{T}$ cells with $\mathrm{GR}^{\mathrm{wt}}$ BMDMs.

Also, in MLR with $\mathrm{GR}^{\mathrm{wt}} \mathrm{T}$ cells and $\mathrm{GR}^{\mathrm{wt}}$ macrophages, IL-2 production was reduced when cells were treated with dex. If $\mathrm{GR}^{\text {lckCre }}$ or $\mathrm{GR}^{\text {dim }} \mathrm{T}$ cells were used, IL-2 production was also reduced (Figure 53).

A

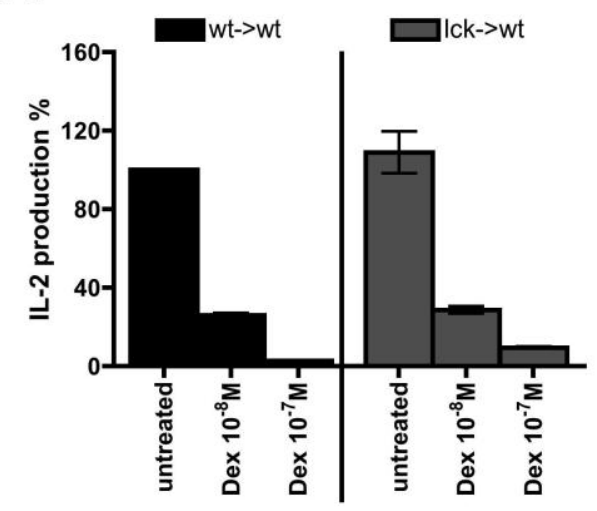

B

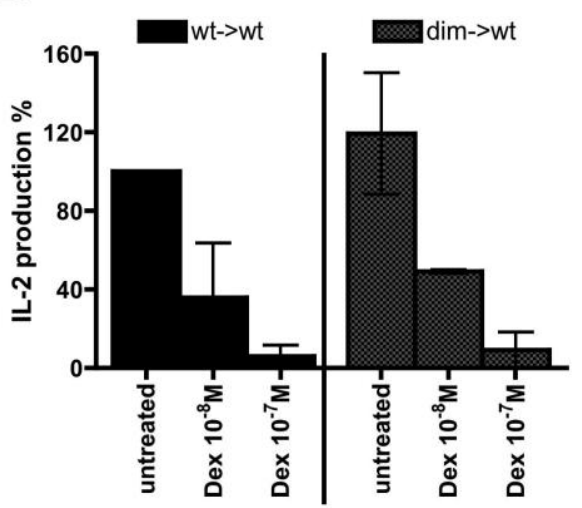

Figure 53: IL-2 in supernatant of MLR of GR $^{\mathrm{wt}}$ macrophages with GR $^{\mathrm{lckCre}}$ or GR $^{\mathrm{dim}} \mathrm{T}$ cells treated with dex $\left(10^{-8} \mathrm{M}\right.$ or $\left.10^{-7} \mathrm{M}\right)$ compared to untreated cells. $10^{5} \mathrm{~T}$ cells and an equal number of BMDMs were mixed and incubated in medium with or without dex for 4 days. Cells were centrifuged and supernatant was collected. IL-2 was measured by ELISA. A representative experiment of $n>3$ is shown; Experimental groups were as follows: $\mathrm{wt} \rightarrow \mathrm{wt}=\mathrm{GR}^{\mathrm{wt}} \mathrm{T}$ cells with $\mathrm{GR}^{\mathrm{wt}}$ BMDMs, lck $\rightarrow \mathrm{wt}=\mathrm{GR}^{\text {lckCre }} \mathrm{T}$ cells with $\mathrm{GR}^{\mathrm{wt}}$ BMDMs (A), $\operatorname{dim} \rightarrow \mathrm{wt}=\mathrm{GR}^{\mathrm{dim}} \mathrm{T}$ cells with $\mathrm{GR}^{\mathrm{wt}}$ BMDMs (B).

Similar to an MLR were $G R^{\text {wt }} T$ cells and $G R^{\text {wt }}$ macrophages were used, if $G R^{\text {wt }}$ $T$ cells were used with $\mathrm{GR}^{\text {lysMcre }}$ or $\mathrm{GR}^{\text {dim }}$ macrophages, dex treatment was able to decrease the number of live $T$ cells (Figure 54). 
A
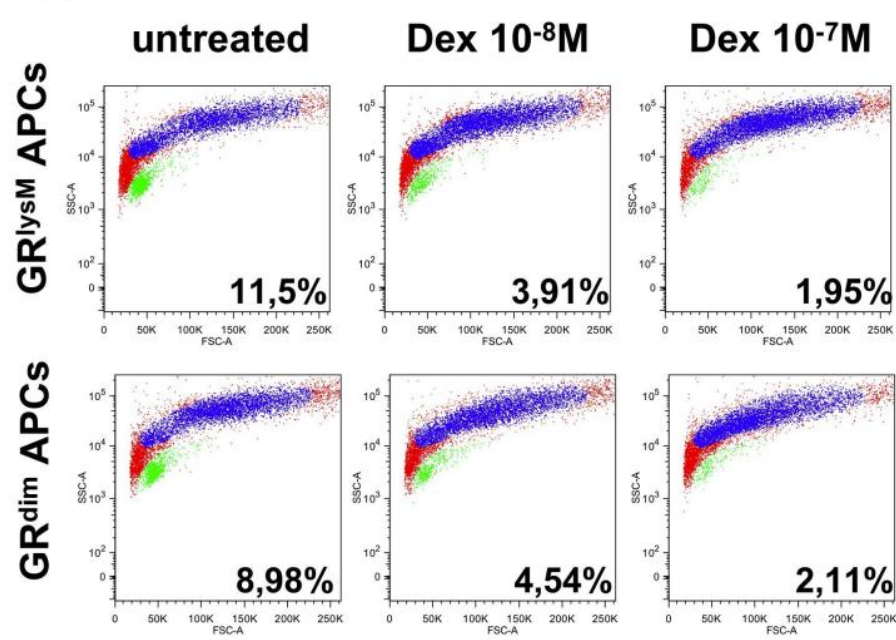

B

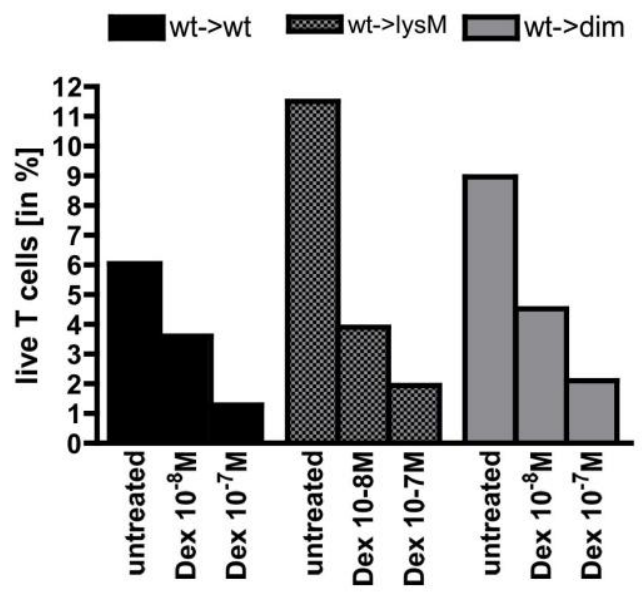

Figure 54: Mixed leukocyte reaction with $G R^{\text {lysMCre }}$ or $G^{\mathrm{dim}}$ macrophages and $\mathbf{G R}^{\mathrm{wt}} \mathbf{T}$ cells treated with dex $\left(10^{-8} \mathrm{M}\right.$ or $\left.10^{-7} \mathrm{M}\right)$ compared to untreated cells. $10^{5} \mathrm{~T}$ cells and an equal number of BMDMs were mixed and incubated in medium with or without dex for 4 days. Cells were centrifuged and resuspended in FACS buffer. (A) FACS plot: green: T cells, blue: macrophages, red: debris. (B) Percentage of live T cells. A representative experiment of $n>3$ is shown; Experimental groups were as follows: $w t \rightarrow w t=G^{w t} T$ cells with $\mathrm{GR}^{\mathrm{wt}} \mathrm{BMDMs}, \mathrm{wt} \rightarrow$ lysM $=\mathrm{GR}^{\mathrm{wt}} \mathrm{T}$ cells with $\mathrm{GR}^{\text {lsyMCre }} \mathrm{BMDMs}$, wt $\rightarrow \mathrm{dim}=\mathrm{GR}^{\mathrm{wt}} \mathrm{T}$ cells with $\mathrm{GR}^{\mathrm{dim}} \mathrm{BMDMs}$.

If $\mathrm{GR}^{\text {lysMCre }}$ or $\mathrm{GR}^{\mathrm{dim}}$ macrophages instead of $\mathrm{GR}^{\mathrm{wt}}$ macrophages were mixed with $\mathrm{GR}^{\mathrm{wt}} \mathrm{T}$ cells, IL-2 secretion was not or ineffectively reduced by dex treatment (Figure $55)$.

A

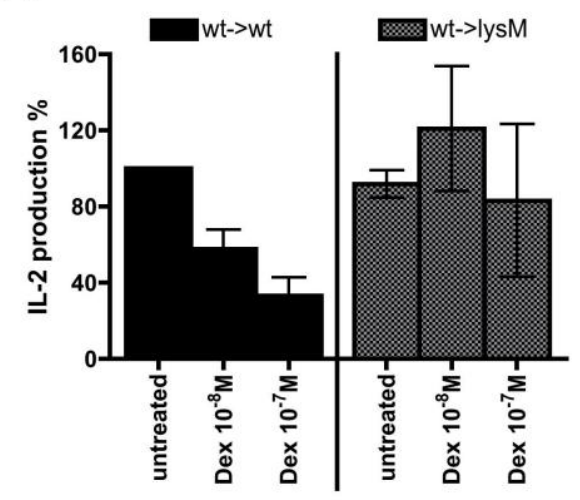

B

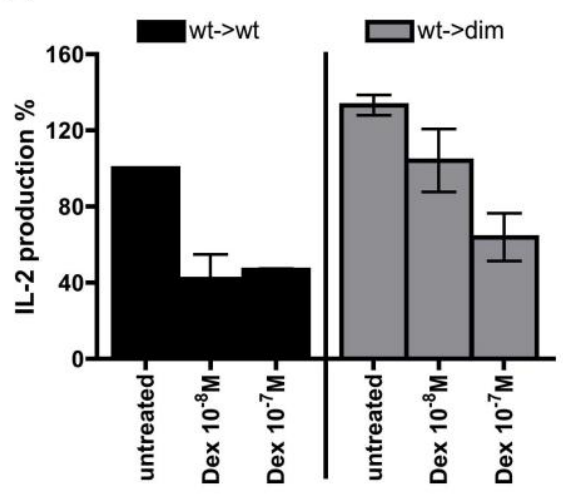

Figure 55: IL-2 in supernatant of MLR with GR ${ }^{\mathrm{lysM}}$ or $\mathbf{G R}^{\mathrm{dim}}$ macrophages and GR ${ }^{\mathrm{wt}} \mathbf{T}$ cells treated with dex $\left(10^{-8} \mathrm{M}\right.$ or $\left.10^{-7} \mathrm{M}\right)$ compared to untreated cells. $10^{5} \mathrm{~T}$ cells and an equal number of BMDMs were mixed and incubated in medium with or without dex for 4 days. Cells were centrifuged and supernatant was collected. IL-2 was measured by ELISA. A representative experiment of $n>3$ is shown; Experimental groups were as follows: $w t \rightarrow w t=G^{\text {wt }}$ T cells with $\mathrm{GR}^{\mathrm{wt}}$ BMDMs, wt $\rightarrow$ lysM $=\mathrm{GR}^{\mathrm{wt}} \mathrm{T}$ cells with $\mathrm{GR}^{\mathrm{LysM}}$ BMDMs (A), $\operatorname{dim} \rightarrow \mathrm{wt}=\mathrm{GR}^{\mathrm{wt}} \mathrm{T}$ cells with $\mathrm{GR}^{\mathrm{dim}}$ BMDMs (B). 


\section{Discussion}

\subsection{The role of different aspects of acute graft-versus-host disease (aGvHD) pathogenesis for the mode of action of endogenous and therapeutic glucocorticoids (GCs)}

\subsubsection{Mortality and morbidity}

High mortality in $\mathrm{GR}^{\mathrm{wt}}$ mice receiving $\mathrm{GR}^{\mathrm{lckCre}}$ or $\mathrm{GR}^{\mathrm{dim}} \mathrm{T}$ cells and also in $\mathrm{GR}^{\text {dim }}$ recipients receiving $G^{\text {wt }} T$ cells impressively demonstrated the importance of the $G C$ receptor (GR) in both donor T cells and in recipients for control of aGvHD by endogenous GCs.

Treatment of aGvHD with $100 \mathrm{mg} / \mathrm{kg}$ dexamethasone (dex) from day 3 to 6 in $\mathrm{GR}^{\text {wt }}$ mice receiving $G^{\text {wt }} T$ cells showed that morbidity was clearly ameliorated by GCs. No apparent effect on mortality could be observed, because acute mortality was generally low in the $\mathrm{GR}^{\mathrm{wt}}$ setting. In $G R^{\text {dim }}$ mice receiving $\mathrm{GR}^{\mathrm{wt}} \mathrm{T}$ cells and in $\mathrm{GR}^{\text {wt }}$ mice receiving $G^{\text {dim }} T$ cells, however, acute mortality was higher and was indeed prevented by GC treatment. Another important observation was that treatment in the acute phase did not prevent relapse.

In a haploidentical aGvHD model, which showed a later onset of disease than the fully mismatched model, Bouazzaoui et al. could show that treatment with $2 \mathrm{mg} / \mathrm{kg}$ prednisolone starting on day 10 after transplantation was also able to reduce morbidity and mortality in aGvHD. They also found that if treatment was delayed until day 28 after transplantation, mice had evolved aGvHD that was resistant to prednisolone treatment (Bouazzaoui et al., 2011). The haploidentical model differs in severity from the MHC-mismatched model used in this work. Also, disease onset in the mismatched model was much earlier. Differences in findings may therefore be due to these discrepancies. But despite these disparities, treatment in the early phase alleviates morbidity and mortality in both models and GC treatment appears to be ineffectual in the late phase.

\subsubsection{Total $T$ cell number}

The effect of endogenous GCs on T cells or recipient cells did not impact total T cell number, since the T cell/granulocyte ratio in the blood, the total count of T cells in lymph nodes and the extent of target organ infiltration was similar for all groups. 
Infiltration in $\mathrm{GR}^{\text {dim }}$ recipients was even slightly lower than in $\mathrm{GR}^{\text {wt }}$ littermates. The exacerbated disease course in mice receiving $G^{\text {lckCre }}$ or $G^{\text {dim }} T$ cells compared to mice receiving $G^{w t} T$ cells and of $G R^{d i m}$ recipients compared to $G R^{\text {wt }}$ recipients is therefore not caused by a greater number of $T$ cells.

Upon treatment with dex in $\mathrm{GR}^{\mathrm{wt}}$ mice receiving $\mathrm{GR}^{\mathrm{wt}} \mathrm{T}$ cells the $\mathrm{T}$ cell population was significantly reduced in lymph nodes, blood, target organs and in the in vitro MLR. This confirms the finding by Bouazzaoui et al. that $T$ cell number in spleen and T cell expansion in vitro were reduced by treatment with prednisolone (Bouazzaoui et al., 2011). In mice receiving $\mathrm{GR}^{\mathrm{lckCre}}$ or $\mathrm{GR}^{\mathrm{dim}} \mathrm{T}$ cells, however, there was only a slight and not significant tendency for reduction or no reduction at all (e.g. for infiltration of jejunum in mice receiving $\mathrm{GR}^{\mathrm{lckCre}} \mathrm{T}$ cells). Also, in vitro, if an MLR was treated with dex, this did not effect the $T$ cell population in the case of $\mathrm{GR}^{\text {lckCre }}$ or $G^{\text {dim }} T$ cells. Dex treatment significantly decreased the amount of $T$ cells in lymph nodes and blood of $\mathrm{GR}^{\text {dim }}$ recipients. In target organs of $\mathrm{GR}^{\text {dim }}$ recipients infiltration was not decreased, because it was generally lower to begin with. In MLR with $G^{\text {dim }}$ as well as $\mathrm{GR}^{\text {lysMCre }}$ macrophages, the $T$ cell population was decreased after dex treatment.

It can therefore be concluded that the reduction of total $\mathrm{T}$ cell number upon treatment with dex is dependent on the GR in T cells and its dimerisation, but not on the GR in antigen presenting cells (APCs). The reduction of T cell number, however, does not appear to be essential for treatment, because mice receiving $G^{\text {dim }} T$ cells are treatable despite the lack of reduction in T cell number.

The GR, more specifically its transactivating activity, is required for GC-induced apoptosis (Reichardt et al., 1998). Because aGvHD in mice receiving GR $^{\text {dim }}$ T cells was susceptible to treatment with dex, treatment of aGvHD cannot depend on apoptosis of $T$ cells. The slight reduction in number of $T$ cells in mice receiving $\mathrm{GR}^{\mathrm{lckCre}}$ or $\mathrm{GR}^{\mathrm{dim}} \mathrm{T}$ cells may be explained by an effect on the APCs.

The fact that in the MLR with GR-deficient APCs IL-2 production was not reduced by dex treatment even though the T cell population was, indicates that in vitro without an effect on the APCs GCs cannot limit expansion of T cells, but will cause subsequent apoptosis of T cells. In the MLR with GR-deficient T cells, on the other hand, IL-2 was reduced while the $T$ cell population was not. This indicates that even though dex could not cause apoptosis of $T$ cells it could still limit expansion due to an effect on the APCs. Both effects were dimerisation dependent. Experimental results from the 
mouse experiments, however, indicate that in vivo the effect on T cells is much more important than the effect on APCs.

\subsubsection{Activation of $\mathrm{CD4} 4^{+} \mathrm{T}$ cells in lymph nodes}

Surprisingly, in $\mathrm{GR}^{\mathrm{wt}}$ mice receiving $\mathrm{GR}^{\mathrm{wt}} \mathrm{T}$ cells a higher percentage of $\mathrm{CD} 4^{+} \mathrm{T}$ cells in the lymph node was activated $\left(\mathrm{CD} 44^{+}\right)$than in mice receiving $\mathrm{GR}^{\text {lckCre }}$ or $\mathrm{GR}^{\text {dim }}$ $T$ cells, or in $\mathrm{GR}^{\mathrm{dim}}$ recipients of $\mathrm{GR}^{\mathrm{wt}} \mathrm{T}$ cells. A possible explanation is that due to a generally more pro-inflammatory milieu in the other groups, with up-regulation of adhesion molecules and chemokines, more activated T cells migrate into the bloodstream or into target organs instead of remaining in the lymph nodes. This theory, however, could not be confirmed by the results of the analysis of blood, jejunum and liver. Another possibility is that in the $G^{\text {wt }}$ situation, non-activated bystander $T$ cells are more effectively removed than in the other groups, because of the more inflammatory environment in the other groups that may protect nonactivated T cells.

\subsection{4. $C D 4 / C D 8$ ratio in blood and target organs}

The CD4/CD8 ratio in blood of mice suffering from aGvHD is strongly skewed towards $\mathrm{CD} 8^{+} \mathrm{T}$ cells. In liver, as aGvHD target organ, the prevalence of $\mathrm{CD} 8^{+} \mathrm{T}$ cells is even more marked. This underlines the importance of $C D 8^{+} \mathrm{T}$ cells in aGvHD in general and specifically for target organ damage. The CD4/CD8 ratio does not differ between groups and it does not change upon dex treatment. Therefore, dex treatment appears to affect the amount of both, $\mathrm{CD} 4^{+}$and $\mathrm{CD} 8^{+} \mathrm{T}$ cells. This is in accordance with results by Bouazzaoui et al. who found that CD4+ and CD8+ T cells in the spleen were reduced by $36.5 \%$ and $36.7 \%$, respectively (Bouazzaoui et al., 2011).

\subsubsection{T cell infiltration and damage in target organs}

The degree of $T$ cell infiltration in jejunum and liver did not appear to differ between groups, although damage of jejunum was more extensive in mice receiving $\mathrm{GR}^{\text {lckCre }}$ or, less markedly, in mice receiving $G^{\text {dim }} T$ cells. Therefore, the effect of endogenous GCs on T cells does not appear to regulate infiltration of target organs. If the effect on recipient cells is important to regulate infiltration (e.g. by regulating expression of adhesion molecules), transactivation is not necessary, as GR ${ }^{\text {dim }}$ recipients show normal or even slightly less infiltration. After treatment with dex, 
infiltration of $T$ cells in jejunum was reduced and damage was also alleviated in $\mathrm{GR}^{\text {wt }}$ mice receiving $G R^{\text {wt }} T$ cells. In mice receiving $G R^{\text {dim }} T$ cells this effect was incomplete and in mice receiving $\mathrm{GR}^{\text {lckCre }} \mathrm{T}$ cells there was no improvement at all. Hence, for treatment with dex, both transactivation and transrepression in $\mathrm{T}$ cells seems to be important to reduce target organ infiltration and tissue destruction.

In comparison of aGvHD with other diseases, in experimental autoimmune encephalomyelitis (EAE) GC treatment also reduces target organ infiltration by a direct effect on T cells (Wüst et al., 2008), which is dimerisation-independent (personal communication, Holger Reichardt). In antigen-induced arthritis (AIA), the reduction of infiltrate is also crucial for GC treatment, but is dimerisation-dependent (Baschant et al., 2012). In contrast, the GR in T cells is not required to reduce leukocyte infiltration into the skin in contact hypersensitivity (CHS) (Tuckermann et al., 2007).

In EAE the down-regulation of adhesion molecules plays an important role to reduce infiltration (Wüst et al., 2008). And in fact, Bouazzaoui et al. found an important role for chemokines and adhesion molecules in the treatment of aGvHD with prednisolone. The chemokines CXCL9 (MIG), CXCL10 (IP-10), CXCL11, (I-TAC), CCL2 (MCP-1), CCL3 (MIP-1 $\alpha$ ) and CCL4 (MIP-1 $\beta$ ) in the gut were down-regulated after treatment. Also, the adhesion molecules MadCAM-1 and ICAM-1, but not VCAM-1, were down-regulated in the gut. In liver only ICAM-1 was upregulated after aGvHD reduction, but not influenced by prednisolone treatment. They also looked at the respective ligands, LPAM-1, LAM-1 and LFA-1, which were upregulated in gut and liver. After treatment, they were only down-regulated in gut, but not in liver (Bouazzaoui et al., 2011). It is, however, slightly problematic that they looked at nonperfused liver, as this reflects the composition of blood and not liver. This was shown by analysis of perfused and non-perfused liver in our model, where the CD4/CD8 ratio without perfusion is the same as in blood, whereas after perfusion there were more $\mathrm{CD}^{+} \mathrm{T}$ cells in the liver. Also, when analysing the expression of adhesion molecules, which are expressed on T cells, PCR analysis of the gut may be misleading, because reduced expression of said molecules may simply reflect reduced infiltration, rather than down-regulation of expression in T cells.

In conclusion, it can be said that GC treatment reduces target organ infiltration in aGvHD, an effect that may or may not be mediated by the reduction of adhesion molecules on T cells. It cannot be mediated by reduction of adhesion molecules on 
host cells, because treatment is abrogated when the T cells are GR-deficient, even when host cells express intact $\mathrm{GR}$. Also the effect on infiltration cannot account for all beneficial effects of GCs, because the absence of GR in T cells made no difference for the control of infiltration by endogenous GCs.

\subsubsection{Cytotoxic $T$ cell effector function}

The perforin/granzyme cytotoxic pathway is, next to the Fas/Fas ligand pathway, a major cause of histopathological damage in aGvHD. Therefore, its downregulation could be beneficial for treatment.

The expression of perforin-1 and granzyme $B$ in spleen was increased in mice receiving $G^{\text {lckCre }}$ and $G^{\text {dim }} T$ cells compared to mice receiving $G^{\text {wt }} T$ cells. Therefore, the dimerisation-dependent effect of endogenous glucocorticoids on $T$ cells seems important to regulate cytotoxic $T$ cell activity. Abrogation of this effect correlated with greater mortality.

After high-dose dex therapy, over-expression of cytotoxic effector molecules was reduced in mice receiving $G^{\text {dim }}$ but not in mice receiving $G R^{\text {lckcre }} T$ cells. This is in accordance with the treatment effect in mice receiving $G^{\text {dim }} T$ cells and with resistance to therapy of mice receiving $\mathrm{GR}^{\mathrm{lck} C \mathrm{re}} \mathrm{T}$ cells.

It is likely that the regulation of cytotoxic T cell activity is crucial for the amelioration of aGvHD by both endogenous and therapeutic glucocorticoids.

The attenuation of IFN $\gamma$ by glucocorticoid treatment is most likely not responsible for reducing perforin and perforin mediated cytotoxic activity, as the complete removal of IFN $\gamma$ in experimental aGvHD does not fully inhibit perforin activity although Fas/FasLmediated killing is abrogated (Puliaev et al., 2004).

In addition it would be interesting to investigate the expression and release of perforin and granzyme in target organs. Also, the Fas/Fas ligand pathways would be an interesting mechanism to investigate in GC treatment of aGvHD.

In vitro, however, Bouazzaoui et al. could not confirm reduced CTL function in $\mathrm{Cr}$ release assay (Bouazzaoui et al., 2011). This may be accounted for by different models (haploidentical vs. fully mismatched), different GCs (prednisolone vs. dex) or simply by differences in the in vitro situation compared to the in vivo situation.

\subsubsection{Effect on macrophages}

Macrophages in the jejunum of mice transplanted with $G^{1 c k C r e} T$ cells showed a phenotype that was more activated compared to mice receiving $\mathrm{GR}^{\mathrm{wt}} \mathrm{T}$ cells. This 
may be because increased phagocytic activity is required to clear damage, which is greater in mice receiving $\mathrm{GR}^{\text {lckCre }} \mathrm{T}$ cells or because of increased sIFN $\gamma$ in mice receiving $\mathrm{GR}^{\text {IckCre }} \mathrm{T}$ cells.

After dex treatment, the phenotype of macrophages in jejunum and liver became less activated, which may be caused by a direct effect on the macrophages by dex. This effect may also be responsible for the delayed disease onset after treatment in mice receiving $\mathrm{GR}^{\mathrm{lck} C r e} \mathrm{~T}$ cells. Host $\mathrm{APCs}$ are important in the pathogenesis of aGvHD (Shlomchik et al., 1999), as they are responsible for priming and controlling the T cell response. Surprisingly, macrophages in $\mathrm{GR}^{\mathrm{dim}}$ recipients show the same response upon dex treatment as in $\mathrm{GR}^{\mathrm{wt}}$ recipients, although it has been described that $\mathrm{GR}^{\mathrm{dim}}$ macrophages in vitro are largely resistant to GC treatment, including morphological changes and downreglation of MHCII (Kleiman et al., 2011).

Unlike in CHS (Tuckermann et al., 2007) and sepsis (Kleiman et al., 2011) the effect on macrophages does not appear to be crucial in aGvHD, as both $\mathrm{GR}^{\text {dim }}$ and $\mathrm{GR}^{\text {lysMCre }}$ recipients are treatable using dex.

\subsubsection{Cytokines}

IL-2 in serum was increased on day 5, but not on day 6 , in $\mathrm{GR}^{\mathrm{wt}}$ mice transplanted with $\mathrm{GR}^{\mathrm{wt}} \mathrm{T}$ cells. This transient production fits with the biology of $\mathrm{T}$ cell activation. In mice receiving $G R^{\text {lckCre }} T$ cells or in $G R^{\text {dim }}$ recipients receiving $G^{\text {wt }} T$ cells, serum levels peaked higher than in the wild type setting. This correlated with higher mortality and disease severity. This is in line with the finding that elevated IL-2 in the serum correlates with higher-grade aGvHD (Hua et al., 2010). However, in mice receiving $G^{\text {dim }} T$ cells, which also showed higher mortality than mice receiving $G^{\text {wt }}$ T cells, IL-2 serum levels were not elevated. Elevated IL-2 in mice receiving GR ${ }^{\text {IckCre }}$ $T$ cells may be explained by lack of effect of endogenous GCs on the expanding $T$ cells. On the other hand, in $\mathrm{GR}^{\mathrm{dim}}$ recipients the limited effect on APCs may be responsible for more effective priming of $T$ cells. Therefore, the effect of endogenous GCs on both T cells and APCs is important to regulate IL-2. While the effect on T cells was dimerisation-independent, the effect on APCs required GR-dimerisation. High-dose GC treatment is able to reduce excessive IL-2 production in recipients of $\mathrm{GR}^{\text {lckCre }} \mathrm{T}$ cells and in $\mathrm{GR}^{\mathrm{dim}}$ hosts. This probably means that the effect on either T cells or APCs is sufficient for high therapeutic doses of GCs. In vitro, however, not 
the effect of GCs on T cells, but only on APCs is important to reduce IL-2. Dimerisation of the GR in APCs is not required for this.

The double-edged role of IFN $\gamma$ in aGvHD makes it difficult to judge its effect in pathogenesis and treatment. In recipients of $\mathrm{GR}^{\mathrm{lckCre}}$ or $\mathrm{GR}^{\mathrm{dim}} \mathrm{T}$ cells, which exhibit more severe aGvHD than recipients of $G R^{\text {wt }} T$ cells, disease severity correlates with increased SIFN $\gamma$. Also, in mice receiving $\mathrm{GR}^{\text {lckCre }} \mathrm{T}$ cells, which are resistant to treatment, reduction of sIFN $\gamma$ levels upon treatment is incomplete. On the other hand, in recipients of $\mathrm{GR}^{\mathrm{dim}} \mathrm{T}$ cells good treatment response correlates with a reduction of sIFN $\gamma$. Nevertheless, whether the reduction of IFN $\gamma$ is causative for treatment success or a by-product of the reduction in T cell number remains uncertain. It is also conceivable that the protective effect of IFN $\gamma$, which is attributed to its ability to induce AICD (Li et al., 2001; Refaeli et al., 2002), may also be mediated by inducing the release of endogenous GCs via the hypothalamic-pituitary-adrenal (HPA) axis. Consistent with these findings regarding serum IFN $\gamma$, Bouazzaoui et al. found that prednisolone treatment of aGvHD mice reduces INF $\gamma$ expression in the gut (Bouazzaoui et al.), which may be attributed to reduced T cell infiltration.

The role of IL-17 in aGvHD at this time remains unclear. In mice receiving GR $^{\text {lckCre }}$ T cells both Th1 cytokines and IL-17A were increased, which is another important piece of evidence that the effect of endogenous GCs on T cells is crucial for controlling aGvHD.

For treatment, however, the effect of dex on APCs and host cells was efficient for reducing IL-17A, the GR in T cells was not required. Treatment with dex decreased both, Th1 cytokines and IL-17A. Therefore, GC treatment of aGvHD does not seem to shift the Th1 or Th17 balance in the favour of one of them, but appears to reduce both. In comparison, although like in aGvHD both IFN $\gamma$ and IL-17 are reduced after GC therapy, AIA experiments with IFN $\gamma^{-/}$and IL-17 $17^{-/}$mice showed that the effect on

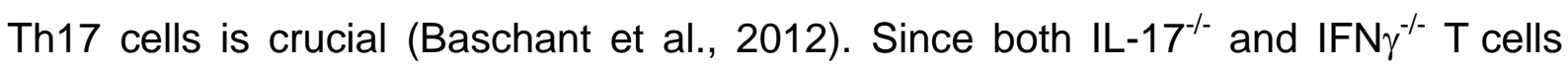
have been shown to be capable of inducing aGvHD, this may be an interesting question to investigate in the future.

Both IL-6 and MCP-1 are mainly secreted by host cells, although IL- 6 may also be produced by $T$ cells. Both cytokines were increased in $\mathrm{GR}^{\mathrm{wt}}$ mice receiving $\mathrm{GR}^{\mathrm{wt}}$ $T$ cells compared to mice receiving only bone marrow, which is in agreement with findings in patients (Ouyang et al., 2008; Schots et al., 2003). Mice receiving $G^{\text {lckCre }}$ or $\mathrm{GR}^{\text {dim }} \mathrm{T}$ cells, however, do not have higher IL-6 levels than mice receiving $\mathrm{GR}^{\mathrm{wt}}$ 
T cells. In GR ${ }^{\text {dim }}$ mice, both IL-6 and MCP-1 were higher than in $\mathrm{GR}^{\text {wt }}$ littermates. This shows the effect of endogenous GCs on host cells is important to regulate these two cytokines and that this effect is dimerisation-dependent. Increased IL-6 is also found in $\mathrm{GR}^{\text {dim }}$ mice in sepsis (Kleiman et al., 2011). MCP-1 is also slightly increased in mice receiving $G R^{\text {lckCre }}$ or $G^{\text {dim }} T$ cells compared to mice receiving $G^{\text {wt }} T$ cells. This points to the possibility that increased $T$ cell activity or tissue damage in turn also induces MCP-1, creating a vicious circle of inflammation and cytokine induction. Both IL- 6 and MCP-1 are downregulated in GR ${ }^{\text {dim }}$ recipients after dex treatment. This may occur directly through an effect on IL-6 and MCP-1 producing cells, or indirectly by limiting $T$ cell activity. IL- 6 can also be repressed in GR $^{\text {dim }}$ mice upon dex treatment in PMA-induced oedema formation (Reichardt et al., 2001). Interestingly, MCP-1 in CHS is not downregulated in GR $^{\text {dim }}$ mice (Tuckermann et al., 2007).

In mice receiving $\mathrm{GR}^{\mathrm{dim}} \mathrm{T}$ cells, increased MCP-1 is also treatable, whereas in mice receiving $\mathrm{GR}^{\mathrm{lckCre}}$ T cells $\mathrm{MCP}-1$ remains high. This may indicate that it is the dimerisation-independent effect on T cells that down-regulates MCP-1 indirectly.

The regulatory cytokine IL-10 has been attributed with a protective effect in aGvHD (e.g. Baker et al., 1999) and is associated with regulatory $T$ cell activity (Hoffmann et al., 2002). IL-10 induction in this model was generally low and GC treatment did not induce IL-10. The treatment response was not dependent on IL-10. Therefore, it seems unlikely that an induction of regulatory $T$ cells by GC treatment mediates the therapeutic effect of GCs in aGvHD. It is desirable, however, to directly analyse regulatory $T$ cells after GC therapy. It has been described for EAE that induction of regulatory T cells does not play a role for GC treatment (Wüst et al., 2008).

$\mathrm{IL}-1 \mathrm{~b}$ and TNF- $\alpha$ are two important effector cytokines in aGvHD and it has been described that IL-1 regulation by GCs is important in CHS (Tuckermann et al., 2007) and in sepsis (Kleiman et al., 2011). However, they were not detectable in the serum at the analysed time points in this aGvHD model.

\subsubsection{Endogenous corticosterone}

Systemic release of inflammatory cytokines stimulates the HPA axis to release corticosterone. After induction of aGvHD corticosterone in the serum was increased. The extent of corticosterone secretion did not depend on the GC response of either donor $\mathrm{T}$ cells or host cells. However, in $\mathrm{GR}^{\mathrm{dim}}$ recipients corticosterone levels appeared to rise earlier than in the other groups, which may indicate problems with 
the regulation of the HPA axis. In sepsis, $\mathrm{GR}^{\text {dim }}$ mice showed no dysregulation of the HPA axis (Kleiman et al., 2011). Therapy with dex repressed endogenous corticosterone production. However, in $\mathrm{GR}^{\mathrm{dim}}$ recipients, reduction was incomplete. This may be because of the impaired response of the HPA axis. In mice receiving $\mathrm{GR}^{\text {lckCre }} \mathrm{T}$ cells, suppression of endogenous corticosterone was also incomplete, possibly due to the high remaining levels of inflammatory mediators.

\subsubsection{Energy expenditure}

aGvHD caused hypoglycaemia, which was especially severe in $\mathrm{GR}^{\text {dim }}$ recipients. Also, $\mathrm{GR}^{\mathrm{dim}}$ recipients were the only group that developed a severe hypothermia. $G^{\text {dim }}$ recipients showed neither higher inflammatory mediators, nor increased infiltration or T cell activity, nor did the HPA axis seem to be dysregulated, as endogenous corticosterone levels were similar to $\mathrm{GR}^{\mathrm{wt}}$ recipients. It is therefore likely that higher mortality in $\mathrm{GR}^{\text {dim }}$ recipients is not caused by an immunological phenotype, but by dysregulation of energy expenditure.

Interestingly, $\mathrm{GR}^{\mathrm{dim}}$ mice show a similar phenotype in sepsis, where aberrant energy expenditure causes increased lethality. The effect was dependent on nonhaematopietic cells. Experiments with ob/ob mice and mice lacking the GR in the forebrain, exhibited the same phenotype in sepsis experiments. Therefore, aberrant energy expenditure is possibly caused by lack of induction of leptin in adipose tissue or leptin-dependent signalling in the hypothalamus (personal communication, Anna Kleiman, Tuckermann lab at the Leibniz Institute for Age Research, Jena).

Both, hypoglycaemia and hypothermia, were fully treatable in $\mathrm{GR}^{\text {dim }}$ recipients. Therefore, the effect of exogenous dex on donor cells suffices to treat aGvHD, so that the energy expenditure problems do not occur, or the dimerisation-independent effect on host cells is enough to prevent problems with energy expenditure. It may therefore be promising to look into the role of energy metabolism in aGvHD and to investigate therapies that target this aspect, e.g. drugs interfering with leptin function. 


\subsection{Role of the GR and its molecular modes in different tissues}

\subsubsection{The role of the $G R$ and its dimerisation in donor $T$ cells for endogenous control of aGvHD}

The absence of the GR or its dimerisation in donor T cells caused exacerbated morbidity. Therefore, the GR in T cells appears to be crucial for control of aGvHD by endogenous glucocorticoids and transactivation is required.

Although total $\mathrm{T}$ cell number in blood, lymph nodes and $\mathrm{T}$ cell infiltration in jejunum and liver in mice receiving $\mathrm{GR}^{\mathrm{lckCre}}$ or $\mathrm{GR}^{\text {dim }} \mathrm{T}$ cells were comparable to mice receiving $G^{\text {wt }} T$ cells, damage to the jejunum seemed to be exacerbated if the GR in donor $\mathrm{T}$ cells was dimerisation-deficient, and even more so when it was completely absent.

One explanation for exacerbated target organ damage may be increased amounts of inflammatory mediators. Serum concentrations of T cell cytokines, such as IL-2, IFN $\gamma$ and IL-17A, were significantly increased if the GR was absent in donor T cells. Also, mRNA expression of IFN $\gamma$ and IL-17 in the spleen was increased. MCP-1 (CCL2) was also slightly raised. If only dimerisation of the GR in donor $T$ cells was absent, IL-2 and IL-17A levels were comparable to levels in mice receiving $\mathrm{GR}^{\mathrm{wt}} \mathrm{T}$ cells, but IFN $\gamma$ was increased slightly. MCP-1 was also increased if only dimerisation was deficient. Hence, the GR in donor T cells is necessary to control the cytokine storm in aGvHD, but dimerisation is not required for the control of all cytokines.

Apart from increased cytokine expression, exacerbated damage may be explained by the increased activity of cytotoxic T cells. The expression of the cytotoxic effector molecules perforin-1 and granzyme B was increased in mice receiving GR-deficient or GR-dimerisation-deficient T cells.

In EAE the effect of endogenous GCs on T cells is also important and in GR ${ }^{\text {lckCre }}$ mice EAE onset occurs earlier than in $\mathrm{GR}^{\text {wt }}$ mice. (Wüst et al., 2008). In $\mathrm{CHS}$, on the other hand, the $G R^{\text {lckCre }}$ mice do not show a different response than $G^{\text {wt }}$ mice (Tuckermann et al., 2007). In AIA, disease severity is also not excacerbated in $G^{\text {lckCre }}$ mice (Baschant et al., 2012). Thus, in this aspect aGvHD seems to be comparable to EAE, where the absence of the GR in T cells has detrimental consequences. 


\subsubsection{The role of the GR and its dimerisation in donor $T$ cells for the treatment of aGvHD with GCs}

Dex treatment did not reduce mortality if GR in donor T cells was absent, but if only dimerisation was impaired, treatment was still partially possible. Thus, the GR in donor T cells, but not its dimerisation, appears to be pivotal for the treatment of aGvHD with GCs.

Treatment reduced total $T$ cell number in mice receiving $\mathrm{GR}^{\text {dim }} \mathrm{T}$ cells, but not in mice receiving $G R^{\text {lckCre }} T$ cells. T cell infiltration in liver was, by trend, reduced in both, mice receiving $G^{\text {lckcre }}$ and $\mathrm{GR}^{\text {dim }} T$ cells. $T$ cell infiltration in jejunum, however, was only reduced in mice receiving $G^{\text {dim }} T$ cells, but not in mice receiving $G R^{\text {lckCre }}$ $T$ cells. As $G^{\text {dim }} T$ cells are not susceptible to $G C$-induced apoptosis, a role for $T$ cell apoptosis in the treatment of aGvHD is unlikely.

In mice receiving $\mathrm{GR}^{\mathrm{dim}} \mathrm{T}$ cells, treatment was able to reduce damage of jejunum. Tissue destruction of jejunum appeared slightly alleviated in mice receiving GR $^{\text {lckCre }}$ T cells on day 6, but treatment appeared to fail on day 7, so that a delayed disease course could be suspected. As a matter of fact, it has been described in EAE that $G^{\text {lckCre }}$ mice showed some treatment effect on the first day before it failed entirely (Wüst et al., 2008). An explanation for this phenomenon could be that the effect on APCs and/or other host cells is able to delay disease temporarily, but not prevent it.

If only dimerisation of the GR in donor T cells was deficient, all cytokines could be reduced adequately by GC treatment. Although IL-2, IFN $\gamma$ and IL-17A could be reduced in case of total absence of $\mathrm{GR}$ in donor $\mathrm{T}$ cells, their concentration remained relatively high. MCP-1 could not be decreased at all by treatment if GR in T cells was absent.

If only dimerisation was absent, endogenous corticosterone was down-regulated sufficiently. The reduction of endogenous corticosterone after treatment was incomplete in mice receiving $T$ cells without GR. This may be due to the fact that cytokine levels still remain high in mice receiving $G^{\text {lckCre }} T$ cells even after treatment.

Furthermore, CD8 effector molecules were reduced in mice receiving $\mathrm{GR}^{\mathrm{dim}} \mathrm{T}$ cells, but not in mice receiving $\mathrm{GR}^{\text {lckCre }} \mathrm{T}$ cells. As mice receiving $\mathrm{GR}^{\mathrm{dim}} \mathrm{T}$ cells are treatable and mice receiving $\mathrm{GR}^{\text {lckCre }} \mathrm{T}$ cells are not, this may be a very important target for GC therapy that is crucial for treatment success. 
It can therefore be concluded that the GR in T cells, but not its dimerisation, is essential for treatment of aGvHD with dex, and it seems that the down-regulation of target tissue infiltration and cytotoxic $T$ cell activity are most crucial.

\subsubsection{The role of GR dimerisation in host cells for endogenous control of $a G v H D$}

Mortality in recipients deficient for GR-dimerisation was increased after aGvHD induction. This leads to the conclusion, that recipient macrophages in $\mathrm{GR}^{\mathrm{dim}}$ mice or other, non-haematopoietic, cells play an important role in aGvHD. Many parameters, however, were unchanged in $\mathrm{GR}^{\text {dim }}$ mice compared to $\mathrm{GR}^{\mathrm{wt}}$ littermates. Total $\mathrm{T}$ cell number and $T$ cell infiltration of target organs was not changed compared to $\mathrm{GR}^{\text {wt }}$ littermates, neither were the T cell cytokines IFN $\gamma$, IL-2 and IL-17A. The expression of cytotoxic effector molecules was also unaffected by dimerisation-deficiency in the host. Destruction of jejunum also remained the same. Hence, it is unlikely that higher $\mathrm{T}$ cell activity and organ damage are responsible for the higher mortality in $\mathrm{GR}^{\text {dim }}$ mice after aGvHD induction.

A slight dysregulation of the HPA axis is possible, as endogenous corticosterone levels started to rise earlier, possibly because of an impaired negative feedback loop. But overall, corticosterone levels are not higher than in $\mathrm{GR}^{\mathrm{wt}}$ littermates.

It has also been described that $\mathrm{GR}^{\mathrm{dim}}$ mice are more susceptible to sepsis, which is caused by a prolonged production of IL-1 $\beta$. IL- 6 and IL-10 were also produced for longer (Kleiman et al., 2011). In this aGvHD model, IL-1 $\beta$ in the serum was not detectable at the time points analysed, although it is described that IL-1 $\beta$ is a key player in aGvHD (Abhyankar et al., 1993). Possibilities are that systemical release of IL-1 $\beta$ after conditioning (Hill et al., 1999) takes place prior to the observed time points and that during the effector phase IL-1 $\beta$ is primarily found in the target organs. TNF $\alpha$ does not appear to play a role in $\mathrm{GR}^{\mathrm{dim}}$ mice in aGvHD or in sepsis. $\mathrm{GR}^{\mathrm{dim}}$ mice had higher IL-6 levels after aGvHD induction than GR $^{\text {wt }}$ littermates, similar to sepsis. In aGvHD, however, sMCP-1 was also increased, unlike in sepsis. For this reason, a role of recipient macrophages cannot be excluded for the exaggerated aGvHD phenotype in $\mathrm{GR}^{\mathrm{dim}}$ recipients.

Most likely, though, increased lethality in $\mathrm{GR}^{\text {dim }}$ hosts is not due to an immunological phenotype, but caused by aberrant energy expentiture, because hypoglycaemia and hypothermia were increased in $\mathrm{GR}^{\mathrm{dim}}$ hosts, like they were in sepsis experiments of 
our co-operation partners (personal communication, Anna Kleiman, Tuckermann lab at the Leibniz Institute for Age Research, Jena).

\subsubsection{The role of GR dimerisation in host cells for the treatment of aGvHD with GCs}

The high mortality of $\mathrm{GR}^{\mathrm{dim}}$ mice could be completely alleviated by dex treatment. Total $T$ cell number was reduced in $\mathrm{GR}^{\text {dim }}$ recipients after treatment. Tissue destruction did improve upon treatment. The reduction of $\mathrm{T}$ cell cytokines was comparable to $\mathrm{GR}^{\mathrm{wt}}$ littermates. MCP-1 and IL-6, which were increased in $\mathrm{GR}^{\text {dim }}$ recipients compared to $\mathrm{GR}^{\mathrm{wt}}$ littermates, were also reduced by $\mathrm{GC}$ treatment. The repression of endogenous corticosterone on day 6 was slightly incomplete. But cytotoxic effector molecules were adequately repressed by dex treatment. Most importantly, the dysregulated energy expenditure was entirely treatable with dex.

Therefore, the effect on T cells and dimerisation independent effects in host cells seem to be sufficient for aGvHD treatment.

In contrast, in CHS, dimerisation, specifically in macrophages and neutrophils, is required for repression of the inflammatory response (Tuckermann et al., 2007).

\subsubsection{Potential implications for patients}

Mortality is increased no matter in what tissue the GR is removed or what molecular mechanism is abrogated. This shows how important GCs are not only for treatment of aGvHD, but also for its endogenous control. This means that both recipient and donor polymorphisms could account for higher susceptibility to aGvHD. On the other hand, for treatment only the donor T cells seem to be relevant. Therefore, recipient polymorphisms should be irrelevant. For example, a GR polymorphism has been described that affects transrepression, but not transactivation (van den Akker et al., 2006).

\subsection{Conclusion}

This work has underlined the importance of endogenous GCs for the regulation of aGvHD. The GR not only in donor T cells, but also in host tissues, was shown to have an influence on mortality and morbidity. Whereas the effects on donor T cells are mainly mediated through regulation of $\mathrm{T}$ cell cytokines and cytotoxic activity, the effect on host tissue appears to work to some degree through cytokines produced by host cells, but more importantly through effects on the energy metabolism. It may 
therefore be promising to look into new therapeutics that target the energy metabolism.

For GC therapy of aGvHD, control of T cells is essential and sufficient and transactivation appears to play a minor role. Reduction of target organ infiltration and suppression of the cytotoxic activity of donor T cells, possibly by an effect on $\mathrm{T}$ cell cytokines, appear to be the crucial mechanisms. This opens up perspectives for the usage of selective GR agonist as therapeutics, which target transrepression, but not transactivation, and have a reduced spectrum of side effects. 


\section{References}

Abhyankar, S., Gilliland, D.G., and Ferrara, J.L. (1993). Interleukin-1 is a critical effector molecule during cytokine dysregulation in graft versus host disease to minor histocompatibility antigens. Transplantation 56, 1518-1523.

Akira, S., Taga, T., and Kishimoto, T. (1993). Interleukin-6 in biology and medicine. Advances in immunology 54, 1-78.

Antin, J.H., and Ferrara, J.L. (1992). Cytokine dysregulation and acute graft-versushost disease. Blood 80, 2964-2968.

Baker, K.S., Roncarolo, M.G., Peters, C., Bigler, M., DeFor, T., and Blazar, B.R. (1999). High spontaneous IL-10 production in unrelated bone marrow transplant recipients is associated with fewer transplant-related complications and early deaths. Bone marrow transplantation 23, 1123-1129.

Barnes, D.W., and Loutit, J.F. (1957). Treatment of murine leukaemia with x-rays and homologous bone marrow. II. British journal of haematology 3, 241-252.

Baschant, U., Frappart, L., Rauchhaus, U., Bruns, L., Reichardt, H.M., Kamradt, T., Brauer, R., and Tuckermann, J.P. (2012). Glucocorticoid therapy of antigen-induced arthritis depends on the dimerized glucocorticoid receptor in T cells. Proceedings of the National Academy of Sciences of the United States of America 108, 1931719322.

Baumann, S., Dostert, A., Novac, N., Bauer, A., Schmid, W., Fas, S.C., Krueger, A., Heinzel, T., Kirchhoff, S., Schutz, G., et al. (2005). Glucocorticoids inhibit activationinduced cell death (AICD) via direct DNA-dependent repression of the CD95 ligand gene by a glucocorticoid receptor dimer. Blood 106, 617-625.

Bay, J.O., Dhedin, N., Goerner, M., Vannier, J.P., Marie-Cardine, A., Stamatoullas, A., Jouet, J.P., Yakoub-Agha, I., Tabrizi, R., Faucher, C., et al. (2005). Inolimomab in steroid-refractory acute graft-versus-host disease following allogeneic hematopoietic stem cell transplantation: retrospective analysis and comparison with other interleukin-2 receptor antibodies. Transplantation $80,782-788$.

Bettelli, E., Oukka, M., and Kuchroo, V.K. (2007). T(H)-17 cells in the circle of immunity and autoimmunity. Nature immunology 8, 345-350.

Billingham, R.E. (1959). Reactions of grafts against their hosts. Science (New York, NY 130, 947-953.

Billingham, R.E. (1966). The biology of graft-versus-host reactions. Harvey lectures 62, 21-78.

Bledsoe, R.K., Montana, V.G., Stanley, T.B., Delves, C.J., Apolito, C.J., McKee, D.D., Consler, T.G., Parks, D.J., Stewart, E.L., Willson, T.M., et al. (2002). Crystal structure of the glucocorticoid receptor ligand binding domain reveals a novel mode of receptor dimerization and coactivator recognition. Cell 110, 93-105.

Bouazzaoui, A., Spacenko, E., Mueller, G., Huber, E., Schubert, T., Holler, E., Andreesen, R., and Hildebrandt, G.C. (2011). Steroid treatment alters adhesion molecule and chemokine expression in experimental acute graft-vs.-host disease of the intestinal tract. Experimental hematology 39, 238-249 e231. 
Bouazzaoui, A., Spacenko, E., Mueller, G., Miklos, S., Huber, E., Holler, E., Andreesen, R., and Hildebrandt, G.C. (2009). Chemokine and chemokine receptor expression analysis in target organs of acute graft-versus-host disease. Genes and immunity 10, 687-701.

Braun, M.Y., Lowin, B., French, L., Acha-Orbea, H., and Tschopp, J. (1996). Cytotoxic $T$ cells deficient in both functional fas ligand and perforin show residual cytolytic activity yet lose their capacity to induce lethal acute graft-versus-host disease. The Journal of experimental medicine 183, 657-661.

Brochu, S., Rioux-Masse, B., Roy, J., Roy, D.C., and Perreault, C. (1999). Massive activation-induced cell death of alloreactive $T$ cells with apoptosis of bystander postthymic $\mathrm{T}$ cells prevents immune reconstitution in mice with graft-versus-host disease. Blood 94, 390-400.

Brok, H.P., Heidt, P.J., van der Meide, P.H., Zurcher, C., and Vossen, J.M. (1993). Interferon-gamma prevents graft-versus-host disease after allogeneic bone marrow transplantation in mice. J Immunol 151, 6451-6459.

Buttgereit, F., and Scheffold, A. (2002). Rapid glucocorticoid effects on immune cells. Steroids 67, 529-534.

Canalis, E., Mazziotti, G., Giustina, A., and Bilezikian, J.P. (2007). Glucocorticoidinduced osteoporosis: pathophysiology and therapy. Osteoporos Int 18, 1319-1328.

Cantrill, H.L., Waltman, S.R., Palmberg, P.F., Zink, H.A., and Becker, B. (1975). In vitro determination of relative corticosteroid potency. The Journal of clinical endocrinology and metabolism 40, 1073-1077.

Carlson, M.J., West, M.L., Coghill, J.M., Panoskaltsis-Mortari, A., Blazar, B.R., and Serody, J.S. (2009). In vitro-differentiated TH17 cells mediate lethal acute graftversus-host disease with severe cutaneous and pulmonary pathologic manifestations. Blood 113, 1365-1374.

Chao, N.J., Holler, E., and Deeg, H.J. (2005). Prophylaxis and Tretment of Acute Graft-vs.-Host Disease. In Graft-vs-Host Disease, J.L. Ferrara, K.R. Cooke, and H.J. Deeg, eds. (New York City, Marcel Dekker), pp. 459-479.

Chao, N.J., Snyder, D.S., Jain, M., Wong, R.M., Niland, J.C., Negrin, R.S., Long, G.D., Hu, W.W., Stockerl-Goldstein, K.E., Johnston, L.J., et al. (2000). Equivalence of 2 effective graft-versus-host disease prophylaxis regimens: results of a prospective double-blind randomized trial. Biol Blood Marrow Transplant 6, 254-261.

Cheung, J., and Smith, D.F. (2000). Molecular chaperone interactions with steroid receptors: an update. Molecular endocrinology (Baltimore, Md 14, 939-946.

Cho, B.S., Lim, J.Y., Yahng, S.A., Lee, S.E., Eom, K.S., Kim, Y.J., Chung, N.G., Jeong, D.C., Lee, S., Kim, H.J., et al. (2011). Circulating IL-17 levels during the peritransplant period as a predictor for early leukemia relapse after myeloablative allogeneic stem cell transplantation. Annals of hematology.

Choi, B., Lee, D.E., Park, H.Y., Jeong, S., Lee, S.M., Ji, E., Park, S., and Oh, J.M. (2012). A meta-analysis of the effects of interleukin-6 -174 g>c genetic polymorphism on acute graft-versus-host disease susceptibility. Clinical therapeutics 34, 295-304.

Cooke, K.R., Kobzik, L., Martin, T.R., Brewer, J., Delmonte, J., Crawford, J.M., and Ferrara, J.L. (1996). An experimental model of idiopathic pneumonia syndrome after bone marrow transplantation: I. The roles of minor $\mathrm{H}$ antigens and endotoxin. Blood 88, 3230-3239. 
Couper, K.N., Blount, D.G., and Riley, E.M. (2008). IL-10: the master regulator of immunity to infection. J Immunol 180, 5771-5777.

Cutler, C., and Antin, J.H. (2001). Peripheral blood stem cells for allogeneic transplantation: a review. Stem cells (Dayton, Ohio) 19, 108-117.

Cutler, C., Giri, S., Jeyapalan, S., Paniagua, D., Viswanathan, A., and Antin, J.H. (2001). Acute and chronic graft-versus-host disease after allogeneic peripheral-blood stem-cell and bone marrow transplantation: a meta-analysis. J Clin Oncol 19, 36853691.

Dander, E., Balduzzi, A., Zappa, G., Lucchini, G., Perseghin, P., Andre, V., Todisco, E., Rahal, D., Migliavacca, M., Longoni, D., et al. (2009). Interleukin-17-producing Thelper cells as new potential player mediating graft-versus-host disease in patients undergoing allogeneic stem-cell transplantation. Transplantation 88, 1261-1272.

De Bosscher, K., Vanden Berghe, W., Beck, I.M., Van Molle, W., Hennuyer, N., Hapgood, J., Libert, C., Staels, B., Louw, A., and Haegeman, G. (2005). A fully dissociated compound of plant origin for inflammatory gene repression. Proceedings of the National Academy of Sciences of the United States of America 102, 1582715832.

Economou, J.S., McBride, W.H., Essner, R., Rhoades, K., Golub, S., Holmes, E.C., and Morton, D.L. (1989). Tumour necrosis factor production by IL-2-activated macrophages in vitro and in vivo. Immunology 67, 514-519.

Ferrara, J.L., and Deeg, H.J. (1991). Graft-versus-host disease. The New England journal of medicine 324, 667-674.

Ferrara, J.L., Levine, J.E., Reddy, P., and Holler, E. (2009). Graft-versus-host disease. Lancet 373, 1550-1561.

Fox, E.S., Thomas, P., and Broitman, S.A. (1989). Clearance of gut-derived endotoxins by the liver. Release and modification of $3 \mathrm{H}, 14 \mathrm{C}$-lipopolysaccharide by isolated rat Kupffer cells. Gastroenterology 96, 456-461.

Freedman, N.D., and Yamamoto, K.R. (2004). Importin 7 and importin alpha/importin beta are nuclear import receptors for the glucocorticoid receptor. Molecular biology of the cell 15, 2276-2286.

Fujii, N., Hiraki, A., Aoe, K., Murakami, T., Ikeda, K., Masuda, K., Matsuo, K., Shinagawa, K., Ishimaru, F., Sugi, K., et al. (2006). Serum cytokine concentrations and acute graft-versus-host disease after allogeneic peripheral blood stem cell transplantation: concurrent measurement of ten cytokines and their respective ratios using cytometric bead array. International journal of molecular medicine 17, 881-885.

Gatti, R.A., Meuwissen, H.J., Allen, H.D., Hong, R., and Good, R.A. (1968). Immunological reconstitution of sex-linked lymphopenic immunological deficiency. Lancet 2, 1366-1369.

Goulmy, E., Schipper, R., Pool, J., Blokland, E., Falkenburg, J.H., Vossen, J., Gratwohl, A., Vogelsang, G.B., van Houwelingen, H.C., and van Rood, J.J. (1996). Mismatches of minor histocompatibility antigens between HLA-identical donors and recipients and the development of graft-versus-host disease after bone marrow transplantation. The New England journal of medicine 334, 281-285.

Goussetis, E., Varela, I., Peristeri, I., Kitra, V., Spanou, K., Moraloglou, O., Paisiou, A., Karatasaki, S., Soldatou, A., Constantinidou, N., et al. (2011). Cytokine gene polymorphisms and graft-versus-host disease in children after matched sibling 
hematopoietic stem cell transplantation: a single-center experience. Cellular \& molecular immunology 8, 276-280.

Gratwohl, A., Brand, R., Frassoni, F., Rocha, V., Niederwieser, D., Reusser, P., Einsele, H., and Cordonnier, C. (2005). Cause of death after allogeneic haematopoietic stem cell transplantation (HSCT) in early leukaemias: an EBMT analysis of lethal infectious complications and changes over calendar time. Bone marrow transplantation 36, 757-769.

Grimm, J., Zeller, W., and Zander, A.R. (1998). Soluble interleukin-2 receptor serum levels after allogeneic bone marrow transplantations as a marker for GVHD. Bone marrow transplantation 21, 29-32.

Hedberg, C.A., Reiser, S., and Reilly, R.W. (1968). Intestinal phase of the runting syndrome in mice. II. Observations on nutrient absorption and certain disaccharidase abnormalities. Transplantation 6, 104-110.

Hempel, L., Korholz, D., Nussbaum, P., Bonig, H., Burdach, S., and Zintl, F. (1997). High interleukin-10 serum levels are associated with fatal outcome in patients after bone marrow transplantation. Bone marrow transplantation 20, 365-368.

Hill, G.R., Crawford, J.M., Cooke, K.R., Brinson, Y.S., Pan, L., and Ferrara, J.L. (1997). Total body irradiation and acute graft-versus-host disease: the role of gastrointestinal damage and inflammatory cytokines. Blood 90, 3204-3213.

Hill, G.R., Teshima, T., Gerbitz, A., Pan, L., Cooke, K.R., Brinson, Y.S., Crawford, J.M., and Ferrara, J.L. (1999). Differential roles of IL-1 and TNF-alpha on graftversus-host disease and graft versus leukemia. The Journal of clinical investigation 104, 459-467.

Hoffmann, P., Ermann, J., Edinger, M., Fathman, C.G., and Strober, S. (2002). Donor-type CD4(+)CD25(+) regulatory T cells suppress lethal acute graft-versus-host disease after allogeneic bone marrow transplantation. The Journal of experimental medicine 196, 389-399.

Holler, E., Roncarolo, M.G., Hintermeier-Knabe, R., Eissner, G., Ertl, B., Schulz, U., Knabe, H., Kolb, H.J., Andreesen, R., and Wilmanns, W. (2000). Prognostic significance of increased IL-10 production in patients prior to allogeneic bone marrow transplantation. Bone marrow transplantation 25, 237-241.

Holowiecki, J. (2008). Indications for hematopoietic stem cell transplantation. Polskie Archiwum Medycyny Wewnetrznej 118, 658-663.

Hua, J.Y., Zhou, X.H., Pang, Y., and Huang, R.W. (2010). [Correlation of donor and recipient serum interleukin 2 and tumor necrosis factor alpha levels to acute graftversus-host disease in hematopoietic stem cell transplantation]. Nan fang yi ke da xue xue bao = Journal of Southern Medical University 30, 831-833.

Jiang, Z., Podack, E., and Levy, R.B. (2001). Major histocompatibility complexmismatched allogeneic bone marrow transplantation using perforin and/or Fas ligand double-defective CD4(+) donor T cells: involvement of cytotoxic function by donor lymphocytes prior to graft-versus-host disease pathogenesis. Blood 98, 390-397.

Kami, M., Matsumura, T., Tanaka, Y., Mikami, Y., Miyakoshi, S., Ueyama, J., Morinaga, S., Mori, S., Machida, U., Kanda, Y., et al. (2000). Serum levels of soluble interleukin-2 receptor after bone marrow transplantation: a true marker of acute graftversus-host disease. Leukemia \& lymphoma 38, 533-540. 
Kappel, L.W., Goldberg, G.L., King, C.G., Suh, D.Y., Smith, O.M., Ligh, C., Holland, A.M., Grubin, J., Mark, N.M., Liu, C., et al. (2009). IL-17 contributes to CD4-mediated graft-versus-host disease. Blood 113, 945-952.

Karabon, L., Wysoczanska, B., Bogunia-Kubik, K., Suchnicki, K., and Lange, A. (2005). IL-6 and IL-10 promoter gene polymorphisms of patients and donors of allogeneic sibling hematopoietic stem cell transplants associate with the risk of acute graft-versus-host disease. Human immunology 66, 700-710.

Keller-Wood, M.E., and Dallman, M.F. (1984). Corticosteroid inhibition of ACTH secretion. Endocrine reviews 5, 1-24.

Kernan, N.A., Collins, N.H., Juliano, L., Cartagena, T., Dupont, B., and O'Reilly, R.J. (1986). Clonable T lymphocytes in T cell-depleted bone marrow transplants correlate with development of graft-v-host disease. Blood 68, 770-773.

Kleiman, A., Hubner, S., Rodriguez Parkitna, J.M., Neumann, A., Hofer, S., Weigand, M.A., Bauer, M., Schmid, W., Schutz, G., Libert, C., et al. (2011). Glucocorticoid receptor dimerization is required for survival in septic shock via suppression of interleukin-1 in macrophages. Faseb J 26, 722-729.

Korngold, R., and Sprent, J. (1978). Lethal graft-versus-host disease after bone marrow transplantation across minor histocompatibility barriers in mice. Prevention by removing mature $T$ cells from marrow. The Journal of experimental medicine 148, 1687-1698.

Kretz, O., Reichardt, H.M., Schutz, G., and Bock, R. (1999). Corticotropin-releasing hormone expression is the major target for glucocorticoid feedback-control at the hypothalamic level. Brain research 818, 488-491.

Ladner, M.B., Martin, G.A., Noble, J.A., Wittman, V.P., Warren, M.K., McGrogan, M., and Stanley, E.R. (1988). cDNA cloning and expression of murine macrophage colony-stimulating factor from L929 cells. Proceedings of the National Academy of Sciences of the United States of America 85, 6706-6710.

Li, X.C., Strom, T.B., Turka, L.A., and Wells, A.D. (2001). T cell death and transplantation tolerance. Immunity 14, 407-416.

Linker, R.A., Weller, C., Luhder, F., Mohr, A., Schmidt, J., Knauth, M., Metselaar, J.M., and Gold, R. (2008). Liposomal glucocorticosteroids in treatment of chronic autoimmune demyelination: long-term protective effects and enhanced efficacy of methylprednisolone formulations. Experimental neurology 211, 397-406.

Luisi, B.F., Xu, W.X., Otwinowski, Z., Freedman, L.P., Yamamoto, K.R., and Sigler, P.B. (1991). Crystallographic analysis of the interaction of the glucocorticoid receptor with DNA. Nature 352, 497-505.

Malek, T.R. (2008). The biology of interleukin-2. Annual review of immunology 26, 453-479.

Maloney, D.G., Grillo-Lopez, A.J., White, C.A., Bodkin, D., Schilder, R.J., Neidhart, J.A., Janakiraman, N., Foon, K.A., Liles, T.M., Dallaire, B.K., et al. (1997). IDECC2B8 (Rituximab) anti-CD20 monoclonal antibody therapy in patients with relapsed low-grade non-Hodgkin's lymphoma. Blood 90, 2188-2195.

Martin, P.J., Schoch, G., Fisher, L., Byers, V., Anasetti, C., Appelbaum, F.R., Beatty, P.G., Doney, K., McDonald, G.B., and Sanders, J.E. (1990). A retrospective analysis of therapy for acute graft-versus-host disease: initial treatment. Blood 76, 1464-1472. 
Miesfeld, R., Okret, S., Wikstrom, A.C., Wrange, O., Gustafsson, J.A., and Yamamoto, K.R. (1984). Characterization of a steroid hormone receptor gene and mRNA in wild-type and mutant cells. Nature 312, 779-781.

Mowat, A., and Socié, G. (2005). Intestinal graft-vs.-host disease. In Graft-vs-Host Disease, F. J.L.M., C. K.R., and D. H.J., eds. (New York, Marcel Dekker), pp. 279327.

Nobelprize.org, The Nobel Prize in Physiology or Medicine 1950 - Press Release, http://www.nobelprize.org/nobel_prizes/medicine/laureates/1950/press.html, retrieved on 21 Mar 2012

Nobelprize.org, The Nobel Prize in Physiology or Medicine 1990 - Press Release, http://www.nobelprize.org/nobel_prizes/medicine/laureates/1990/press.html, retrieved on 25 Jan 2012

Oh, I., Ozaki, K., Meguro, A., Hatanaka, K., Kadowaki, M., Matsu, H., Tatara, R., Sato, K., Iwakura, Y., Nakae, S., et al. (2010). Altered effector CD4+ T cell function in IL-21R-/- CD4+ T cell-mediated graft-versus-host disease. J Immunol 185, 19201926.

Okabe, M., Ikawa, M., Kominami, K., Nakanishi, T., and Nishimune, Y. (1997). 'Green mice' as a source of ubiquitous green cells. FEBS letters 407, 313-319.

Ouyang, M., Ren, H.Y., Yin, Y., Qiu, Z.X., Cen, X.N., Wang, L.H., Ou, J.P., Wang, W.S., Wang, M.J., Li, Y., et al. (2008). [Correlation of chemokine CCL-2/MCP-1 level in the plasma with aGVHD and idiophathic pneumonia syndrome after allogeneic hematopoietic stem cell transplantation]. Zhongguo shi yan xue ye xue za zhi / Zhongguo bing li sheng li xue hui = Journal of experimental hematology / Chinese Association of Pathophysiology 16, 838-842.

Peeke, P.M., and Chrousos, G.P. (1995). Hypercortisolism and obesity. Annals of the New York Academy of Sciences 771, 665-676.

Pidala, J., Kim, J., Kharfan-Dabaja, M.A., Nishihori, T., Field, T., Perkins, J., Perez, L., Fernandez, H., and Anasetti, C. (2011). Dysglycemia following glucocorticoid therapy for acute graft-versus-host disease adversely affects transplantation outcomes. Biol Blood Marrow Transplant 17, 239-248.

Pinana, J.L., Valcarcel, D., Martino, R., Moreno, M.E., Sureda, A., Briones, J., Brunet, S., and Sierra, J. (2006). Encouraging results with inolimomab (anti-IL-2 receptor) as treatment for refractory acute graft-versus-host disease. Biol Blood Marrow Transplant 12, 1135-1141.

Poynton, C.H. (1988). T cell depletion in bone marrow transplantation. Bone marrow transplantation 3, 265-279.

Pujols, L., Mullol, J., Roca-Ferrer, J., Torrego, A., Xaubet, A., Cidlowski, J.A., and Picado, C. (2002). Expression of glucocorticoid receptor alpha- and beta-isoforms in human cells and tissues. American journal of physiology 283, C1324-1331.

Puliaev, R., Nguyen, P., Finkelman, F.D., and Via, C.S. (2004). Differential requirement for IFN-gamma in CTL maturation in acute murine graft-versus-host disease. J Immunol 173, 910-919.

Ratanatharathorn, V., Nash, R.A., Przepiorka, D., Devine, S.M., Klein, J.L., Weisdorf, D., Fay, J.W., Nademanee, A., Antin, J.H., Christiansen, N.P., et al. (1998). Phase III study comparing methotrexate and tacrolimus (prograf, FK506) with methotrexate 
and cyclosporine for graft-versus-host disease prophylaxis after HLA-identical sibling bone marrow transplantation. Blood 92, 2303-2314.

Rauch, A., Seitz, S., Baschant, U., Schilling, A.F., Illing, A., Stride, B., Kirilov, M., Mandic, V., Takacz, A., Schmidt-Ullrich, R., et al. (2010). Glucocorticoids suppress bone formation by attenuating osteoblast differentiation via the monomeric glucocorticoid receptor. Cell metabolism 11, 517-531.

Refaeli, Y., Van Parijs, L., Alexander, S.I., and Abbas, A.K. (2002). Interferon gamma is required for activation-induced death of $T$ lymphocytes. The Journal of experimental medicine 196, 999-1005.

Reichardt, H.M., Kaestner, K.H., Tuckermann, J., Kretz, O., Wessely, O., Bock, R., Gass, P., Schmid, W., Herrlich, P., Angel, P., et al. (1998). DNA binding of the glucocorticoid receptor is not essential for survival. Cell 93, 531-541.

Reichardt, H.M., Tuckermann, J.P., Gottlicher, M., Vujic, M., Weih, F., Angel, P., Herrlich, P., and Schutz, G. (2001). Repression of inflammatory responses in the absence of DNA binding by the glucocorticoid receptor. The EMBO journal 20, 71687173.

Rosen, J., and Miner, J.N. (2005). The search for safer glucocorticoid receptor ligands. Endocrine reviews 26, 452-464.

Scaffidi, C., Fulda, S., Srinivasan, A., Friesen, C., Li, F., Tomaselli, K.J., Debatin, K.M., Krammer, P.H., and Peter, M.E. (1998). Two CD95 (APO-1/Fas) signaling pathways. The EMBO journal 17, 1675-1687.

Schmidt-Hieber, M., Fietz, T., Knauf, W., Uharek, L., Hopfenmuller, W., Thiel, E., and Blau, I.W. (2005). Efficacy of the interleukin-2 receptor antagonist basiliximab in steroid-refractory acute graft-versus-host disease. British journal of haematology 130 , 568-574.

Schots, R., Kaufman, L., Van Riet, I., Ben Othman, T., De Waele, M., Van Camp, B., and Demanet, C. (2003). Proinflammatory cytokines and their role in the development of major transplant-related complications in the early phase after allogeneic bone marrow transplantation. Leukemia 17, 1150-1156.

Schroder, K., Hertzog, P.J., Ravasi, T., and Hume, D.A. (2004). Interferon-gamma: an overview of signals, mechanisms and functions. Journal of leukocyte biology 75 , 163-189.

Shirota, K., LeDuy, L., Yuan, S.Y., and Jothy, S. (1990). Interleukin-6 and its receptor are expressed in human intestinal epithelial cells. Virchows Archiv 58, 303-308.

Shlomchik, W.D. (2007). Graft-versus-host disease. Nature reviews 7, 340-352.

Shlomchik, W.D., Couzens, M.S., Tang, C.B., McNiff, J., Robert, M.E., Liu, J., Shlomchik, M.J., and Emerson, S.G. (1999). Prevention of graft versus host disease by inactivation of host antigen-presenting cells. Science (New York, NY 285, 412415.

Storb, R., Deeg, H.J., Whitehead, J., Appelbaum, F., Beatty, P., Bensinger, W., Buckner, C.D., Clift, R., Doney, K., Farewell, V., et al. (1986). Methotrexate and cyclosporine compared with cyclosporine alone for prophylaxis of acute graft versus host disease after marrow transplantation for leukemia. The New England journal of medicine 314, 729-735. 
Sykes, M., Romick, M.L., Hoyles, K.A., and Sachs, D.H. (1990). In vivo administration of interleukin 2 plus $\mathrm{T}$ cell-depleted syngeneic marrow prevents graft-versus-host disease mortality and permits alloengraftment. The Journal of experimental medicine 171, 645-658.

Takatsuka, H., Takemoto, Y., Okamoto, T., Fujimori, Y., Tamura, S., Wada, H., Okada, M., Yamada, S., Kanamaru, A., and Kakishita, E. (1999). Predicting the severity of graft-versus-host disease from interleukin-10 levels after bone marrow transplantation. Bone marrow transplantation 24, 1005-1007.

Takatsuka, H., Yamada, S., Okamoto, T., Fujimori, Y., Wada, H., Iwata, N., Kanamaru, A., and Kakishita, E. (2000). Predicting the severity of intestinal graftversus-host disease from leukotriene B4 levels after bone marrow transplantation. Bone marrow transplantation 26, 1313-1316.

Thomas, E.D., Lochte, H.L., Jr., Lu, W.C., and Ferrebee, J.W. (1957). Intravenous infusion of bone marrow in patients receiving radiation and chemotherapy. The New England journal of medicine 257, 491-496.

Tischner, D., Theiss, J., Karabinskaya, A., van den Brandt, J., Reichardt, S.D., Karow, U., Herold, M.J., Luhder, F., Utermohlen, O., and Reichardt, H.M. (2011). Acid sphingomyelinase is required for protection of effector memory $\mathrm{T}$ cells against glucocorticoid-induced cell death. J Immunol 187, 4509-4516.

Trapani, J.A., and Smyth, M.J. (2002). Functional significance of the perforin/granzyme cell death pathway. Nature reviews 2, 735-747.

Tronche, F., Opherk, C., Moriggl, R., Kellendonk, C., Reimann, A., Schwake, L., Reichardt, H.M., Stangl, K., Gau, D., Hoeflich, A., et al. (2004). Glucocorticoid receptor function in hepatocytes is essential to promote postnatal body growth. Genes \& development 18, 492-497.

Tuckermann, J.P., Kleiman, A., McPherson, K.G., and Reichardt, H.M. (2005). Molecular mechanisms of glucocorticoids in the control of inflammation and lymphocyte apoptosis. Critical reviews in clinical laboratory sciences 42, 71-104.

Tuckermann, J.P., Kleiman, A., Moriggl, R., Spanbroek, R., Neumann, A., Illing, A., Clausen, B.E., Stride, B., Forster, I., Habenicht, A.J., et al. (2007). Macrophages and neutrophils are the targets for immune suppression by glucocorticoids in contact allergy. The Journal of clinical investigation 117, 1381-1390.

Tuckermann, J.P., Reichardt, H.M., Arribas, R., Richter, K.H., Schutz, G., and Angel, P. (1999). The DNA binding-independent function of the glucocorticoid receptor mediates repression of AP-1-dependent genes in skin. The Journal of cell biology 147, 1365-1370.

Uhmann, A., van den Brandt, J., Dittmann, K., Hess, I., Dressel, R., Binder, C., Luhder, F., Christiansen, H., Fassnacht, M., Bhandoola, A., et al. (2011). T cell development critically depends on prethymic stromal patched expression. J Immunol 186, 3383-3391.

Van Bekkum, D.W., Vos, O., and Weyzen, W.W. (1959). The pathogenesis of the secondary disease after foreign bone marrow transplantation in $\mathrm{x}$-irradiated mice. Journal of the National Cancer Institute 23, 75-89.

van den Akker, E.L., Russcher, H., van Rossum, E.F., Brinkmann, A.O., de Jong, F.H., Hokken, A., Pols, H.A., Koper, J.W., and Lamberts, S.W. (2006). Glucocorticoid 
receptor polymorphism affects transrepression but not transactivation. The Journal of clinical endocrinology and metabolism 91, 2800-2803.

Wagner, J.E., Thompson, J.S., Carter, S.L., and Kernan, N.A. (2005). Effect of graftversus-host disease prophylaxis on 3-year disease-free survival in recipients of unrelated donor bone marrow (T-cell Depletion Trial): a multi-centre, randomised phase II-III trial. Lancet 366, 733-741.

Wang, W., Meadows, L.R., den Haan, J.M., Sherman, N.E., Chen, Y., Blokland, E., Shabanowitz, J., Agulnik, A.I., Hendrickson, R.C., Bishop, C.E., et al. (1995). Human $\mathrm{H}-\mathrm{Y}$ : a male-specific histocompatibility antigen derived from the SMCY protein. Science (New York, NY 269, 1588-1590.

Welniak, L.A., Blazar, B.R., Anver, M.R., Wiltrout, R.H., and Murphy, W.J. (2000). Opposing roles of interferon-gamma on CD4+ $\mathrm{T}$ cell-mediated graft-versus-host disease: effects of conditioning. Biol Blood Marrow Transplant 6, 604-612.

Willenbacher, W., Basara, N., Blau, I.W., Fauser, A.A., and Kiehl, M.G. (2001). Treatment of steroid refractory acute and chronic graft-versus-host disease with daclizumab. British journal of haematology 112, 820-823.

Wüst, S., van den Brandt, J., Tischner, D., Kleiman, A., Tuckermann, J.P., Gold, R., Luhder, F., and Reichardt, H.M. (2008). Peripheral T cells are the therapeutic targets of glucocorticoids in experimental autoimmune encephalomyelitis. J Immunol 180, 8434-8443.

Yadav, A., Saini, V., and Arora, S. (2010). MCP-1: chemoattractant with a role beyond immunity: a review. Clinica chimica acta; international journal of clinical chemistry 411, 1570-1579.

Yi, T., Chen, Y., Wang, L., Du, G., Huang, D., Zhao, D., Johnston, H., Young, J., Todorov, I., Umetsu, D.T., et al. (2009). Reciprocal differentiation and tissue-specific pathogenesis of Th1, Th2, and Th17 cells in graft-versus-host disease. Blood 114, 3101-3112.

Yi, T., Zhao, D., Lin, C.L., Zhang, C., Chen, Y., Todorov, I., LeBon, T., Kandeel, F., Forman, S., and Zeng, D. (2008). Absence of donor Th17 leads to augmented Th1 differentiation and exacerbated acute graft-versus-host disease. Blood 112, 2101 2110.

Zhao, J., Zhang, T., He, H., and Xie, Y. (2010). Interleukin-2 inhibits polarization to T helper type 1 cells and prevents mouse acute graft-versus-host disease through upregulating suppressors of cytokine signalling-3 expression of naive CD4+ T cells. Clinical and experimental immunology 160, 479-488. 


\section{Acknowledgements}

First of all I would like to thank my supervisor Prof. Dr. Holger Reichardt for his guidance and support throughout my thesis project. I am thankful for the opportunity of doing my $\mathrm{PhD}$ in his laboratory and for his scientific expertise, patience and the opportunity to discuss ideas open-mindedly.

I would also like to thank my thesis committee members Prof. Dr. Steven Johnsen and Dr. med. Tobias Pukrop for their input and interest in my project.

I would like to thank Jens van den Brandt for training me and helping me with too many things to count at the beginning of my project.

Many thanks also go to our co-operation partners:

Dr. Fred Lühder and Dr. Simone Wüst at the IMSF in Göttingen

Dr. Jan Tuckermann and Dr. Anna Kleimann at the FLI in Jena

Prof. Dr. med. Hermann-Josef Gröne at the DKFZ in Heidelberg

PD Dr. Martin Fassnacht at the University Hospital in Würzburg

Margret Rave-Fränk and Alexandra Bitter from the Strahlentherapie at the

UMG Göttingen.

I am also greatly indebted to Dr. Petra Hoffmann at the University Hospital in Regensburg for invaluable advice on aGvHD mouse models.

I thank our technicians, Amina and Julian, for their assistance on many a stressful workday and for relieving me of many tasks, as well as the staff at the ENI and ZTE. I would also like to thank the rest of the Department of Cellular and Molecular Immunology, specifically the AG Oppermann for ELISA assistance and Prof. Dr. med. Ralf Dressel for histological counselling. I thank Rosemarie Döhne and Ingrid Teuteberg for guiding me through the jungle of bureaucracy. Special thanks go to the rest of the AG Reichardt for a great time. Also, I thank my interns Tim, Michelle, Magdalena and Elena.

Last, but not least, I want to thank my parents for unconditional support and Hans for everything and the rest of my family. 


\section{Curriculum Vitae}

\section{Personal data}

Name: Jennifer Theiss-Sünnemann, née Theiss

Date of birth: December $14^{\text {th }}, 1984$

Place of birth: Hagen/Westfalen, Germany

Nationality: German

\section{Education}

since 09/2008 Doctoral thesis

Georg-August-Universität Göttingen, Germany

Project: "Molecular and cellular mechanisms of glucocorticoids in the treatment of acute graft-versus-host disease"

10/2007 - 07/2008 Master of Science in Molecular Medicine University of Dublin, Trinity College, Ireland

Project: „Production and Characterisation of a Vaccine Candidate against Helicobacter pylori Infection"

10/2004 - 07/2007 Bachelor of Science in Molecular Medicine

Georg-August-Universität Göttingen, Germany

Project: "The influence of SOCS proteins on the cytokine response of lymphoma cells"

09/1995 - 06/2004 Allgemeine Hochschulreife

Christian-Rohlfs-Gymnasium, Hagen, Germany

\section{Awards}

since 10/2009

Promotionsstipendium der Studienstiftung des deutschen Volkes

10/2007 - 07/2008 „Jahresstipendium für Graduierte und Promovierte aller Fachrichtungen", Deutscher Akademischer Austauschdienst (DAAD)

10/2007 - 05/2008 "One of five Government of Ireland Exchange Scholarships for German students 2007/2008“"

\section{Additional publications}

Tischner, D.*, Theiss, J. ${ }^{*}$ Karabinskaya, A. ${ }^{*}$, van den Brandt, J., Reichardt, S.D., Karow, U., Herold, M.J., Lühder, F., Utermöhlen, O., and Reichardt, H.M. (2011). Acid sphingomyelinase is required for protection of effector memory $T$ cells against glucocorticoid-induced cell death. J Immunol 187, 4509-4516. *joint first authorship 